University of Louisville

ThinkIR: The University of Louisville's Institutional Repository

Electronic Theses and Dissertations

$8-2020$

\title{
A novel role for RASSF1A in the regulation of RAS activation.
}

Desmond Ramón Harrell Stewart

University of Louisville

Follow this and additional works at: https://ir.library.louisville.edu/etd

Part of the Cancer Biology Commons

\section{Recommended Citation}

Harrell Stewart, Desmond Ramón, "A novel role for RASSF1A in the regulation of RAS activation." (2020). Electronic Theses and Dissertations. Paper 3505.

https://doi.org/10.18297/etd/3505

This Doctoral Dissertation is brought to you for free and open access by ThinkIR: The University of Louisville's Institutional Repository. It has been accepted for inclusion in Electronic Theses and Dissertations by an authorized administrator of ThinkIR: The University of Louisville's Institutional Repository. This title appears here courtesy of the author, who has retained all other copyrights. For more information, please contact thinkir@louisville.edu. 


\title{
A NOVEL ROLE FOR RASSF1A IN THE REGULATION OF RAS ACTIVATION
}

\author{
By
}

\author{
Desmond Ramón Harrell Stewart \\ B.S., Xavier University of Louisiana, 2014
}

\begin{abstract}
A Dissertation
Submitted to the Faculty of the

University of Louisville School of Medicine

In Partial Fulfillment of the Requirements

For the Degree of
\end{abstract}

Doctor of Philosophy in Pharmacology and Toxicology
Department of Pharmacology and Toxicology
University of Louisville
Louisville, KY

August 2020 
Copyright 2020 by Desmond Ramón Harrell Stewart

All Rights Reserved 



\section{A NOVEL ROLE FOR RASSF1A IN THE REGULATION OF RAS ACTIVATION \\ By \\ Desmond Ramón Harrell Stewart \\ B.S., Xavier University of Louisiana, 2014}

A Dissertation Approved on

June 5,2020

by the following Dissertation Committee:

Dr. Geoffrey J. Clark, Dissertation Chair

Dr. Howard Donninger, Committee Member

Dr. Levi Beverly, Committee Member

Dr. Leah J. Siskind, Committee Member

Dr. Brian F. Clem, Committee Member 


\section{DEDICATION}

"One ever feels his twoness-an American, a Negro; two souls, two thoughts, two unreconciled strivings; two warring ideals in one dark body, whose dogged strength alone keeps it from being torn asunder." -Dr. W.E.B. Dubois, "The Souls of Black Folk"

Principally, this work is dedicated to my fellow Xavierite, Atatiana Jefferson. We walked the same halls. We shared a common dream, and they deprived us all of the chance to see to what great heights you would climb. In my heart of hearts, I know that the whole of your Xavier family now climbs for you.

This dissertation is also dedicated to Breonna Taylor, Ahmaud Arbery, Botham Jean, Jonathan Ferrell, Renisha McBride, Stephon Clark, Jordan Edwards, Jordan Davis, Alton Sterling, Aiyana Stanley-Jones, Michael Brown, Tamir Rice, Trayvon Martin, Sandra Bland, Philando Castille, Sean Bell, John Crawford III, Corey Jones, Keith Scott, Claude Reese, Eric Garner, Freddie Gray, Walter Scott, Clementa Pinckney, Cynthia Hurd, Susie Jackson, Ethel Lance, Depayne Middleton-Doctor, Tywanza Sanders, Daniel Simmons, Sharonda Coleman-Singleton, Myra Thompson, and countless others lost before their time at the hands of groundless hatred and prodigious cowardice. This nation has always worked to hold us back by any means; your deaths are recent evidence this. However, bruised, bloodied, but never broke, we always march on; this work is proof of that. Rest easy. 


\section{ACKNOWLEDGEMENTS}

My great grandmother, Alla Pearl Thompson, moved to this city in the thick of Jim Crow with her seven daughters. She never graduated high school—I don't think she ever even started—and provided for her family by cleaning houses in rich neighborhoods. With immeasurable strength, unending love, and fervent prayer, she raised her seven girls into seven phenomenal women who nurtured my family into existence. Big Mama, I still miss you all these years later. You created something wonderful, and I can't thank you enough.

Thank you to my loving husband, Jesse David Harrell Stewart. You've been there every step of this journey, at times the only light I could see to guide my way. I could not have done this without you. To my parents, Wendell and Marilyn Stewart, my list of thanks is endless. Every redeemable quality I have I can trace back to your teachings over the years. I am the man that I am today because of you two. To my brother, Wendell Stewart II, thank you for always being there. I've said many times that I did not deserve a brother as kind as you, and I declare it again here. Thank you for being my biggest cheerleader throughout my life. To my grandmothers, Florida Evelyn Groves and Nannie Ruth Britt, my grandfather James Rollins Britt (1923-2006), my aunts, uncle, and innumerable cousins: your love, encouragement, and camaraderie over the past 28 years is priceless to me. Thank you for always believing in me. 
I must thank each of my committee members individually. Dr. Geoffrey J. Clark, were it not for you seeing potential in a clumsy summer student, I never would have had the opportunity to earn a Ph.D. Thank you for taking a chance on me. Dr. Howard Donninger, you have been an indispensable mentor and friend these past four years. Thank you for all of your help. Dr. Brian Clem, Chicken King and Royals. You know what I mean. Dr. Levi Beverly, thank you for being a calm, encouraging voice. Your full-throated commitment to your students is something I hope to emulate in my career. Dr. Leah J. Siskind, thank you for your thoughtfulness and concern for me, not just as a student but also as a person. You helped start me on a mental health journey that saved and changed my life. For that I will be forever grateful.

Last, but not least, thank you to my friends, lab mates, and colleagues: Dr. M. Lee Schmidt, Dr. Jessica Mezzanotte Sharpe, Rachel Ferrill, Jordan Noe, Samantha Morrissey, Annie Geller, David Mauser, Sibel Sologan, and Melinda Ruberg. Each in your own way, you've been vital to this journey. 


\begin{abstract}
A NOVEL ROLE FOR RASSF1A IN THE REGULATION OF RAS ACTIVATION

Desmond Ramón Harrell Stewart
\end{abstract}

June 5, 2020

Ras is the most frequently activated oncogene in human cancer. It is not only the most frequently mutated oncogene, but is also rendered hyperactive in the wildtype form by aberrant regulation. Ras drives transformation and contributes to tumor aggressiveness by activating multiple downstream mitogenic effectors. Ras also possesses the paradoxical ability to induce apoptosis and senescence. Rasinduced apoptosis is not well understood, but has been largely attributed to the RASSF tumor suppressors, particularly RASSF1A. RASSF1A mediates Rasinduced apoptosis by activating pro-apoptotic proteins such as the MST kinases and BAX. RASSF1A is among the most frequently inactivated tumor suppressors in human cancer. Loss of RASSF1A expression by promoter hypermethylation uncouples Ras from its pro-apoptotic effectors, thus promoting unrestrained Ras mitogenic signaling. More recently, it has been suggested that RASSF1A may be not only an apoptotic effector for Ras, but also a general inhibitor of Ras activity. Several groups have reported modulation of Ras mitogenic signaling in response to RASSF1A suppression. However, the mechanism by which this occurs has not yet been elucidated. This dissertation establishes a novel, endogenous interaction 
between RASSF1A and an important negative regulator of Ras, the RasGAP DAB2IP. We show that RASSF1A expression is an important determinant of DAB2IP protein levels. Loss of RASSF1A dramatically downregulates DAB2IP. This results in increases in Ras-GTP levels, Ras mitogenic pathway activation, and cell proliferation in both wild-type and mutant Ras lung cancer cells. This is the first example of a Ras effector regulating a Ras inhibitor, and the first example of a Ras effector influencing the activation state of Ras. 


\section{TABLE OF CONTENTS}

PAGE

$\begin{array}{lc}\text { DEDICATION } & \text { iii } \\ \text { ACKNOWLEDGEMENTS } & \text { iv } \\ \text { ABSTRACT } & \text { vi } \\ \text { LIST OF FIGURES } & \mathrm{x}\end{array}$

\section{CHAPTER}

I. BACKGROUND AND INTRODUCTION

1.1 Overview 1

1.2 Discovery of Ras 3

1.2.1 Regulation of Ras 4

1.2.1.1 GTPase activating proteins 6

1.2.1.2 Guanine nucleotide exchange factors 7

1.2.2 Structure and function $\quad 8$

$\begin{array}{llll}\text { 1.2.2.1 Domain overview and isoform } & \\ \text { homology } & \end{array}$

1.2.2.2 3-dimensional structure and

1.2.2.3 Post-translational modification 12

1.2.3 Signaling, mutation, and cancer 15

1.2.3.1 Canonical mitogenic Ras signaling $\quad 15$

1.2.3.2 Mutation in cancer 17

$\begin{array}{lll}1.3 & \text { The RASSF tumor suppressors } & 20\end{array}$

1.3.1 The RASSF1A tumor suppressor 23

1.3.1.1 RASSF1A in Ras-mediated apoptosis 24

1.3.1.2 Other tumor suppressive effects of RASSF1A

1.3.2 A role for RASSF1A in Ras regulation 27

1.4 DAB2IP: RasGAP, tumor suppressor, TNF transducer 30

1.4.1 Discovery of DAb2IP 30

1.4.2 DAB2IP in cancer 31

1.4.2.1 DAB2IP favors apoptosis over survival 31

1.4.2.2 DAB2Ip restrains EMT and metastasis $\quad 33$

1.4.2.3 DAB2IP suppresses inflammatory angiogenesis

II. MATERIALS AND METHODS

2.1 Plasmids $\quad 35$

2.2 Cell Lines 36 
2.3 Cell culture, treatment, and genetic manipulation 38

2.3.1 Cell culture 38

2.3.2 Chemicals for cell treatment 39

2.3.3 Transfection reagents 40

2.3.4 Lysis buffers 41

2.4 Molecular biology 42

2.4.1 Bacterial transformation 42

2.4.2 Plasmid Purification 43

2.4.3 Generation of stable RASSF1A and DAB2IP knockdown lines 44

2.5 Biological assays 45

2.5.1 Growth assays 46

2.5.1.1 2D growth curves 46

2.5.1.2 Xenograft growth curves 47

2.5.2 Western blot analysis 48

2.5.2.1 Antibodies 49

2.6 Protein biochemistry 53

2.6.1 Co-immunoprecipitations 53

2.6.1.1 Immunoprecipitation of overexpressed proteins 53

2.6.1.2 Immunoprecipitation of endogenous proteins 54

2.6.2 Active Ras pulldown assay 56

$\begin{array}{lll}\text { III. } & \text { RASSF1A BINDS THE RASGAP DAB2IP } & \\ 3.1 \quad \text { Introduction } & 58\end{array}$

3.2 Results 61

3.3 Discussion 72

IV. EFFECTS PF RASSF1A AND DAB2IP ON GROWTH AND RAS SIGNALING

3.1 Introduction 76

$\begin{array}{lll}3.2 & \text { Results } & 78\end{array}$

3.3 Discussion 81

V. CONCLUSIONS AND FUTURE DIRECTIONS

5.1 Conclusion 90

5.2 Future directions 20

REFERENCES $\quad 94$

CURRICULUM VITAE 126 


\section{LIST OF FIGURES}

FIGURE $\quad$ PAGE

1. Model for Ras activation $\quad 5$

2. Overview of Ras isoforms 10

3. 3-dimensional structure of Ras 11

4. Targeting of Ras to plasma membrane by post-translational $\begin{array}{ll}\text { modification } & 14\end{array}$

5. Ras regulates mitogenic and growth-inhibitory pathways 21

6. The classical RASSF proteins 22

7. Overview of DAB2IP signaling 29

8. RASSF1A and DAB2IP co-localize at microtubules 63

9. RASSF1A and DAB2IP co-immunoprecipitate when overexpressed 65

10. RASSF1A and DAB2IP form an endogenous complex 66

11. Confirmation of shRNA knockdown of RASSF1A/DAB2IP 69

12. Exogenous re-expression of RASSF1A upregulates DAB2IP 70

13. Effects of Chloroquine and MG-132 treatment on DAB2IP protein levels

14. Correlation of RASSF1A and DAB2IP expression in patient lung adenocarcinoma tumors

15. Effects of RASSF1A/DAB2IP suppression on Ras activation 
16. Effects of RASSF1A/DAB2IP suppression on in vitro Ras signaling

17. Effects of RASSF1A/DAB2IP suppression on in vitro lung cancer growth

18. Effects of RASSF1A/DAB2IP suppression on xenograft growth

19. Ras pathway activation in xenograft lysates 


\section{CHAPTER I}

\section{BACKGROUND AND INTRODUCTION}

\subsection{Overview}

Cancer is the second leading cause of death in the United States, with more than 1.8 million new cases and over 600,000 new deaths expected in 2020 [1]. The past three decades have seen a dramatic reduction in both the incidence and mortality of cancer. This is owed in large part to public health campaigns and advancements in screening and treatment. Indeed, the lung cancer death rate in the United States underwent its most precipitous decline on record in the past five years. Unfortunately, this shining accomplishment is somewhat dulled when put into context, in that the mortality rate of lung cancer had reached the greatest height from which to fall relative to other cancers. Still today, nearly one quarter of all cancer-related deaths are due to lung cancer-more than the next four deadliest cancers (prostate, breast, colorectal, and brain) combined [1].

The three Ras genes-HRAS, KRAS, and NRAS—are probably the best characterized oncogenes in the human genome. Together referred to as simply Ras, they comprise the most frequently activated oncogenes in human cancer, with activating point mutations occurring in roughly one third of tumors across all 
tissue types [2]. The frequency of Ras mutations underscores its importance in carcinogenesis. Mutational activation of Ras results in constitutive activation of multiple mitogenic pathways that regulate survival, transformation, and growth [3]. These pathways synergize to mediate transformation [4].

Early experiments involving Ras mutants demonstrated that Ras alone could only transform immortalized cells, and primary cells first required immortalization by cooperating mutations in genes such as p53 $[5,6]$. Without immortalization, oncogenic Ras would induce apoptosis and premature senescence $[7,8]$. It has since been determined that this paradoxical growthinhibitory ability of Ras is indeed physiological, and has largely been attributed to the RaIGDS/AF-6 Ras association domain family (RASSF) of tumor suppressors [9]. RASSF1A is the best characterized member of the RASSF proteins and is an important mediator of Ras-induced apoptosis and cell cycle restriction [10-12].

Interestingly, induction of apoptosis may not be the only mechanism by which RASSF1A mediates tumor suppression. It has been shown that in addition to induction of apoptosis, RASSF1A can modulate Ras mitogenic effector signaling, suggesting that RASSF1A may directly regulate Ras activation [13-17]. This work focuses on the mechanism by which RASSF1A modulates Ras mitogenic signaling.

While searching for novel binding partners for the RASSF1A tumor suppressor, we identified a direct interaction with another tumor suppressor, disabled homologue 2 interacting protein (DAB2IP), which is an important negative regulator of Ras [18]. Suspecting that this interaction was the basis for the 
observed downregulation of Ras mitogenic signaling by RASSF1A, we confirmed this interaction and began to investigate its biological significance. Indeed, we discovered a novel role for RASSF1A. In this work, we present evidence that RASSF1A is a potent positive regulator of DAB2IP. We show that suppression of RASSF1A results in a concomitant and drastic reduction in DAB2IP protein levels in human lung cancer cells. This RASSF1A-mediated suppression of DAB2IP results in a corresponding upregulation of Ras-GTP and Ras mitogenic signaling in both mutant and wild-type Ras lung cancer cells. Furthermore, we show that simultaneous downregulation of RASSF1A and DAB2IP, both frequent events in cancer, enhances Ras signaling and growth in wild-type Ras cancer cells. Thus, we describe the first ever mechanism of Ras regulation by a downstream effector.

\subsection{Discovery of Ras}

In the 1960s, two murine retroviruses were discovered that possessed the ability to transform infected cells in rodent newborns $[19,20]$. Some two decades later, it was revealed that the causative genes in these viruses were in fact rat genes that had been transduced into retroviral genomes [21, 22]. They were called Ha-ras and Ki-ras, after the Harvey and Kirsten rat sarcoma viruses in which they were discovered. Around the same time, the presence of oncogenes in the human genome was discovered, and in 1982 three independent groups realized that the human oncogenes being feverishly investigated were homologues of the rat ras 
genes discovered 10 years prior [23, 24]. That same year, a third Ras gene was discovered in a neuroblastoma cell line; it was called NRAS $[25,26]$.

Now, 38 years after their discovery, these once marginally relevant rat genes are known to be the most frequently mutated oncogenes in human cancer [27]. As such, the Ras oncogenes have been the subjects of intense scrutiny in the field of cancer research. Early on, it was revealed that Ras was regulated much the same as other small G proteins, and the mutations found in cancer served to disrupt the normal GTPase cycle [23, 24].

\subsubsection{Regulation of Ras}

Given the potent ability of Ras to induce transformation, it comes as no surprise that the Ras GTPase cycle is tightly regulated. Indeed, the transition between on and off states is controlled in both directions by two families of regulatory proteins. Guanine nucleotide exchange factors (GEFs) serve as positive regulators, catalyzing exchange of GDP for GTP. GTPase activating proteins (GAPs) negatively regulate Ras by potently stimulating its intrinsic GTPase activity (figure 1) [28]. 


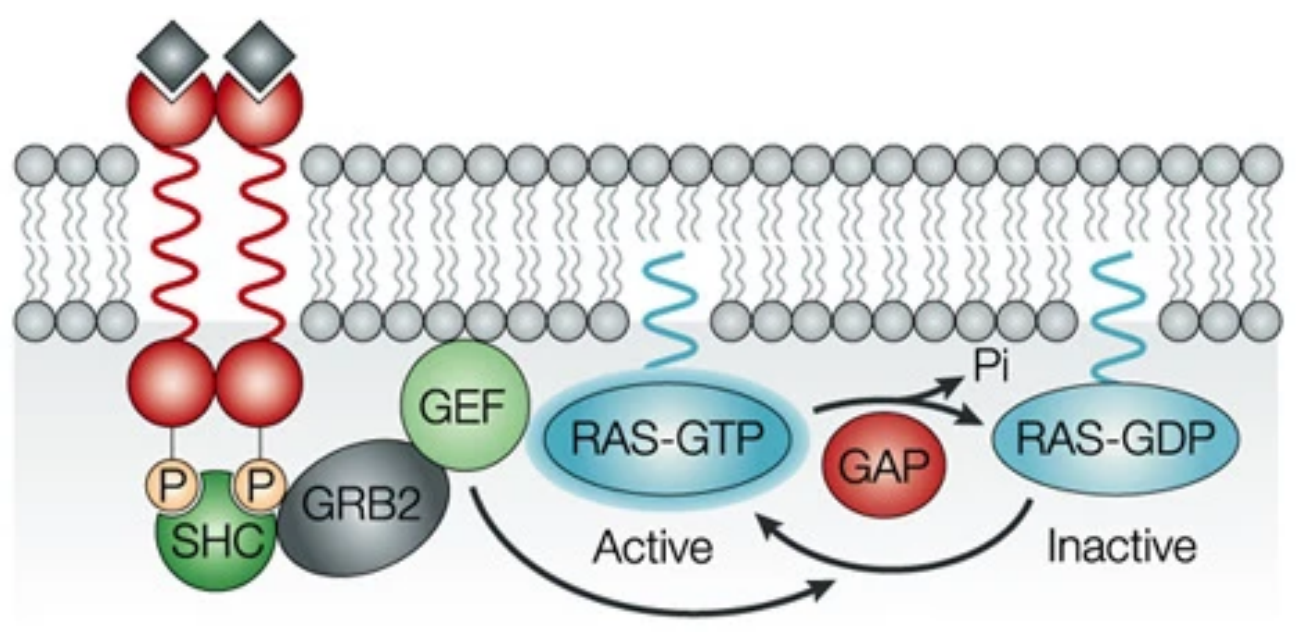

Nature Reviews | Cancer

Reprinted with permission from Springer Nature: [Nat Rev Cancer] (Downward, Targeting RAS signaling pathways in cancer. Nat Rev Cancer, 2003. 3(1): p. 11-22.) Copyright 1969

Reproduction Lic. \#4827190088816

Figure 1: Model for Ras regulation. Ras is primarily localized to the inner leaflet of the plasma membrane. Ras is activated by mitogenic stimuli, such as binding of growth factors to their respective receptors. Receptor activation recruits, through adapter proteins, guanine nucleotide exchange factors (GEFs) to the plasma membrane, which bind inactive Ras and facilitate GDP release, allowing GTP to bind and activate Ras. Ras then recruits and activates mitogenic effectors such as Raf. Ras signaling is silenced by stimulation of its intrinsic GTPase activity by GTPase activating proteins (GAPs). 


\subsubsection{GTPase Activating Proteins}

In the mid-1980s, multiple reports demonstrated that Ras mutants commonly found in patient tumors exhibited diminished GTPase activity compared to its wild-type form. However, in vitro and in vivo data did not appear to correlate. The ability of Ras mutants to induce transformation in vivo was striking, but in vitro GTPase assays revealed only a modest impedance of GTPase activity in mutants [29]. This discrepancy was resolved in 1987, when it was discovered that a cytoplasmic protein called GTPase Activating Protein (GAP, now called p120GAP or RASA1) was responsible for the dramatic increases in GTPase activity of wildtype Ras observed in vivo [30-32]. Three years later, a second RasGAP was discovered and called neurofibromin. This is the protein product of the causative gene in the eponymous heritable tumor syndrome neurofibromatosis type 1 (NF1) $[33,34]$. NF1 was identified because of the high degree of homology between its catalytic GAP-Related Domain (GRD) and the GAP domain of p120GAP.

A total of 14 RasGAPs have bene described in the literature today [35]. RasGAP proteins are a profoundly heterogeneous group apart from their GAP domains, sharing little to no sequence homology outside of that region and possessing different functional domains that confer unique biological properties $[36,37]$. Critical to GAP activity is a highly conserved arginine residue, called an arginine finger. Upon Ras-RasGAP binding, the arginine finger is inserted into the active site wherein it serves two functions. First, the positive charge of the side chain neutralizes charges at the active site in the transition state of GTP hydrolysis. 
Second, the arginine residue forms a hydrogen bond with the catalytic glutamine residue in the switch II region of Ras (GIn61), which positions it appropriately in the active site to catalyze GTP hydrolysis [38].

\subsubsection{Guanine nucleotide Exchange Factors}

Just as GTP hydrolysis by Ras requires stimulation from regulatory RasGAPs, GDP-GTP exchange is also a tightly regulated process. The first RasGEF, CDC25, was identified in 1987 in yeast; however, its ability to catalyze nucleotide exchange in Ras was not discovered until 1991 [39-41]. That same year, the RasGEF Son of Sevenless (SOS) was identified as a downstream effector of EGF in Drosophila; its homology to yeast CDC25 was reported the following year $[42,43]$. These studies led to the discovery of mammalian RasGEFs in 1992 [24].

GEFs do not actively exchange GTP for GDP, rather they bind to Ras-GDP and facilitate GDP dissociation. GTP is present at higher concentrations than GDP in the cell, and therefore predominantly fills the empty nucleotide binding site on Ras [44]. GEF structure is conserved within subfamilies, therefore the mechanisms by which GEFs facilitate GDP dissociation are dependent on the GEF subfamily and the GTPase being activated [28, 45]. They do, however, share a general mechanism of remodeling the switch regions of Ras to lower phosphate binding affinity [28]. RasGEFs are members of the CDC25 family. CDC25 family GEFs

contain a highly conserved CDC25 domain and, usually, an N-terminal Ras 
Exchanger Motif (REM). The mechanism by which these family members catalyze GDP dissociation is two-fold. First, the GEF inserts a projection (an alpha-helix in the case of the RasGEF SOS1) into the active site of Ras, which distorts switch I away from the active site. Second, it induces a conformational change in switch II, which results in a $\mathrm{Mg}^{2+}$ ion that is critical for stabilizing the nucleotide being occluded from the active site by switch II residues [46]. As a result, the alpha and beta phosphate are destabilized in the active site, and GDP is ultimately released. The GEF is then displaced by the binding of a new nucleotide [28].

\subsubsection{Structure and function}

Early investigations into the nature of these transforming genes revealed that their oncogenic properties were conferred by an alarmingly simple mechanism: a single missense mutation [47-50]. The ability of Ras proteins to bind GDP and GTP was appreciated early on [24]. It was suspected that Ras may function like the small $G$ proteins known to transduce hormone signals into the cell [51]. The apparent wide tissue distribution and high frequency of mutation of Ras in human tumors underscored the need to understand its role in the molecular basis of cancer [24, 52].

\subsubsection{Domain overview and isoform homology}


In humans, there are three Ras genes-HRAS, KRAS, and NRAS-that encode four 188-189 amino acid proteins (KRAS produces two splice variants, KRas4A and K-Ras4B) [53]. The Ras proteins share $80-90 \%$ primary sequence homology as well as a high degree of structural homology, particularly in the $\mathrm{N}$ terminal half of the sequence (figure 2) [54]. This region, residues 1-86, has been termed the effector lobe and has $100 \%$ sequence identity among the Ras proteins. Residues $87-166$ constitute the allosteric lobe, which has a sequence identity of $90 \%$. Together, these lobes represent the catalytic G-domain of Ras, which is responsible for GTP binding and hydrolysis as well as effector binding. At the extreme C-terminus lies the hypervariable region (HVR) that contains posttranslational modification sites. As the name implies, the HVR exhibits very little sequence identity [55].

\subsubsection{3-dimensional structure and mechanistic function}

In 3 dimensions, the G-domain of Ras consists of six beta-sheets and five alpha-helices, forming a hydrophobic core connected by 10 loops (figure 3) [56]. Five of these loops exist on one facet of the G-domain and collectively mediate nucleotide and effector binding; loops 1-3 are in the effector lobe while loops 4 and 5 are in the allosteric lobe. Loop 1 (also called the P-loop or Walker A motif) and loop 4 (containing an N/TKXD motif, which is conserved in GTP binding 


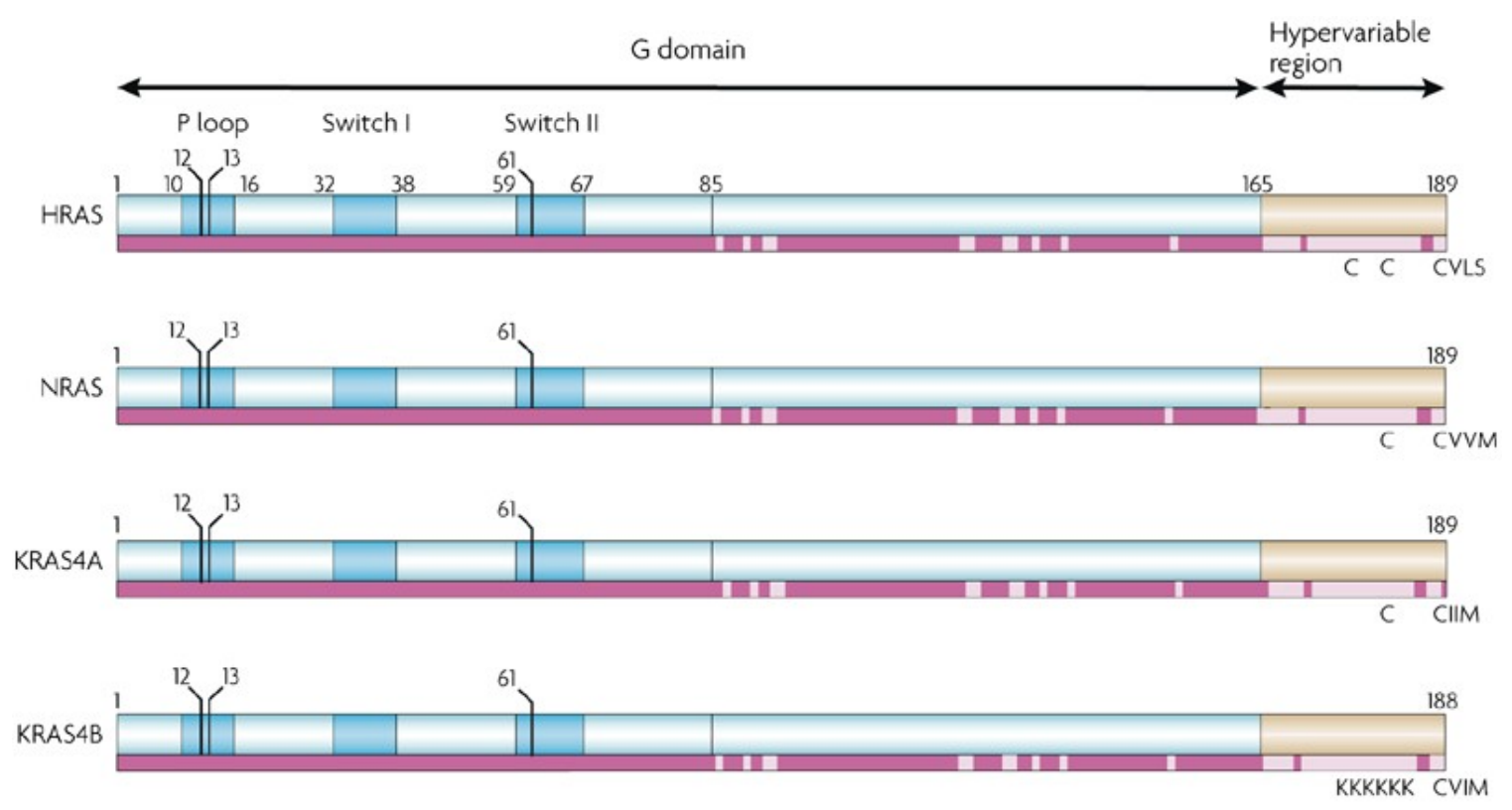

Nature Reviews | Cancer

Reprinted with permission from Springer Nature: [Nat Rev Cancer] (Schubbert et al., Hyperactive Ras in developmental disorders. Nat Rev Cancer, 2007. 7(4): p. 295-308.) Copyright 1969

Reproduction Lic. \#4827301455060

Figure 2: Overview of Ras isoforms. In humans, there are three Ras genesKRAS, HRAS, and NRAS, that code for four Ras proteins (KRAS is alternatively spliced at exon 4 to give rise to $\mathrm{K}-\operatorname{Ras} 4 \mathrm{~A}$ and $\mathrm{K}-\mathrm{Ras} 4 \mathrm{~B}$, of which $\mathrm{K}-\mathrm{Ras} 4 \mathrm{~B}$ is the major isoform). The effector lobe (residues 1-86 are identical in all 4 protein, and overall the $G$ domains share $\sim 95 \%$ sequence homology. At the extreme Cterminus lies the hypervariable region. This region exhibits almost no homology among the Ras isoforms, save for the ending CAAX motif. These last four residues are required for post-translational farnesylation, a modification that is critical to proper function and subcellular localization. 


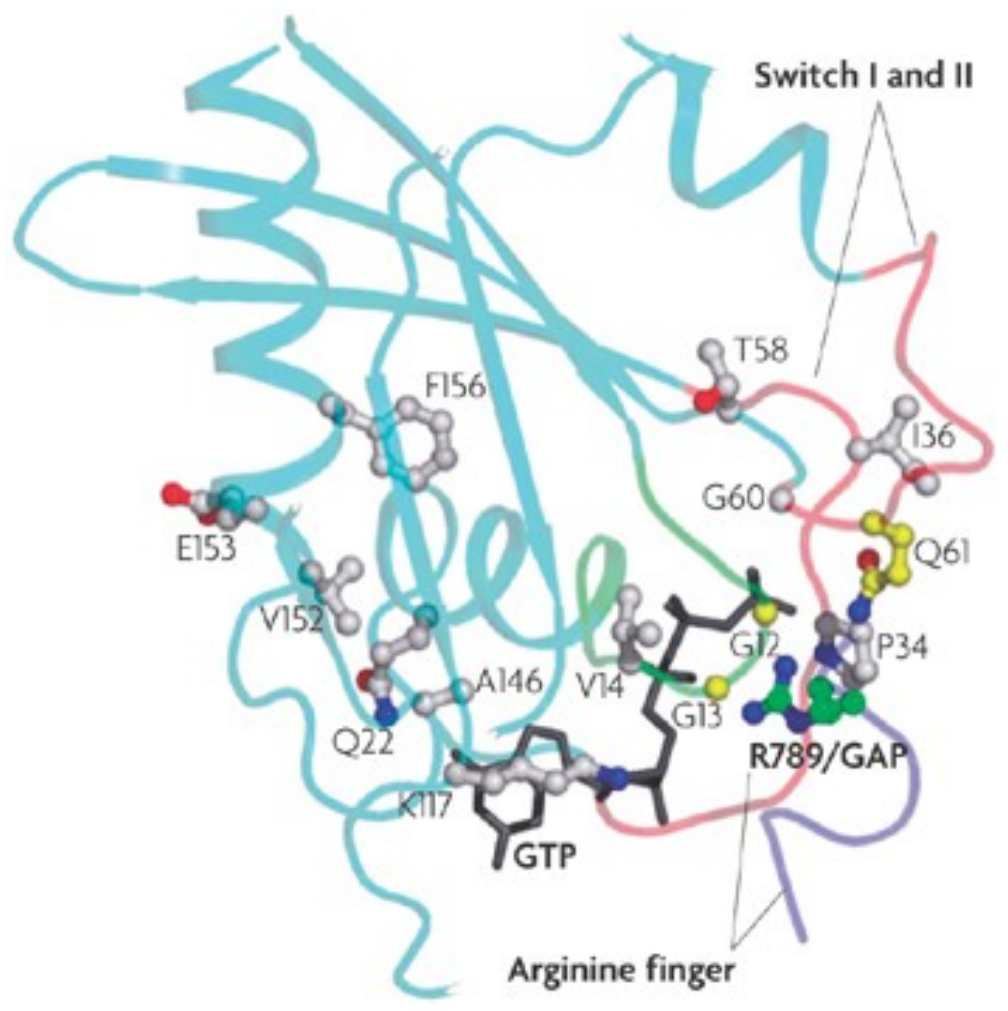

Nature Reviews | Cancer

Reprinted with permission from Springer Nature: [Nat Rev Cancer] (Schubbert et al., Hyperactive Ras in developmental disorders. Nat Rev Cancer, 2007. 7(4): p. 295-308.) Copyright 1969

Reproduction Lic. \#4827301455060

Figure 3: 3-dimensional structure of Ras. Ras proteins contain a hydrophobic core made of six beta-sheets and five alpha-helices, connected by 10 loops. Five of these loops are on the cytoplasmic-facing facet of the protein and constitute the nucleotide and effector binding domains. The model shows Ras in complex with the catalytic arginine figure of a GTPase activating protein (GAP, purple loop), which coordinates critical residues on Ras-G12, G13, and Q61 (yellow spheres)—to facilitate GTP hydrolysis. 
proteins) are responsible for beta/gamma phosphate stabilization and guanine nucleotide specificity, respectively $[44,55]$. Loop 5 also contributes to nucleotide binding, mostly indirectly through stabilization of loop $4[55,57]$. Loops 2 and 3 are major components of two highly mobile regions of Ras, the switch I and switch II regions, respectively.

Switch I and II regions undergo conformational changes in response to GTP binding and hydrolysis due to interactions with the gamma phosphate. The conformational change in these regions is responsible for the "switch" between on and off states of Ras [44, 58]. In the on, GTP-bound state, the switch regions form a platform to which effectors may bind. Different effectors interact with Ras in different (and sometimes multiple) ways, but there is a strong preference for binding to the switch I region [59]. The switch II region contains the catalytic glutamine residue (Gln61) that is responsible for GTP hydrolysis [60].

\subsubsection{Post-translational modification}

It was understood very early that Ras was not a cytosolic protein, but rather was localized to the membrane [61, 62]. The first investigations into what modifications of Ras may confer membrane localization revealed three important characteristics: 1) that $\mathrm{H}$-Ras could be palmitoylated, 2) that the C-terminusspecifically Cys 186 - was critical to membrane localization, and 3) that membrane localization was necessary for Ras to transform cells [63, 64]. This led to the incorrect assumption that H-Ras must be palmitoylated on Cys186 [24]. It would 
be several years before it was discovered that the critical Cys 186 residue was part of a motif known in yeast to result in protein prenylation.

The C-terminus contains almost all the sequence and structural variability of the Ras proteins, particularly the last $22-23$ residues that make up the HVR (figure 2). However, Cys 186 is part of a highly conserved CAAX consensus sequence, first identified in yeast, that is a signal for three post-translational modifications [65]. The CAAX motif-wherein $C$ is cysteine, $A$ is an aliphatic residue, and $X$ is any amino acid-is farnesylated (at Cys186), cleaved, and methylated in all Ras isoforms [66-69]. After farnesylation, the variability present in the HVR dictates which of two divergent paths Ras takes to the plasma membrane. Present in the HVRs of H-Ras, N-Ras, and K-Ras4A are one or two additional cysteine residues that are palmitoylated, resulting in their trafficking through the exocytic pathway to the plasma membrane [70, 71]. The HVR of KRas4B lacks additional cysteine residues, but rather contains a poly-lysine sequence that interacts with negatively charged membranes (figure 4). K-Ras4B concentrates at the inner leaflet of the plasma membrane through a complex mechanism. First, upon synthesis, K-Ras4B binds to cytosolic transport protein such as PDE- $\delta$, which shield the poly-lysine HVR from binding to endomembranes [72]. K-Ras4B is unloaded from PDE-delta onto perinuclear membranes, and is ultimately shuttled to the plasma membrane by the recycling endosome $[72,73]$. Interestingly, K-Ras4A utilizes both a palmitoylated cysteine and a poly-lysine sequence to achieve membrane localization [74]. 


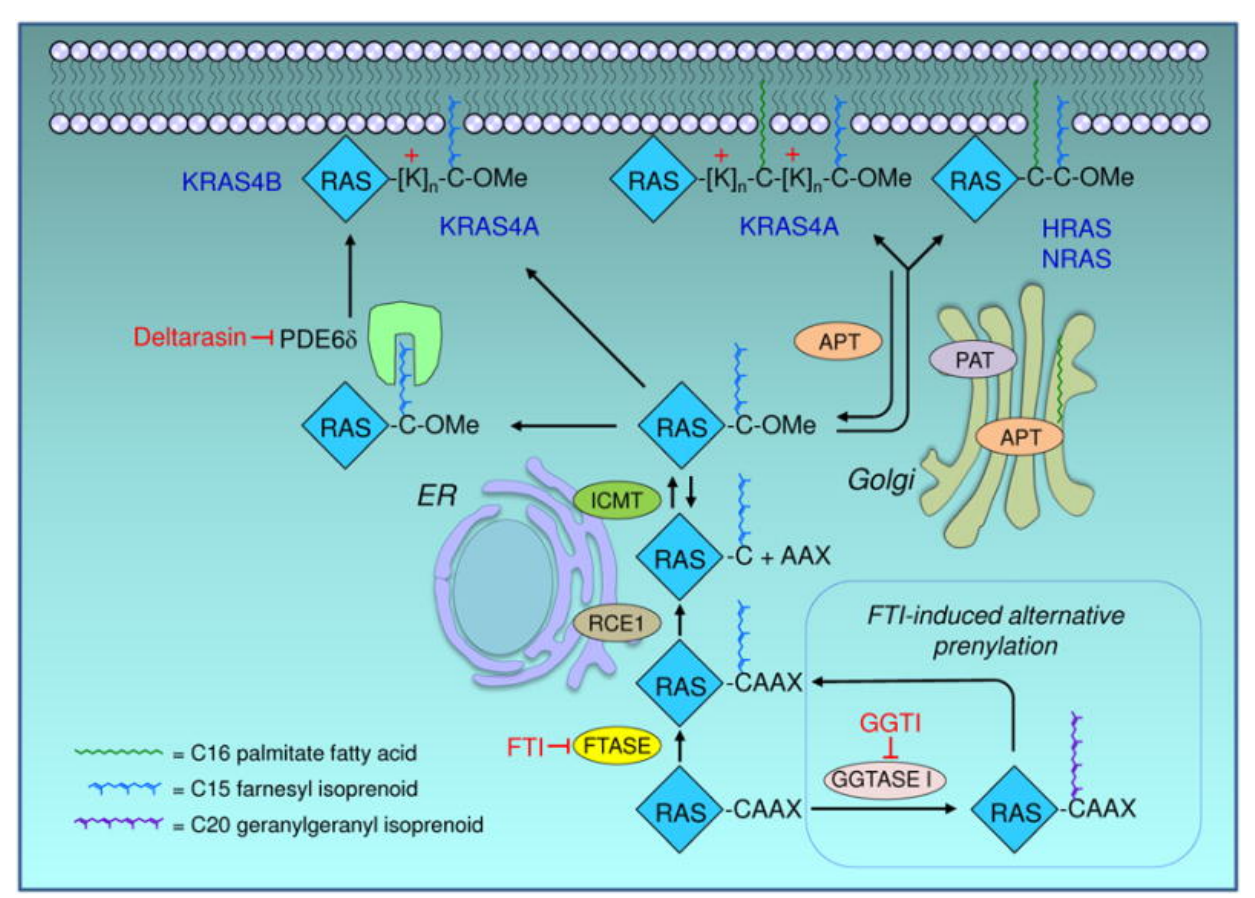

Reprinted with permission from American Association for Cancer Research: [Clin Cancer Res.] (Cox et al., Targeting RAS Membrane Association: Back to the Future for Anti-RAS Drug Discovery? Clin Cancer Res, 2015. 15;21(8):1819-27.) Copyright 2015

Reproduction Lic. \#4827310117028

\section{Figure 4. Targeting of Ras to plasma membrane by post-translational} modification. All Ras proteins possess a C-terminal CAAX motif, a signal for cysteine farnesylation. H-Ras, N-Ras, and K-Ras4A contain additional cysteine residues in the hypervariable region (HVR) that are palmitoylated by the Golgi and target Ras to the plasma membrane via the exocytic pathway. K-Ras-4B (as well as K-Ras 4A) contain a polybasic sequence in the HVR that targets Ras to the membrane via the recycling endosome system, utilizing chaperone protein such as PDE6- $\delta$. 


\subsubsection{Signaling, mutation, and cancer}

The Ras proteins were initially discovered because of their potent ability to transform cells. By the early 1990s, the basic biochemistry of Ras-the GTPase cycle, gross effects of mutation on GTP hydrolysis, and the physical state of the protein necessary for transformation—had been well established. Still unknown were the factors activated by Ras-GTP that confer its oncogenic nature. To identify Ras effector proteins, several groups performed yeast two-hybrid screens. In swift succession, the three canonical Ras effectors were identified.

\subsubsection{Canonical mitogenic Ras signaling}

Classical activation of Ras signaling begins at the cell surface with the binding of a ligand, epidermal growth factor (EGF) or platelet-derived growth factor (PDGF) to their respective receptors EGFR and PDGFR [75]. Receptor activation leads to binding of growth factor receptor-bound protein 2 (GRB2) [76], which in turn recruits the RasGEF SOS1 to the plasma membrane where it can activate membrane-bound Ras [77-80]. Activated Ras-GTP is then able to bind and activate its effectors. The first Ras effector identified was the well-known viral oncoprotein Raf [81].

The serine/threonine kinase Raf was identified as a downstream binding partner of Ras-GTP in Drosophila, C. elegans, and mammalian cells by multiple groups in 1993 [82-86]. Prior knowledge about the oncogenic properties of Raf 
combined with more recent evidence of both Ras- and Raf- mediated activation of the mitogen-activated protein kinase (MAPK) cascade led to the rapid elucidation of the first Ras-regulated signaling pathway: Ras-Raf-MEK-ERK $[23,24,87]$. Raf is recruited to and activated at the plasma membrane by Ras-GTP [88]. There are three Raf isoforms: c-Raf/Raf-1, A-Raf, and B-Raf. All three are capable of phosphorylating the first component of the MAPK cascade, MAPK/extracellular signal-regulated kinase (ERK) kinase 1/2 (MEK1/2) [89]. MEK1/2 then activate ERK1/2, which regulate transcriptional activity by phosphorylating transcription factors [87], some of which have been implicated in Ras-mediated transformation [90].

In 1991, it was reported that phosphatidylinositol 3-kinase (PI3K) activity increased in response to Ha-ras mediated transformation in epithelial cells [91]. In 1994, the direct, GTP-dependent interaction between Ras and the catalytic p110 subunit of PI3K was reported, thus establishing the second canonical Ras effector [92]. As its name suggests, $\mathrm{PI} 3 \mathrm{~K}$ catalyzes the phosphorylation of phosphatidylinositol 4,5-bisphosphate $\left(\mathrm{PIP}_{2}\right)$ to form phosphatidylinositol 3,4,5triphosphate $\left(\mathrm{PIP}_{3}\right.$ ), which activates the Ser/Thr kinase AKT (also known as protein kinase $B(P K B)$ ) [93]. AKT has multiple substrates that confer to it control of cell growth, proliferation, and survival [94, 95]. Specifically, AKT activates the prosurvival/anti-apoptotic transcription factor NFKB, inhibits the pro-apoptotic BAD and Bax proteins, and antagonizes p53-induced apoptosis in order to favor cell survival [96]. PI3K-AKT promotes growth and favors transformation by activating 
mammalian target of rapamycin (mTOR) signaling [97], a pathway that is dysregulated in most cancers [98]. PI3K-AKT also regulates the cell cycle [95].

The third canonical Ras effector identified is an activator of two other small GTPases that are structurally related to Ras. The Ras-like (Ral) GTPases, RalA and RalB, were discovered in 1986 and have been implicated in cellular processes ranging from vesicular trafficking to tumor formation and metastasis [99]. As a small GTPase, the Ral GTPase cycle is regulated by GEFs and GAPs. In 1994, the RalGEF Ral guanine nucleotide dissociation stimulator (RalGDS) was identified in a yeast two-hybrid screen as a Ras effector protein [100-102]. RalGDS activates the Ral GTPases, but not structurally similar GTPases such as Ras, Rho, or Rab [99]. The Ras-RalGDS pathway was not given a great deal of attention initially, as it appeared to play only a minor role in Ras-mediated transformation [24]. The Ral GTPases has been shown to be involved in a broad spectrum of biological processes [99]. Indeed, Ral has since been shown to play critical roles in several human cancers, and has even been deemed necessary for tumor development in an H-Ras-driven mouse model of skin cancer [103, 104].

\subsubsection{Mutation in cancer}

The importance of Ras mutations to carcinogenesis was apparent at the inception of the Ras field, as it was the transforming power of Ras mutants that initially garnered the attention of researchers and led to its characterization. Numerous reports of mutations in codon 12 , normally a glycine, in cancer cell lines 
were published in the early 1980s [47, 48, 50]. Two 1984 publications demonstrating the presence of mutant Ras in tumor cells, yet the absence thereof in normal cells from the same patient, definitively proved that the link between Ras point mutation and malignancy was a naturally-occurring phenomenon, not just an artifact of serial passaging in cell culture $[105,106]$.

Ras is predominantly mutated at codon 12 in human cancers, followed by codon 13 [107]. Mutations at codon 61 are observed in certain cancers, such as melanoma [35]. In fact, $97-99 \%$ of Ras mutations in all three isoforms are found in these three codons [24]. The most common mutations render Ras oncogenic by inhibiting GTP hydrolysis; however, these effects are more attributable to the inhibition of GAP activity than the intrinsic GTPase activity of Ras [29]. Targeted mutation of codon 12 demonstrated that every amino acid except glycine-present in the wild-type protein-and proline rendered Ras oncogenic [108]. The initial report concluded that an alpha-helical secondary structure must be required for Ras GTPase activity. However, analysis of the crystal structure of Ras bound to the p120GAP catalytic domain revealed that introduction of the arginine finger into the active site of Ras creates steric constraints therein such that even alanine is incapable of fitting in that space [38]. Interestingly, Gly12 mutants are still able to bind to RasGAPs, suggesting that glycine is more important for transition state formation as opposed to ground state [109].

The same can largely be said for codon 13 mutations. Gly13 is positioned further away from the RasGAP arginine residue [38]. It thus appears that mutations here are slightly more forgiving, in that alanine and valine mutants are able to form 
the transition state whereas larger amino acids cannot $[38,110]$. Gln61 is the catalytic residue of Ras that activates a water molecule for GTP hydrolysis. Therefore, mutations at this codon do technically disrupt the intrinsic GTPase activity of Ras. However, differences in Ras GTPase activity are only appreciable upon stimulation with GAPs $[28,29]$. As with the other mutation hotspots, extremely few amino acid substitutions-in this case, proline and glutamate-are non-transforming at position 61 [111].

Analysis of the pan-tumor mutation spectrum of Ras reveals patterns in the frequency and types of mutations in the three Ras genes that are dependent on the tissue type. This suggests that Ras isoforms may vary in their predisposition for activation from cell type to cell type [35]. Across all tissues, KRAS is the most frequently activated Ras gene by far, with mutations occurring in $22 \%$ of samples in the COSMIC database, followed by NRAS at $7 \%$, then HRAS at $3 \%$.

KRAS mutations are predominant in cancers of the pancreas, colon, and lung [112-114]. KRAS mutations affect codon 12 in $80 \%$ of cancer cases of all types. G12D and G12V are the most common substitutions, representing in $36 \%$ and $24 \%$ of all KRAS mutations, respectively. Interestingly, G12C mutations, which account for just under $15 \%$ of KRAS mutations overall, are overwhelmingly represented in lung cancer, where its frequency surpasses that of G12D and G12V mutations combined [35]. It was recently discovered that $\mathrm{K}-\mathrm{RAS}{ }^{\mathrm{G} 12 \mathrm{C}}$ retains the ability to complete the GTPase cycle $[115,116]$. The implications of this are threefold: K-RAS ${ }^{G 12 C} 1$ ) is susceptible to activation by upstream signals, 2) may be 
rendered hyperactivated by upstream deregulation, and 3) may confer susceptibility to upstream targeted therapies such as tyrosine kinase inhibitors.

Despite representing less than $10 \%$ of Ras mutations overall, NRAS is the predominant isoform mutated in melanoma and acute myelogenous leukemia (AML) $[117,118]$. NRAS is mutated in $30 \%$ of melanomas, making it the second most common oncogenic driver in melanoma behind BRAF [119]. NRAS is mutated primarily at codon 61 [35]. HRAS is the least frequently mutated isoform, found in $3 \%$ of tumors. HRAS is associated with squamous cell cancers of the head and neck, and is mutated at codons 12 and 61 at roughly equal rates [35, 54]. Whatever the specific substitution, mutational activation of Ras leads to sustained signaling through the canonical mitogenic effectors, which can synergize to mediate transformation. However, Ras can paradoxically stimulate apoptosis and senescence in response to mutational activation as a protective mechanism against transformation.

\subsection{RASSF family of tumor suppressors}

1997 reports demonstrating the ability of Ras to induce senescence and apoptosis naturally led to the hypothesis that additional effectors proteins for Ras must exist that regulate these effects (figure 5). In a span of three years, this hypothesis was confirmed with the discovery of NORE1A (also known as RASSF5) and RASSF1A, the founding RASSF members [120-122]. 


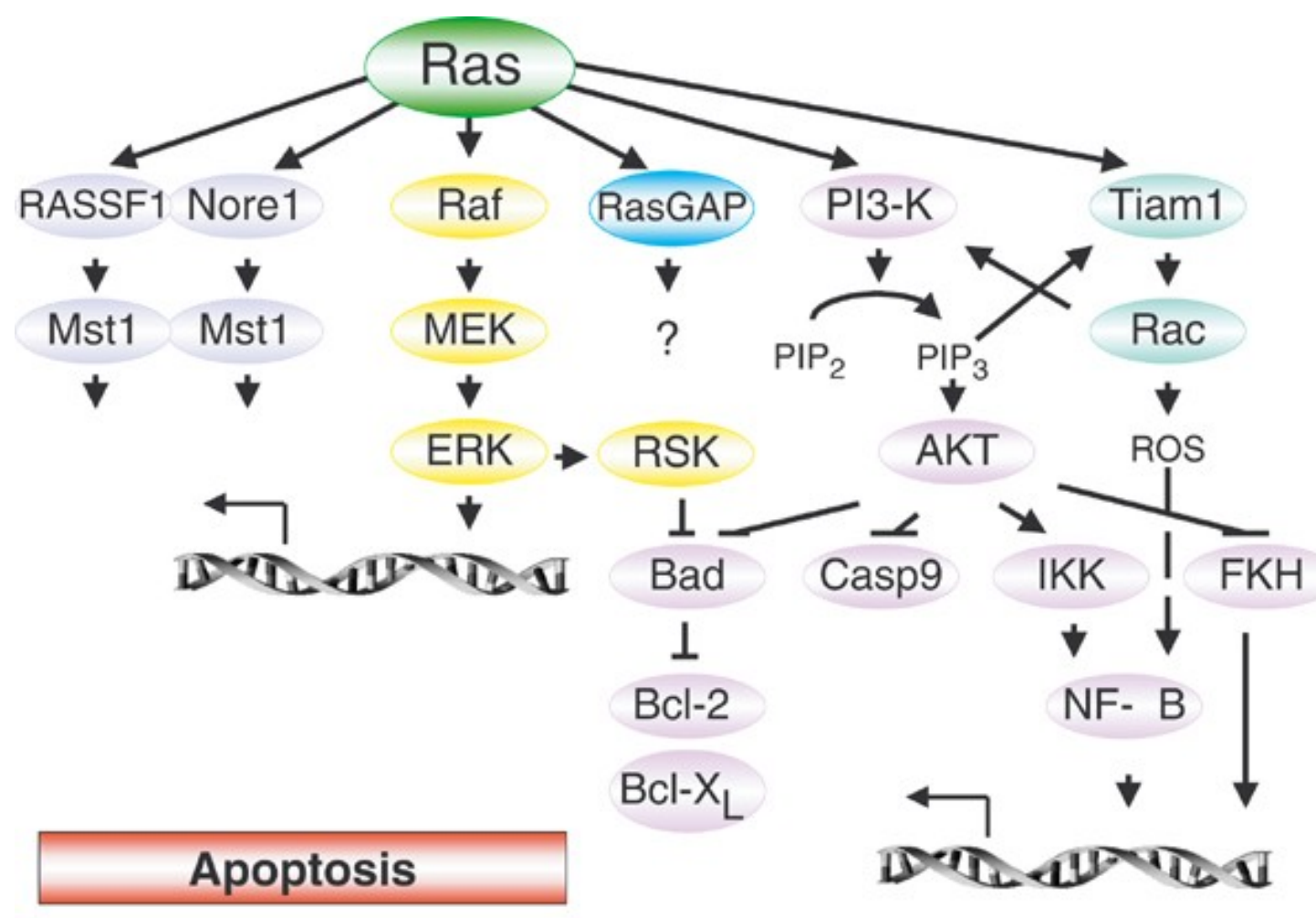

\section{Anti-Apoptosis}

Reprinted with permission from Springer Nature: [Oncogene] (Cox et al., Targeting RAS Membrane Association: Back to the Future for Anti-RAS Drug Discovery? Oncogene, 2003. 22(56):8999-9006. Copyright 2003.

Reproduction Lic. \#4827310445954

Figure 5. Ras regulates mitogenic and growth-inhibitory pathways. Ras, in both wild-type and oncogenic forms, possess the paradoxical ability to stimulate both growth-promoting and growth-inhibiting signaling pathways. Canonical Ras effectors-Raf, PI3K, and RalGDS—-predominantly favor growth. Conversely, several Ras effectors, particularly RASSF proteins, induce apoptosis and senescence in response to Ras stimulation. Loss of RASSF expression uncouples Ras from growth inhibition, thus favoring transformation. 


\section{RASSF1C}

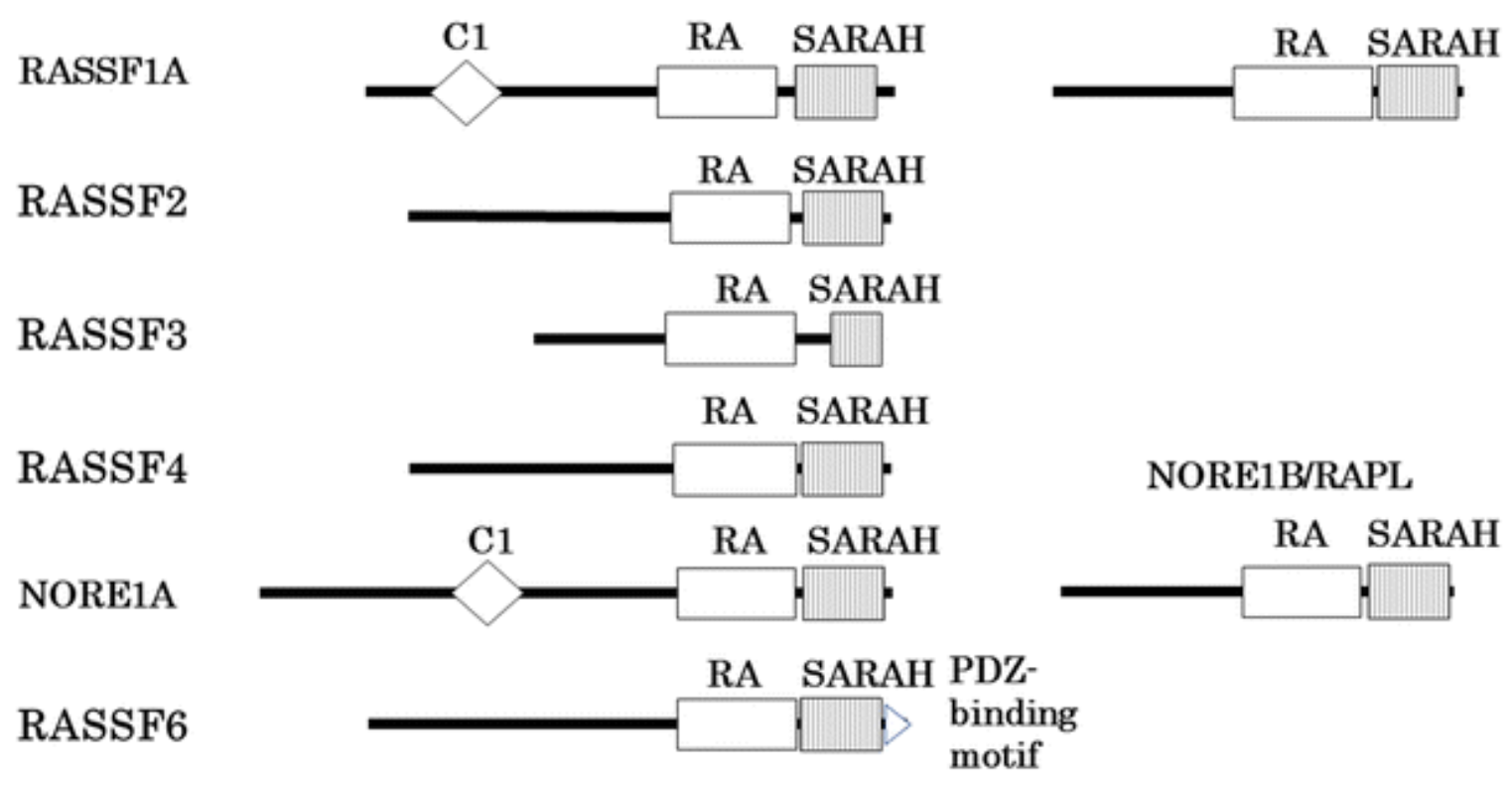

Reprinted with permission from Springer Nature: [Cell Mol Life Sci.] (Iwasa et al., tumor suppressor C-RASSF proteins. Cell Mol Life Sci., 2018. 75(10):1773-1787. Copyright 2018.

Reproduction Lic. \#4827320549900

Figure 6. The classical RASSF proteins. The 10 RASSF proteins can be divided into two subfamilies, classical/C-RASSF and N-RASSF. Classical RASSF proteins have been extensively implicated in tumor suppression. They contain a conserved C-terminal Salvador-RASSF-Hippo (SARAH) domain and adjacent RaIGDS/AF-6 Ras association (RA) domain. RASSF1A and NORE1A/RASSF5, the major members of the family, also contain a C1/Diacylglycerol binding domain. Both RASSF1A and NORE1A are alternatively spliced to give rise to multiple isoform. RASSF1 has 8 isoforms, RASSF1A-H, of which RASSF1C is the major variant. 
NORE1A and RASSF1A were identified because of their RalGDS/AF-6 Ras Association (RA) domains. There are 10 RASSF proteins, which can be divided into two groups based on the location of the RA domain: C-terminal or $\mathrm{N}$-terminal [123]. RASSF1-RASSF6 are in the C-terminal group and are considered the classical RASSF proteins (figure 6). They contain a conserved Salvador/Ras/Hippo (SARAH) domain adjacent to the RA domain that facilitates homo- and heterodimerization as well as connection to the Hippo kinases MST1 and 2 [124]. The classical RASSF proteins are downregulated in human cancers, and most have been characterized as tumor suppressors $[9,123]$. The $\mathrm{N}$-terminal RASSF proteins, RASSF7-RASSF10, do not contain SARAH domains and their role in human disease is much less understood [125].

\subsubsection{The RASSF1A tumor suppressor}

RASSF1A is perhaps the best characterized member of the RASSF proteins. Numerous studies indicated that the 3p21.3 locus underwent loss of heterozygosity frequently and very early in lung cancer development, suggesting that a tumor suppressor gene was located there [126]. In 2000, the RASSF1 gene was discovered at that locus, and the resultant protein was shown to induce apoptosis in a Ras-dependent manner [121, 122]. RASSF1A has since been identified as a key tumor suppressor and mediator of cellular homeostasis [127129]. 
The RASSF1 gene utilizes two promoters and eight exons that are alternatively spliced to give rise to eight isoforms, RASSF1A-H [127]. RASSF1A and RASSF1C are the predominant isoforms and are ubiquitously expressed. Their expression is driven by different promoters located in different $\mathrm{CpG}$ islands, and therefore may be differentially regulated by promoter methylation [130]. Indeed, hypermethylation of the RASSF1A promoter is a frequent and early event in many human cancers $[127,131]$. Somatic mutations in RASSF1A have also been reported [132]; however, this is not considered a major mechanism of RASSF1A inactivation. Early studies in mice, wherein rassf1a ${ }^{-/}$animals were more susceptible to spontaneous tumor formation than wild-type littermates, established the role of RASSF1A in cancer as a bona fide tumor suppressor [133].

\subsubsection{RASSF1A in RAS-mediated apoptosis}

When the RASSF1 gene was first identified, it was immediately noted that it possessed the ability to suppress in vitro and in vivo growth of lung cancer cells and induce apoptosis in a GTP-dependent manner [121, 122]. It has since been demonstrated that RASSF1A utilizes several pathways to mediate this apoptotic effect. Perhaps the best characterized mechanism of RASSF1A-mediated apoptosis is activation of the Hippo pathway [134]. The Hippo pathway is a highly conserved kinase cascade, first identified in Drosophila as a regulator of tissue growth, that has since emerged as a critical mediator of malignancy and metastasis $[135,136]$. 
The Hippo pathway begins at the MST kinases (MST 1/2). In response to Ras activation, RASSF1A binds MST1/2 and stabilizes their active state by preventing dephosphorylation by PP2A domain [137-140]. When activated, MST1/2 phosphorylate the kinases LATS1/2. LATS1/2 in turn phosphorylate their targets YAP and TAZ. This leads to cytoplasmic retention and subsequent degradation of YAP and TAZ, and a switch in YAP affinity from pro-proliferative TEAD and SMAD family transcription factors to pro-apoptotic $p 73[138,141,142]$. LATS1 also binds to and inhibits the ubiquitin ligase MDM2, a negative regulator of the p53 tumor suppressor, thereby stabilizing p53 and inducing apoptosis [137]. RASSF1A can also directly bind MDM2 after phosphorylation following DNA damage [143]. This leads to MDM2 auto-ubiquitination and degradation [144].

RASSF1A can also induce mitochondrial apoptosis by activating BAX. In response to TNF or mutant K-RAS, RASSF1A binds to modulator of apoptosis (MOAP-1), opening the conformation of MOAP-1 to facilitate binding to the proapoptotic protein BAX $[11,145]$. The MOAP-1-BAX interaction induces conformational change of BAX, insertion into the mitochondrial membrane, and cytoplasmic release of cytochrome c [146].

\subsubsection{Other tumor suppressive effects of RASSF1A}

In the cell, RASSF1A does far more than serve as a kill switch for Ras mutants. Since its discovery, roles for RASSF1A have been found in cell motility, invasion, and metastasis [12, 147]; cell cycle progression [10]; DNA damage repair 
[148]; organelle trafficking and cell-cell communication [149]; and inflammation [9, 150]. Interestingly, much of RASSF1A activity, including its regulation of cell proliferation and apoptosis, is mediated through its interaction with and stabilization of microtubules [129].

RASSF1A binds to microtubule associated proteins (MAPs), which mediate its interaction with microtubule filaments [151, 152]. This interaction prevents deacetylation of microtubules by histone deacetylase 6 (HDAC6), resulting in the accumulation of hyper-stable circular microtubule bundles [152, 153]. RASSF1Amediated stabilization of microtubules is also associated with mitotic arrest and inhibition of DNA synthesis $[151,152]$. Mitotic arrest is mediated by regulation of centrosomes by RASSF1A. Centrosomes are critical regulators of mitotic spindle assembly [154]. Whereas knockdown of RASSF1A results in multipolar spindle formation, overexpression of RASSF1A inhibits centrosome separation, providing an explanation for why RASSF1A promotes G2/M arrest specifically [151, 155, 156].

RASSF1A appears to regulate cell migration and cell cycle progression by multiple parallel mechanisms. Increases in invasion and metastasis observed upon RASSF1A depletion have also been attributed to disruption of cell-cell adhesions $[12,157]$. RASSF1A negatively regulates Janus kinase (JNK) activity and subsequent cyclin D1 accumulation, thereby inhibiting G1-S transition in addition to G2-M [158].

More recently, the ability of RASSF1A to regulate inflammation has been reported. Chronic inflammation is an important driver of tumor development and 
progression [159, 160]. RASSF1A-deficient animals and tumors exhibit elevated IL-6 production [14, 150]; tumors also exhibit increased macrophage invasion [14]. Part of the oncogenic program of YAP is upregulation of II-6 production[161]. Moreover, II-6 has been shown induce epithelial-to-mesenchymal-transition (EMT). Thus, control of inflammation and apoptosis by RASSF1A may be linked [129].

\subsubsection{A role for RASSF1A in RAS regulation}

A final and curious aspect of RASSF1A activity is its ability to modulate mitogenic effectors of Ras. Modulation of the three canonical Ras mitogenic pathways-PI3K-AKT, Raf-MEK-ERK, and RaIGEF-Ral-in response to RASSF1A depletion have been reported $[13,14]$. Some of this may be explained by simple stoichiometry. Less RASSF1A-bound Ras will inevitably lead to more PI3K, RAF, and RalGDS-bound Ras. However, RASSF1A has been shown to directly modulate both AKT and RAF activity through the MST kinases [9, 162, 163]. MST2 binds Raf and inhibits its activation by Ras [16]. RASSF1A competes with Raf for MST2 binding [138], and therefore titrates the degree of Raf inhibition by MST2. These interactions suggest that RASSF1A should serve to positively regulate Raf [9]. However, MST2 is also regulated by AKT, which phosphorylates MST2 and increases its affinity for RASSF1A [15]. This should theoretically result in simultaneous activation of RASSF1A-Hippo and Raf-MEK-ERK pathways, thus 
the ultimate outcome of these interactions is unclear. Others have shown that RASSF1A loss activates Raf $[14,17]$.

As AKT regulates MST2, RASSF1A1 regulates AKT activity, in part through MST1 $[13,162,163]$. MST1 directly binds AKT1 and both MST2 kinases suppress activating phosphorylation of AKT at T308 and S473 [163]. In addition to preventing dephosphorylation, RASSF1A also stabilizes MST1/2 protein levels through an unknown mechanism [140, 162]. RASSF1A suppression depletes MST1 protein and results in increased AKT phosphorylation at T308 [162].

While the ability of RASSF1A to inhibit PI3K-AKT activity is established, reports describing the interactions between RASSF1A, Raf, and the MST kinases do not provide a concise mechanism of RASSF1A-mediated regulation of Raf. Moreover, they do not correlate with observed increases in Raf activity upon RASSF1A depletion. The recent report of RASSF1A negatively regulating Ral activation underscores the potential for a simpler, universal mechanism by which RASSF1A restrains Ras mitogenic signaling. The Clark group recently identified and confirmed a novel binding partner for RASSF1A that explains its control over Ras activity: the RasGAP DAB2IP (Harrell Stewart et al., in press). 


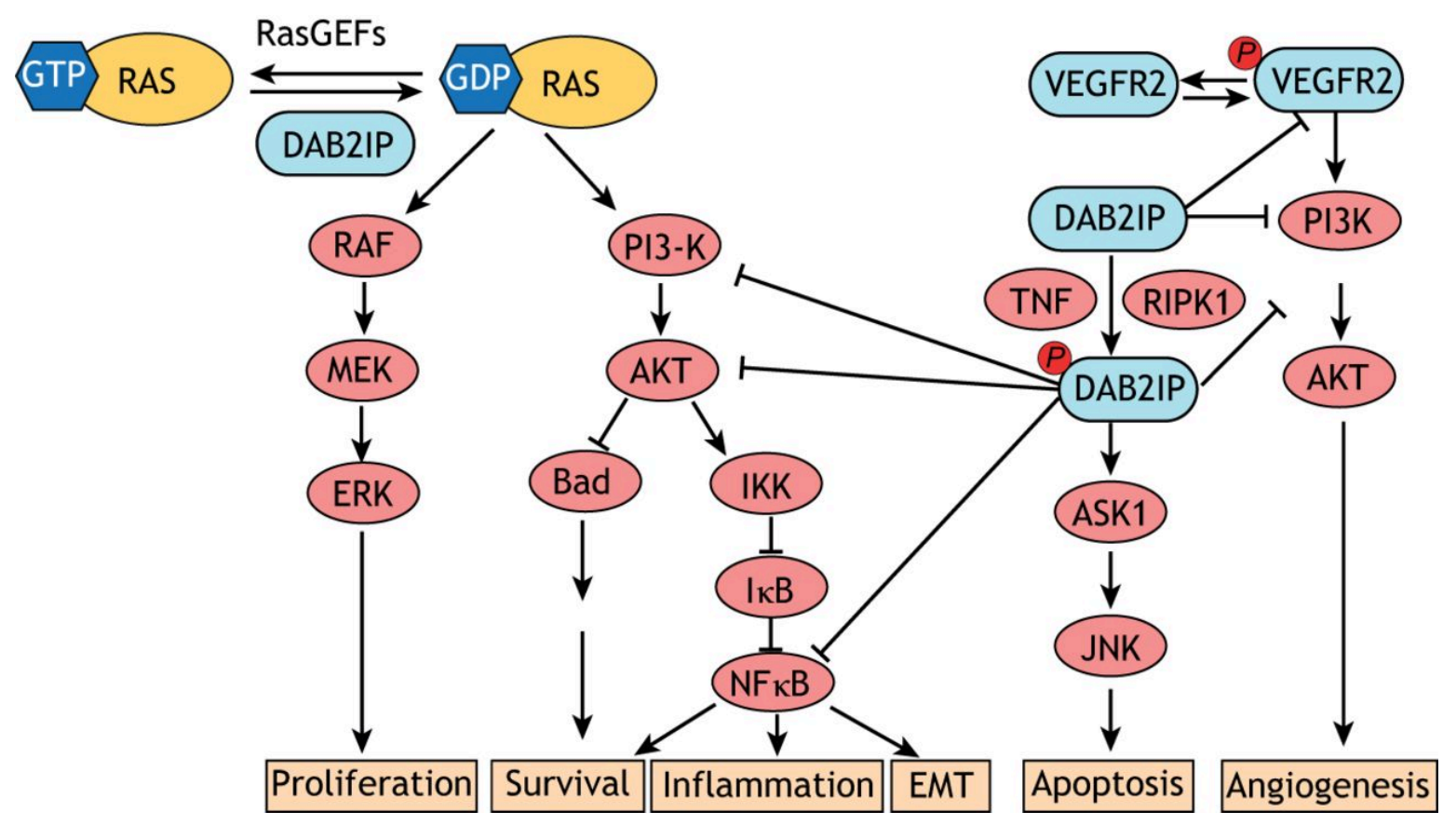

Reprinted with permission from Company of Biologists: [J Cell Sci.] (Harrell Stewart and Clark, Pumping the brakes on RAS - negative regulators and death effectors of RAS. J Cell Sci, 2020. 133(3):jcs238865. Copyright 2020.

Reproduction Lic. \#1035577-1

Figure 7. overview of DAB2IP signaling. DAB2IP is a RasGAP and bona fide tumor suppressor with multiple Ras-independent functions. DAB2IP can directly modulate Ras activation through its GAP domain. DAB2IP can bind to activated VEGFR2 and inhibit its induction of angiogenesis. Finally, DAB2IP is a critical mediator of TNF-induced apoptosis. Upon TNFR activation, DAB2IP is phosphorylated, which allow for simultaneous activation of pro-apoptotic ASKJNK signaling, direct inhibition of the pro-survival PI3K-AKT complex, and suppression of TRAF2-induced activation of NFkB, an important regulator of survival, inflammation, and transformation. 
1.4. DAB2IP: RasGAP, tumor suppressor, TNF transducer

Disabled homologue 2(DAB2) interacting protein (DAB2IP) is one of fourteen RasGAPs in the human genome and is among the best characterized [36]. While its GAP activity is required for full expression of its tumor suppressive power, additional functional domains of DAB2IP allow it modulate numerous biological processes involved in cancer, including angiogenesis, inflammation, proliferation, and apoptosis [164-167].

\subsubsection{Discovery of DAB2IP}

Disabled homologue 2 (DAB2) interacting protein (DAB2IP) was first identified in a 2002 yeast two-hybrid screen as an N-terminal binding partner for the tumor suppressor DAB2, originally called differentially expressed in ovarian carcinoma-2 (DOC2) [18]. Its original characterization established several important aspects of the function of DAB2IP and its role in human cancer [18]. DAB2IP was found to possess several putative functional domains, including RasGAP homology (GAP), proline rich (PR), leucine zipper dimerization (LZ), and Src homology 3 (SH3). The RasGAP activity of DAB2IP was confirmed in vitro and in prostate cancer cells, with corresponding suppression of Raf-MEK-ERK signaling and 2D growth when overexpressed. It was found to be expressed in wide variety of normal tissues including prostate, as well as in primary prostate tumor cell lines, but was markedly downregulated in metastatic cell lines. This led 
to the correct speculation that DAB2IP was involved in prostate cancer progression[18, 168].

\subsubsection{DAB2IP in cancer - regulation and signaling}

DAB2IP activity is frequently lost multiple cancers, including prostate, breast, and lung [169]. One report mentions mutational inactivation of DAB2IP in breast cancer; otherwise, mutation of DAB2IP appears to be a rare event [170]. Instead, tumors utilize a variety of mechanisms to subvert DAB2IP-mediated tumor suppression [171]. Aberrant histone deacetylation and promoter methylation has been reported in prostate cancer $[168,172]$. Aberrant promoter methylation has also been reported in breast, lung, gastrointestinal, and brain cancers [173-176]. DAB2IP activity can also be suppressed by microRNA-mediated downregulation, ubiquitin-mediated degradation, inhibitory phosphorylation, and sequestration by mutant p53 [171, 177-179]. The multifaceted approach employed to abrogate DAB2IP activity in cancer implies both that loss of DAB2IP confers significant survival and/or proliferative advantage to tumor cells, and that DAB2IP must be a powerful tumor suppressor (figure 7).

\subsubsection{DAB2IP favors apoptosis over survival}

A second group identified DAB2IP in a yeast two-hybrid screen as a binding partner of apoptosis signal-regulating kinase 1 (ASK1) and named it ASK1 
interacting protein (AIP1) [180]. ASK1 is an upstream activator of c-Jun N-terminal kinase (JNK) and p38 MAPK which regulate survival and apoptosis [181]. In a series of reports, these two groups elucidated a mechanism in which DAB2IP serves as a critical determinant in the decision between survival and apoptosis in response to TNF-TNFR signaling [180, 182-184].

In resting cells, DAB2IP is in a closed conformation in complex with TNFR $[180,182]$. The PR domain of DAB2IP is responsible for maintaining this closed conformation [182]. Upon TNFR activation by TNF, TRADD is recruited to the receptor and serves as a platform for the formation of a large complex involving TRAF2, DAB2IP, ASK1, RIPK1, IKK, and MAP3K [184-187]. TRAF2 is an important transducer of TNFR signaling, capable of stimulating pro-apoptotic ASKJNK and pro-survival NFKB pathways [188]. This complex is released into the cytoplasm, where DAB2IP adopts an open conformation and is phosphorylated at S604 by either RIPK1 or ASK1, a required modification for activation of ASK1 [184]. ASK1 is then dephosphorylated by PP2A and 14-3-3, the inhibitor of ASK1, is transferred to phosphorylated DAB2IP, allowing for ASK1-mediated activation of JNK and subsequent induction of apoptosis $[180,184,189]$. The interaction between DAB2IP and ASK1 is significantly enhanced by TRAF2 [180]. DAB2IP simultaneously inhibits TNF-induced activation of NFKB, an important pathway in cell survival $[182,190]$.

DAB2IP further tips the scales in favor of apoptosis over survival by inhibiting the PI3K-AKT pathway [165]. AKT negatively regulates ASK1 by phosphorylation at S83 [191]. PI3K-AKT is also an important positive regulator of 
NFKB [192]. DAB2IP inhibits AKT by preventing its phosphorylation at $S 473[165]$. This is mediated by inhibitory interactions between DAB2IP and both AKT and the p85 regulatory subunit of $\mathrm{PI} 3 \mathrm{~K}[165,167]$.

\subsubsection{2. $D A B 2 I P$ restrains $E M T$ and metastasis}

The initial characterization of DAB2IP revealed that its overexpression in metastatic prostate cancer cells could suppress their growth in culture [18]. At that time, it was speculated that DAB2IP played a role in metastatic prostate cancer. It has since been firmly established that DAB2IP is an important regulator of EMT and metastasis in multiple cancers [166, 193-197].

Regulation of EMT and metastasis by DAB2IP occurs through simultaneous inhibition of Ras-Raf-MEK-ERK and PI3K-AKT-NFKB signaling pathways [167]. Using a combination of in vitro and in in vivo techniques, it was demonstrated that DAB2IP-mediated suppression of EMT and tumor initiation was a result of GTPase activity, whereas inhibition of metastasis was caused by NFKB suppression [167]. NFKB suppression by DAB2IP here was mediated by the same mechanisms described in 1.4.2.1.

DAB2IP also inhibits metastasis through suppression of $\mathrm{Wnt} / \beta$-catenin signaling. Wnt is frequently activated in cancer [198]. Canonical Wnt signaling involves stabilization of the transcriptional activator $\beta$-catenin [199]. DAB2IP suppresses this pathway by recruiting PP2A to the kinase GSK-3 $\beta$ [200]. 
Dephosphorylation of GSK-3 $\beta$ at S9 is activating, allowing it to phosphorylate $\beta$ catenin and target it for degradation [201].

\subsubsection{DAB2IP suppresses inflammatory angiogenesis}

DAB2IP knockout mice were generated in 2008 to investigate the function of the protein in vivo. It was discovered that DAB2IP was key regulator of inflammatory angiogenesis [164]. The initial report demonstrated suppression of VEGFR and AKT activation caused by DAB2IP, and that GAP activity on Ras was not responsible for AKT inhibition. Instead, DAB2IP was found to bind directly to the VEGFR2-PI3K complex and prevent VEGFR2-mediated activation of PI3K. However, Ras does still activate PI3K, and Ras and NFKB signaling are linked [202]. Thus it appears, that the regulatory roles of DAB2IP are tightly interweaved, and the importance of DAB2IP in disease is due to concomitant deregulation of all of these pathways [203]. 


\section{CHAPTER II}

Materials and Methods

\subsection{Plasmids}

pCDNA3-HA-RASSF1A - pcDNA3-HA-RASSF1A was described previously [152]. pcDNA ${ }^{\text {TM } 3.1 ~ m a m m a l i a n ~ e x p r e s s i o n ~ v e c t o r ~ w a s ~ p u r c h a s e d ~ f r o m ~ I n v i t r o g e n ~(C a t . ~}$ \#V79020). This vector was modified to express a fused hemagglutinin (HA) epitope tag by Dr. Geoffrey Clark. The full length RASSF1A coding sequence was cloned from pcDNA3.1-RASSF1A into pcDNA3-HA as a BamHI/Notl restriction fragment.

KATE-RASSF1A - pmKate2-C-RASSF1A has been described previously [10]. The BamHI/EcoR1 restriction fragment from pcDNA3-HA-RASSF1A was cloned in to the pmKate2-C vector (Evrogen, Moscow, Russia, Cat. \#FP181).

K-RAS ${ }^{G 12 V}$ - pCGN-KRASG12V was described previously [204].

GFP-DAB2IP - pEGFP-DAB2IP was a gift from Dr. Karen Cichowski (Harvard). 
shRASSF1A - pBRS-ShRASSF1A was generated by cloning the shRNA sequence from pRS-RASSF1A 777 (Origene, Cat. \#TR307696) into the pGFP-BRS vector (Origene, Cat. \#TR30018).

shDAB2IP - pGIPZ-shDAB2IP was a generous gift from Jer-Tsong Hsieh (UT Southwestern) [205].

\subsection{Cell lines}

HEK-293T - Human Embryonic Kidney 293 T (HEK-293T) cells were purchased from the ATCC. These cells are modified with the SV40 Large T-antigen, allowing for enhanced protein expression. This cell line is easy to transfect and is therefore useful in overexpressed co-immunoprecipitation studies. HEK-293T cells were maintained in Dulbecco's modified Eagle medium (DMEM) supplemented with $10 \%$ fetal bovine serum (FBS) and 1\% penicillin/streptomycin (pen/strep).

COS-7 - COS-7 (CV-1 in Origin with SV40 genes) cells were purchased from the ATCC. These fibroblast-like cells are derived from the African green monkey (Cercopithecus aethiops) kidney cells. Morphologically, these cells are large and flat, making them particularly useful for imaging fluorescently tagged proteins. COS-7 cells were maintained in DMEM supplemented with 10\% FBS and $1 \%$ pen/strep. 
$\mathrm{NCl}-\mathrm{H} 1299$ - These cells were purchased from the ATCC. H1299 is a non-small cell lung carcinoma line derived from the lymph node of a 43-year-old Caucasian male. This line harbors a Q61K mutation in the NRAS gene. It is also p53-null, resulting from a homozygous partial deletion of TP53. Additionally, these cells have lost endogenous expression of RASSF1A [206]. H1299 cells were maintained in RPMI 1640 medium (RPMI) supplemented with 10\% FBS and 1\% pen/strep.

$\mathrm{NCl}-\mathrm{H} 1792-\mathrm{NCl}-\mathrm{H} 1792$ cells were purchased from the ATCC. This is a stage 4 non-small cell lung adenocarcinoma cell line derived from the pleural effusion of a 50-year-old Caucasian male. It harbors a G12C mutation in the KRAS gene [115]. $\mathrm{NCl}-\mathrm{H} 1792$ cells were maintained in RPMI supplemented with $10 \%$ FBS and $1 \%$ pen/strep

$\mathrm{NCl}-\mathrm{H} 1437-\mathrm{H} 1437$ cells were purchased from the ATCC. This is a stage 1 nonsmall cell lung adenocarcinoma cell line derived from the pleural effusion of a 60year-old Caucasian male. H1437 cells were maintained in RPMI supplemented with $10 \%$ FBS and $1 \%$ pen/strep. H1437 cells retain wild-type Ras expression [207].

MCF-10A - MCF-10A breast epithelial cells were purchased from the ATCC. This is an immortalized, non-transformed epithelial cell line derived from the mammary gland of a 36-year-old Caucasian female [208]. As a non-tumorigenic line, MCF- 
$10 \mathrm{~A}$ cells have not undergone hypermethylation of the RASSF1A promoter, making them a useful tool for RASSF1A co-immunoprecipitation studies. MCF-10A cells were maintained in DMEM/F12 50:50 mix supplemented with $5 \%$ horse serum, $20 \mathrm{ng} / \mathrm{mL}$ epidermal growth factor (EGF), $0.5 \mu \mathrm{g} / \mathrm{mL}$ hydrocortisone, 10 $\mu \mathrm{g} / \mathrm{mL}$ insulin, and $1 \%$ pen/strep.

2.3. Cell culture, treatment, and genetic manipulation

\subsubsection{Cell culture}

Growth Media - Cell lines used in this work were maintained in conditions recommended by the ATCC. All growth media were purchased from Corning. DMEM (Cat. \#10-013-CV) and contains L-glutamine, sodium pyruvate, and $4.5 \mathrm{~g} / \mathrm{L}$ glucose. DMEM was supplemented with 10\% FBS (Corning, Cat. \#35-010-CV) and 1\% penicillin/streptomycin (Corning, Cat. \#30-002-Cl). RPMI 1640 (Cat. \#10-040CV) contains L-glutamine and was supplemented with $10 \%$ FBS and $1 \%$ pen/strep. DMEM/F12 50:50 Mix (Cat. \#15-090-CV) is a 50:50 mixture of DMEM and Ham's F12 medium. It contains L-glutamine and was supplemented with $5 \%$ horse serum (Gibco, Cat. \#26050-07), 20 ng/mL EGF (Gibco, Cat. \#PHG0311), $0.5 \mu \mathrm{g} / \mathrm{mL}$ hydrocortisone (Sigma, Cat. \#H0888), $10 \mu \mathrm{g} / \mathrm{mL}$ insulin (Sigma, Cat. \#192780$5 \mathrm{ML})$, and $1 \%$ pen/strep. 
Passaging - Trypsin-EDTA (0.25\%) was purchased from Corning (Cat. \#25-053$\mathrm{Cl}$ ) and was used to remove adherent cells from culture vessels. Culture medium was aspirated and cells were washed once with sterile 1X phosphate-buffered saline (PBS) (Corning, Cat. \#21-040-CM). The PBS was aspirated, then trypsinEDTA was applied to the cells and incubated at $37^{\circ} \mathrm{C}$ for several minutes until cells were detached from the culture vessel. Trypsin was neutralized with complete medium (containing FBS) and cells were collected via centrifugation at $1500 \mathrm{rpm}$ for 5 minutes. The resulting supernatant was aspirated and the cells were resuspended in complete medium and plated as needed.

\subsubsection{Chemicals for cell treatment}

To elucidate mechanisms of protein stabilization we treated cells with various inhibitors. MG-132 (Selleckchem, Cat. \#S2619) is a reversible proteasome inhibitor. MG-132 powder was reconstituted in DMSO (Sigma, Cat. \#D2438) at a stock concentration of $50 \mathrm{mM}$ and diluted in culture media to a final concentration of $50 \mu \mathrm{M}$. In these experiments, cells were treated with MG-132 for 4 hours prior to lysis. Chloroquine (Sigma, Cat. \#C6628) is an anti-malarial medication that is used in cell culture to inhibit the lysosome. Chloroquine powder was dissolved in DMSO to a stock concentration of $50 \mathrm{mM}$ and diluted in complete media to a final concentration of $50 \mu \mathrm{M}$. In these experiments, cells were treated with chloroquine for 24 hours prior to lysis. Cycloheximide (Sigma, Cat. \#7698) is an inhibitor of

protein synthesis. Cycloheximide powder was dissolved in ethanol (Sigma, Cat. 
\#E7023) to a stock concentration of $20 \mathrm{mg} / \mathrm{mL}$ and diluted in complete media to a final concentration of $20 \mu \mathrm{g} / \mathrm{mL}$. Cells were treated for $0,2,4$, and 8 hours prior to lysis.

\subsubsection{Transfection reagents}

jetPRIME $®$ - The jetPRIME $®$ DNA/siRNA transfection reagent is manufactured by Polyplus Transfection (IIlkirch, France, Cat. \#114-07) and can be purchased from VWR (Cat. \#89129-922). jetPRIME® was primarily used for transient transfections. $1 \mu \mathrm{g}$ of each plasmid DNA construct to be transfected was diluted in $200 \mu \mathrm{L}$ of jetPRIME® transfection buffer, provided by the manufacturer, and vortexed briefly. To this, $2 \mu \mathrm{L}$ of jetPRIME $®$ was added per microgram of DNA. The mixture was then vortexed for 10 seconds, spun down for 10 seconds, then incubated at room temperature for 10 minutes. After incubation, the mixture was added dropwise to cells in a $60 \mathrm{~mm}$ culture dish, evenly dispersed by gentle rocking, and incubated for 16 hours at $37^{\circ} \mathrm{C}$. This reaction can be scaled for culture vessels of different sizes. Also, if cytotoxicity is observed, the $37^{\circ} \mathrm{C}$ incubation can be performed for 6 8 hours, followed by overnight incubation in fresh complete medium.

Lipofectamine $^{\mathrm{TM}} 3000$ - Lipofectamine ${ }^{\mathrm{TM}} 3000$ (Invitrogen, Cat. \#L3000008) is a lipid nanoparticle-based transfection reagent designed for cells that are difficult to transfect using other transfection reagents such as jetPRIME®. NCl-H1792, NCl$\mathrm{H} 1437$, and $\mathrm{NCl}-\mathrm{H} 1299$ cells were transfected using Lipofectamine $3000 \AA$ 
according to the manufacturer's protocol for generation of stable knockdown cell lines. For these transfections, $2-5 \mu \mathrm{g}$ of plasmid DNA and $2 \mu \mathrm{L}$ of $\mathrm{P} 3000^{\mathrm{TM}}$ reagent (provided by the manufacturer) were diluted in $125 \mu \mathrm{L}$ Opti-MEM reduced serum media (Gibco, Cat. \#31985070), briefly vortexed, and spun down for 2-3 seconds. $7.5 \mu \mathrm{L}$ of Lipofectamine ${ }^{\text {TM }} 3000$ reagent was diluted in another $125 \mu \mathrm{L}$ of OptiMEM, briefly vortexed, and spun down. $125 \mu \mathrm{L}$ of each mixture was combined and incubated at room temperature for 10 minutes. The mixture was then added dropwise to one well of cells in a 6-well plate and incubated at $37^{\circ} \mathrm{C}$ for 24 hours. Fresh media was then applied and the cells were incubated for an additional 24 hours prior to antibiotic selection.

\subsubsection{Lysis buffers}

Co-immunoprecipitation reactions require cell lysis to be performed in buffers that can disrupt the plasma membrane while leaving intact cytoplasmic protein-protein interactions. For this purpose, a modified RPIA buffer (NP-40 buffer) was used. This buffer consists of $50 \mathrm{mM}$ Tris- $\mathrm{HCl}$ pH $7.5200 \mathrm{mM} \mathrm{NaCl}$, and 1\% Tergitol ${ }^{\mathrm{TM}}$ Type NP-40 (Sigma, Cat. \#NP40). Cell lysates that did not require preservation of protein-protein interactions were prepared in RIPA buffer (Sigma, Cat. \#R0278), which contains $150 \mathrm{mM} \mathrm{NaCl,} \mathrm{1.0 \%} \mathrm{IGEPAL®} \mathrm{CA630,}$ $0.5 \%$ sodium deoxycholate, $0.1 \%$ sodium dodecyl sulfate (SDS), and $50 \mathrm{mM}$ Tris $\mathrm{pH}$ 8.0. Lysates for Active Ras pulldown assays were prepared in Active Ras

Pulldown Cell Lysis Buffer provided by the manufacturer (Cytoskeleton, Cat. 
\#BK008). It contains $50 \mathrm{mM}$ Tris $\mathrm{pH} 7.5,10 \mathrm{mM} \mathrm{MgCl}_{2}, 0.5 \mathrm{M} \mathrm{NaCl}$, and 2\%IGEPAL $®$ CA630. All lysis buffers were prepared fresh at time of cell lysis and supplemented with Protease Inhibitor Cocktail (Sigma, Cat. \#P8340), $1 \mathrm{mM}$ $\mathrm{Na}_{3} \mathrm{VO} 4$, and $1 \mathrm{mM} \mathrm{NaF}$.

\subsection{Molecular Biology}

During the course of this work, multiple plasmid constructs were used to confirm a novel protein-protein interaction and characterize its function. Overexpressed co-immunoprecipitations, fluorescent co-localization studies, and shRNA knockdown of endogenous proteins all employ the use of plasmid DNA constructs that can be propagated and purified from competent $E$. coli.

\subsubsection{Bacterial transformation}

Chemically competent DH5a cells were purchased from Invitrogen (Cat. \#18261-017). For bacterial transformation, approximately $100 \mathrm{ng}$ of whole plasmid was mixed with $30 \mu \mathrm{L} \mathrm{DH5 \alpha}$ bacteria and incubated on ice for 30 minutes. The bacteria were subjected to a $42^{\circ} \mathrm{C}$ heat shock for 45 seconds, allowing DNA to enter through pores in on the bacterial surface. This was followed by another 2minute incubation on ice. $200 \mu \mathrm{L}$ of SOC media (Corning, Cat. \#46-003-CR) was added to the mixture and incubated at $37^{\circ} \mathrm{C}$ for 1 hour. Following this, bacteria were gently resuspended and $100 \mu \mathrm{L}$ of this suspension was streaked on to LB 
agar plates [2\% LB Base (Invitrogen, Cat. \#12780052), 1\% Select Agar (Invitrogen, Cat. \#30391023)] containing the appropriate antibiotic based on the bacterial resistance marker of the plasmid. For these experiments, the antibiotic used was either Ampicillin (Sigma, Cat. \#A9518) at a concentration of $100 \mu \mathrm{g} / \mathrm{mL}$, or Kanamycin sulfate (Calbiochem, Cat. \#420331) at a concentration of $50 \mu \mathrm{g} / \mathrm{mL}$. Plates were incubated, inverted, overnight at $37^{\circ} \mathrm{C}$.

\subsubsection{Plasmid purification}

Following transformation, individual colonies were picked from the LB agar plates and grown in $5 \mathrm{~mL}$ a sterilized $2 \%$ solution of LB Base in water containing the appropriate antibiotic, using a shaking incubator at $37^{\circ} \mathrm{C}, 300$ RPM. $5 \mathrm{~mL}$ cultures were grown overnight and immediately used for DNA Plasmid Mini-Prep (Qiagen, Cat. \#27106), or used to inoculate $100 \mathrm{~mL}$ cultures for Midi-Prep (Qiagen, Cat. \#12145; Sigma, Cat. \#NA0200-1KT). Both DNA preparations were performed according to the manufacturer's protocol. Briefly, they involve lysis of the bacterial membrane followed by precipitation and pelleting of bacterial genomic DNA. Plasmid DNA is bound to a column, proteins and RNA are washed away, and plasmid DNA is finally eluted from the column. DNA concentration was determined using a NanoDrop ${ }^{\text {TM }} 8000$ Spectrophotometer (Thermo Scientific, Cat. \#ND-8000$\mathrm{GL})$.

2.4.3. Generation of stable RASSF1A and DAB2IP knockdown lines 
In order to characterize the interaction between RASSF1A and DAB2IP, we generated matched sets of $\mathrm{NCl}-\mathrm{H} 1792$ and $\mathrm{NCl}-\mathrm{H} 1437$ cells that were either wildtype or stably knocked down for DAB2IP and/or RASSF1A. We also generated a matched set of $\mathrm{NCl}-\mathrm{H} 1299$ cells in which DAB2IP was knocked down and RASSF1A was overexpressed.

Knockdown of RASSF1A in NCl-H1792 cells was described previously [11]. Briefly, an shRNA against RASSF1A was cloned into the pSM2 vector and transfected into NCl-H1792 cells. Cells were then selected in puromycin. pGIPZ and pSM2 both contain puromycin resistance markers, so lentiviral infection was used by Dr. Howard Donninger to knockdown DAB2IP these cells. To generate DAB2IP knockdown cells, 293FT cells were transfected with pGIPZ-shDAB2IP (see section 2.1) and viral packaging plasmids pLP1, pLP2, and pLP/VSVG (Invitrogen) at a ratio of 1:3 using jetPRIME® transfection reagent. 48-72 hours after transfection, growth medium containing viral particles was harvested and clarified by centrifugation at $2 \mathrm{krpm}$ for 5 minutes. $2 \mathrm{~mL}$ of the clarified viral supernatant supplemented with $5 \mu \mathrm{g} / \mathrm{mL}$ polybrene was applied to $\mathrm{NCl}-\mathrm{H} 1792$ cells overnight at $37^{\circ} \mathrm{C}$. Fresh medium was applied to the $293 \mathrm{FT}$ cells and the viral transduction was performed two additional times. After transduction, GFP-positive cells (which express GFP from stable incorporation of the DAB2IP shRNA) were selected using a MoFlo XDP Cell Sorter (Beckman Coulter).

Stable knockdown of DAB2IP and RASSF1A in NCl-H1437 cells was achieved by Lipofectamine ${ }^{\mathrm{TM}} 3000$ transfection followed by antibiotic selection. 
pGIPZ-shDAB2IP was transfected into $\mathrm{NCl}-\mathrm{H} 1437$ cells. 48 hours after transfection, cells were selected in $1.5 \mu \mathrm{g} / \mathrm{mL}$ puromycin (Sigma, Cat. \#883310MG). Stable transfectants were expanded and assayed/frozen as an early passage pooled population of cells. H1437-shDAB2IP and control cells were then transfected with pBRS-shRASSF1A 777 in a similar fashion, and selected in 6 $\mu \mathrm{g} / \mathrm{mL}$ blasticidin (Sigma, Cat. \#15205-25MG).

Stable re-expression of HA-RASSF1A in NCl-H1299 cells was described previously [148]. Briefly, $1 \mu \mathrm{g}$ of pZip-neoHA-RASSF1A was transfected into H1299 cells using Lipofectamine ${ }^{\mathrm{TM}}$ 2000, a precursor to Lipofectamine ${ }^{\mathrm{TM}} 3000$. Stable transfectants were selected in $500 \mu \mathrm{g} / \mathrm{mL}$ G4138 sulfate. Knockdown of DAB2IP in these cells was achieved in the same manner as in H1437 cells (see above). For each stably expressed shRNA or tagged expression construct, a stable line expressing an empty vector was generated to create a matched set of four lines that are $+/+,+/-,-/+$, and $-/-$ for RASSF1A/DAB2IP expression, respectively, in each lung cancer cell line.

\subsection{Biological assays}

Confirming and characterizing a novel protein binding interaction requires the use of many biological techniques. Some of the assays employed in this work to test the hypotheses established herein are technically involved and are performed over the course of several days or weeks. In vitro and in vivo growth 
assays and Western blot analysis of signaling pathways were utilized in this work. A detailed account of how these assays were performed is provided below.

\subsubsection{Growth assays}

A classical method of measuring the tumor suppressive ability of a protein is to assay its ability to restrict the growth of cultured cancer cells. There are multiple growth assays that will provide differing degrees of physiological relevance. Generally, the degree of relevance of a particular result is a dependent on the amount of stress applied to the cell in the course of the assay. For example, enhanced in vitro 2D growth in response to RASSF1A loss implicates RASSF1A as a suppressor of growth. Enhanced anchorage-independent growth or, better, enhanced xenograft growth in response to RASSF1A loss more clearly demonstrates the importance of RASSF1A in tumor suppression as it highlights the heartiness of RASSF1A-deficient cells and their ability to survive unfavorable conditions. In this investigation, two growth assays were used: a 2D growth curve and a subcutaneous xenograft growth curve.

\subsubsection{1. $2 D$ growth curves}

2D growth curves were performed in triplicate in 6-well plates. For each cell line, $10^{4}$ cells in log phase growth were plated in 9 wells of 6 -well plates. 24 hours after plating, 3 wells were trypsinized, pelleted, resuspended in complete growth 
medium, and counted on a hemocytometer. 3 wells were again counted on days 3 and 7.

\subsubsection{Xenograft growth curves}

Immunodeficient mice can be used to measure the in vivo effects of a protein on tumor formation. To identify differences in in vivo growth of the matched sets of knockdown cells, each cell line was seeded at low density in several T75 flasks and allowed to propagate for 3 days to reach log phase growth. Cells were trypsinized, pelleted, and washed twice in 1X PBS by resuspension and repelleting. Cells were finally resuspended at a concentration of $10 \times 10^{6} \mathrm{cells} / \mathrm{mL}$ in 1X PBS and placed on ice. For each cell line 6 NRG mice were anesthetized with isoflurane and $100 \mu \mathrm{L}$ of cell suspension containing $1 \times 10^{6}$ cells was injected subcutaneously into the left flank. Animals were monitored and tumor length and width measurements were taken with calipers. Tumor volume was calculated using

the formula $V=\frac{L \times W^{2}}{2}$. When the first tumors reached a diameter at $1.5 \mathrm{~cm}$, all animals were sacrificed and tumors were harvested and snap frozen in liquid nitrogen.

\subsubsection{Western blot analysis}

Western blotting was performed under reducing conditions. For this, $450 \mu \mathrm{L}$ 4X LDS sample buffer (Invitrogen, Cat. \#NP0007) was mixed with $50 \mu \mathrm{L}$ of 2- 
mercaptoethanol and stored in an amber microcentrifuge tube. Washed IP beads resuspended in RIPA buffer and whole cell lysates were combined with prepared LDS buffer and vortexed thoroughly to mix. Tubes were boiled at $95^{\circ} \mathrm{C}$ for 10 minutes to denature proteins, then spun down briefly to collect condensation on the tube lids. Samples were loaded onto a precast NuPAGE ${ }^{\mathrm{TM}} 4-12 \%$ Bis-Tris polyacrylamide gel (Invitrogen, Cat. \#NP0321BOX, NP0322BOX, NP0336BOX). Electrophoresis was performed at $120 \mathrm{~V}$ in $1 \mathrm{X}^{\mathrm{N}}$ NuPAGE ${ }^{\mathrm{TM}}$ MOPS SDS Running buffer (Invitrogen, Cat. \#NP0001) until the dye front reached the bottom of the gel.

Resolved proteins were transferred to a $0.2 \mu \mathrm{m}$ pore nitrocellulose membrane (Invitrogen, Cat. \#LC2009) using complete immersion (wet) transfer in 1X Transfer Buffer (5\% NuPAGE ${ }^{\mathrm{TM}}$ Transfer Buffer (20X) (Invitrogen, Cat. \#NP00061), 20\% methanol, 75\% DI water). Transfer buffer was cooled prior to use. Transfers were performed using the Mini Blot Module (Life Technologies, Cat. \#B1000) at $10 \mathrm{~V}$ for at least 3 hours.

After transferring, membranes were blocked for 1 hour in a $5 \%$ solution of non-fat dry milk in TBS-T. Membranes would then be washed twice for 2 minutes in TBS-T, then incubated with primary and secondary antibody as described in section 2.5.2.1. After each antibody incubation, membranes were washed 3 times for 5 minutes in TBS-T before continuing to the next incubation. After the secondary incubation, a fourth wash of 10 minutes in TBS-T was performed to ensure minimal background detection. Blots were then immersed in West Pico PLUS solution for 5 minutes. Bands were detected using chemi-luminescent detection film (MidSci ${ }^{\mathrm{TM}}$, Cat. \#EBA45). 


\subsubsection{Antibodies}

Hemagglutinin (HA) - Mouse a-HA monoclonal antibody was purchased from Covance (Cat. \#MMS-101P). For detection of HA-tagged proteins, the antibody was diluted at 1:10,000 in a 5\% solution of non-fat dry milk in Tris-buffered saline with Tween-20(TBS-T: $50 \mathrm{mM}$ Tris- $\mathrm{HCl} \mathrm{pH}$ 7.5, $150 \mathrm{mM} \mathrm{NaCl}, 0.1 \%$ Tween-20). Membranes were incubated in primary antibody overnight at $4^{\circ} \mathrm{C}$ with constant agitation, then in HRP-linked $\alpha$-mouse secondary antibody (Cell Signaling Technology, Cat. \#7076S) at a dilution of 1:10,000 in TBS-T for 1 hour at room temperature with constant agitation. Detection was performed using SuperSignal ${ }^{\mathrm{TM}}$ West Pico PLUS Chemi-Luminescence substrate (Thermo Scientific, Cat. \#34579).

Green fluorescent protein (GFP) - Mouse a-GFP (B2) monoclonal antibody was purchased from Santa Cruz Biotechonology (Cat. \#sc-9996). For detection of GFPtagged proteins, the antibody was diluted at $1: 200$ in a $5 \%$ solution of non-fat dry milk in TBS-T. Membranes were incubated in primary antibody overnight at $4^{\circ} \mathrm{C}$ with constant agitation, then in HRP-linked a-mouse secondary antibody at a dilution of 1:10,000 in TBS-T for 1 hour at room temperature with constant agitation. Detection was performed using West Pico PLUS. 
Phospho-S473 AKT - The Ser/Thr kinase AKT is phosphorylated at S473 in response to activation by Ras. Phosphorylation of AKT at S473 serves as a measure of Ras activity. Endogenous phosphorylated AKT was detected using a rabbit a-P-S473AKT polyclonal antibody (Cell Signaling Technology, Cat. \#4060S). The antibody was diluted at 1:1,000 in a $5 \%$ s solution of BSA in TBS-T. Membranes were incubated overnight at $4^{\circ} \mathrm{C}$ with constant agitation, then in HRPlinked a-rabbit secondary antibody at a dilution of 1:10,000 in TBS-T for 1 hour at room temperature with constant agitation. Detection was performed using West Pico PLUS.

AKT - Endogenous AKT was detected using a rabbit a-P-S536 NFkB p65 polyclonal antibody (Cell Signaling Technology, Cat. \#9272S). The antibody was diluted at $1: 1,000$ in a $5 \%$ s solution of BSA in TBS-T. Membranes were incubated overnight at $4^{\circ} \mathrm{C}$ with constant agitation, then in HRP-linked a-rabbit secondary antibody at a dilution of 1:10,000 in TBS-T for 1 hour at room temperature with constant agitation. Detection was performed using West Pico PLUS.

Phospho-ERK - Extracellular signal-regulated kinase 1/2 (ERK 1/2) is the terminal effector of the Ras-Raf-MEK-ERK pathway. Upon activation, ERK $1 / 2$ are phosphorylated on T202 and Y204, respectively. Endogenous phosphorylated ERK 1/2 were detected using a rabbit $\alpha-P-T 202 / Y 204$ ERK antibody (Cell Signaling Technology, Cat. \#9101S). The antibody was diluted at 1:1,000 in a 5\% solution of BSA in TBS-T. Membranes were incubated overnight at $4^{\circ} \mathrm{C}$ with 
constant agitation, then in HRP-linked a-rabbit secondary antibody at a dilution of 1:10,000 in TBS-T for 1 hour at room temperature with constant agitation. Detection was performed using West Pico PLUS.

ERK - Endogenous ERK 1/2 was detected using a rabbit $\alpha$-ERK 1/2 polyclonal antibody (Cell Signaling Technology, Cat. \#9102S). The antibody was diluted at $1: 1,000$ in a $5 \%$ solution of BSA in TBS-T. Membranes were incubated overnight at $4^{\circ} \mathrm{C}$ with constant agitation, then in HRP-linked $\alpha$-rabbit secondary antibody at a dilution of 1:10,000 in TBS-T for 1 hour at room temperature with constant agitation. Detection was performed using West Pico PLUS.

$D A B 2 I P$ - Endogenous DAB2IP was detected using a mouse $\alpha$-DAB2IP monoclonal antibody (Aviva Systems Biology, Cat. \#OAAL00940). The antibody was diluted at 1:1,000 in a 5\% solution of non-fat dry milk TBS-T. Membranes were incubated overnight at $4^{\circ} \mathrm{C}$ with constant agitation, then in HRP-linked $\alpha$-mouse secondary antibody at a dilution of 1:10,000 in TBS-T for 1 hour at room temperature with constant agitation. Detection was performed using West Pico PLUS.

RASSF1A - Endogenous RASSF1A was detected using a mouse a-RASSF1 (3F3) monoclonal antibody (Abcam, Cat. \#ab23950). The antibody was diluted at 1:200 in a $5 \%$ solution of non-fat dry milk in TBS-T. Membranes were incubated overnight at $4^{\circ} \mathrm{C}$ with constant agitation, then in HRP-linked a-mouse secondary 
antibody at a dilution of 1:2000 in TBS-T for 1 hour at room temperature with constant agitation. Detection was performed using West Pico PLUS. Expression of RASSF1A is often suppressed in cancer, making endogenous RASSF1A protein difficult to detect in some cell lines. To increase sensitivity, West Pico PLUS was supplemented with SuperSignal ${ }^{\mathrm{TM}}$ West Femto Maximum Sensitivity Substrate (Thermo Scientific, Cat. \#34094) at concentration of 10-15\%, as needed.

TrueBlot $®$ Mouse Secondary - For co-immunoprecipitation experiments, the primary antibodies used to detect endogenous protein were of the same species as conjugated antibody used in the agarose immunoprecipitation beads. This leads to detection of $\lg G$ heavy and light chain bands that may obscure bands of interest on Western blots. To avoid this, a TrueBlot $₫$ mouse secondary was used (Rockland Inc., Cat. \#18-8817-33), which does not detect IgG chains. TrueBlot mouse secondary was diluted at $1: 1,000$ in a $5 \%$ solution of non-fat dry milk. Incubation and detection were performed as with the standard mouse secondary antibody.

\subsection{Protein biochemistry}

\subsubsection{Co-immunoprecipitations}

Co-immunoprecipitation (Co-IP) is a widely-used technique for investing protein-protein interactions in cells. In this technique a protein of interest is bound 
by an antibody, and the protein-antibody complex is precipitated using beads, typically made of agarose, that bind to the Fc region of the antibody. In the case of exogenous tagged proteins, antibody pre-conjugated to agarose is commercially available to simplify the protocol. Whatever the case, the use of mild detergents in the lysis buffer is critical, as strong detergents like SDS readily disrupt proteinprotein interactions. This assay is straightforward in principle; however, the length of the assay and the multiple binding interactions that must be maintained ex-vivo for multiple days makes successful co-immunoprecipitation quite difficult to achieve, particularly for endogenous proteins that are expressed in low abundance.

\subsubsection{Immunoprecipitation of overexpressed proteins}

In this work, HEK-293T cells were transfected in $60 \mathrm{~mm}$ dishes 24 hours prior to lysis. Cells were scraped in an appropriate volume of NP-40 buffer, typically $350 \mu \mathrm{L}$, and transferred to a microcentrifuge tube. Cell suspensions were placed on a rotator and incubated at $4^{\circ} \mathrm{C}$ for 4 hours. The lysates were passed through a 21 ga needle five times, then centrifuged at $\geq 14 \mathrm{krpm}$ for 5 minutes at $4^{\circ} \mathrm{C}$. The supernatants were reserved and immediately placed on ice; the pellets were discarded. The protein concentrations of the lysates were determined using the Bio-Rad protein quantification assay (Cat. \#5000006). $1 \mathrm{mg}$ of whole cell lysate was used per immunoprecipitation (500 $\mu \mathrm{g}$ if there was insufficient volume for 1 $\mathrm{mg}$ ) and brought to a volume of $1 \mathrm{~mL}$ with NP-40 buffer in microcentrifuge tubes. 
$5 \mu \mathrm{L}$ of GFP-nAb ${ }^{\mathrm{TM}}$ agarose (Allele Biotechnology, Cat. \#ABP-nAb-GFPA025) was added to each tube. Samples were placed on a rotator and incubated at $4^{\circ} \mathrm{C}$ overnight. The next day, the beads were pelleted by centrifugation at $3 \mathrm{krpm}, 4^{\circ} \mathrm{C}$ for 3 minutes. The supernatant was aspirated and the beads were washed with $500 \mu \mathrm{L}$ of NP-40 buffer. This was repeated two additional times. After the third wash was aspirated, beads were resuspended in $10 \mu \mathrm{L}$ RIPA buffer and $4 \mu \mathrm{L}$ NuPAGE ${ }^{\text {TM }}$ LDS Sample Buffer (Invitrogen, Cat. \#NP0007). IPs and $30 \mu \mathrm{g}$ of whole cell lysate were resolved on SDS-PAGE gels and analyzed as described in section 2.5.2.

\subsubsection{Immunoprecipitation of endogenous proteins}

Endogenous proteins are immunoprecipitated using antibodies that recognize three-dimensional epitopes on the surface of the protein. Therefore, not all antibodies that recognize a protein on a Western blot, where the protein has been denatured, are appropriate for immunoprecipitation. In this particular experiment, the precipitated protein, RASSF1A, is endogenously expressed at low levels, and therefore large quantities of protein are needed for immunoprecipitation. This can be challenging using mild detergents like NP-40; however, such detergents are required for this assay and thus other steps were taken to maximize protein yield. Multiple $10 \mathrm{~cm}$ dishes were growth to confluence and scraped into a small volume of NP-40, typically $500 \mu \mathrm{L}$ for 2 dishes. The cell suspension was placed on a rotator and incubated at $4^{\circ} \mathrm{C}$ for 8 hours. The 
lysate was then passed through a 21 ga needle 5 times and centrifuged at $\geq 14$ $\mathrm{krpm}, 4^{\circ} \mathrm{C}$ for 10 minutes. The supernatant was transferred to a new microcentrifuge tube and centrifuged again if needed to obtain a clear lysate. Protein concentration was again determined using the Bio-Rad protein quantification assay. $8 \mathrm{mg}$ of whole cell lysate was aliquoted into two microcentrifuge tubes ( $4 \mathrm{mg}$ per tube) and each was diluted to a final volume of 1 $\mathrm{mL} .1 \mathrm{~mL}$ of NP-40 buffer was added to a third tube. The buffer tube and one of the lysate tubes served as negative controls. To one lysate-containing tube and the buffer only tube, the immunoprecipitation antibody was added. NP-40 buffer was added to remaining tube as a blank. All tubes were placed on a rotator and incubated at $4^{\circ} \mathrm{C}$ overnight. The next morning, $20 \mu \mathrm{L}$ of TrueBlot $\AA$ IP beads (Rockland Inc., Cat. \#00-8800-25) were added to each tube, and tubes were rotated at $4^{\circ} \mathrm{C}$ for 2 hours. The beads were washed three times with NP-40 buffer and resuspended as described in section 2.6.1.1.

\subsubsection{Active Ras pulldown assay}

Analysis of downstream signaling activity is a useful method of determining the activation state of a particular protein if downstream targets are known and reagents to detect their activation are available. In cancer, however, such a method can often lead to inconclusive results. First, the complex networks involved in cell signaling result in effector proteins usually having multiple upstream regulators, and so the activity of an effector may not be readily attributable to the regulator of 
interest. Indeed, this is the case in homeostatic tissue as well. Additionally, a hallmark of cancer is dysregulation of cell signaling. Mutations or other disruption in different parts of a particular pathway may obscure the activity of the protein of interest. Thus, a method of directly measuring the activation state of a protein is favorable when possible.

Fortunately, since Ras is a small GTPase whose binding affinity depends on its activation state, the degree of activation of Ras can be determined directly by precipitating the active GTP-bound form of Ras using an exogenously expressed Ras Binding Domain (RBD) conjugated to agarose beads. The Active Ras Pulldown Kit (Cytoskeleton, Cat. \#BK008) was used to perform this assay according to the manufacturer's protocol. $10 \mathrm{~cm}$ dishes of each cell line were seeded at $5 \times 10^{5}$ cells per dish and incubated for 72 hours to achieve log phase growth. Cells were then washed once with ice-cold 1X PBS and scraped, on ice, into Cell Lysis Buffer provided by the manufacturer (see section 2.4.4). Cell suspensions were transferred to microcentrifuge tubes and were passed through a 21 ga needle five times, then centrifuged at $10 \mathrm{krpm}$ for 10 minutes. After centrifugation, the supernatants were transferred to clean microcentrifuge tubes. $30 \mu \mathrm{L}$ of each lysate was aliquoted for protein quantification using the Pierce ${ }^{\mathrm{TM}}$ BCA Protein Assay (Thermo Scientific, Cat. \#23225). The remaining lysates were snap frozen in liquid nitrogen to prevent GTP hydrolysis. After quantification, lysates were thawed in a room temperature water bath and immediately placed on ice. $500 \mu \mathrm{g}$ of whole cell lysate was diluted to a final volume of $500 \mu \mathrm{L}$, and $10 \mu \mathrm{L}$ Raf-RBD agarose beads were added to each sample. Samples were placed on a 
rotator and incubated at $4^{\circ} \mathrm{C}$ for 1 hour. Beads were pelleted by centrifugation at $3,000 \times \mathrm{g}, 4^{\circ} \mathrm{C}$ for 1 minute. The -supernatants were aspirated, then beads were washed once with $500 \mu \mathrm{L}$ of Wash Buffer provided by the manufacturer. Beads were again pelleted by centrifugation at $5,000 \times \mathrm{g}, 4^{\circ} \mathrm{C}$ for 3 minutes. The Wash Buffer was aspirated and the beads were resuspended in $10 \mu \mathrm{L}$ RIPA buffer and $4 \mu \mathrm{L}$ LDS Sample Buffer. IPs and $30 \mu \mathrm{g}$ whole cell lysate were resolved on SDSPAGE gels and analyzed as described in section 2.6.2. 


\section{CHAPTER III}

\section{RASSF1A BINDS THE RASGAP DAB2IP}

\subsection{Introduction}

Ras is the most frequently activated oncogene in human cancer, with point mutations occurring in approximately $30 \%$ of all tumors [27]. Experimentally, mutant Ras has been shown repeatedly to rapidly transform cultured cells [209211]. Upon activation, Ras binds multiple downstream mitogenic effectors, whose activities synergize to confer potent transforming abilities to Ras. The three best characterized mitogenic effectors are Raf, PI3K, and RaIGDS [212]. For decades, attempts have been made to target the Ras proteins therapeutically as a treatment for cancer, and for decades those attempts have failed [213]. That is, until very recently. Several reports in the past five years have revealed a previously unknown characteristic of a particular Ras mutant. In the course of developing covalent inhibitors of K-Ras ${ }^{\mathrm{G} 12 \mathrm{C}}$, it was demonstrated that this mutant actively undergoes GTP-GDP cycling in tumors, and these inhibitors work by trapping the Ras mutant in the GDP-bound state [116].

While Ras can transform immortalized cells, it invokes apoptosis and premature senescence in primary cells $[8,214]$. Much about this paradoxical 
growth inhibitory nature of Ras remains to be discovered; however, the RASSF family of tumor suppressors has been implicated in mediating these effects, particularly RASSF1A $[9,127]$. In order to induce transformation, Ras requires cooperating mutations, such as deletion of p53 or activation of MYC [215-217]. This aids Ras-mediated transformation in part by blocking apoptosis/senescence in response to Ras hyperactivation $[218,219]$. Similarly, loss of RASSF1A expression, a frequent event in human cancer primarily caused by promoter hypermethylation, has also been shown to contribute to Ras-mediated transformation [14, 127, 131]. RASSF1A binds Ras directly and induces apoptosis in a GTP-dependent manner [11, 122]. Mechanisms of RASSF1A-induced growth arrest are not fully described, but among the best characterized RASSF1A effectors are the Hippo kinases MST1/2 and Bax, an inducer of mitochondrial apoptosis.

RASSF1A lacks apparent enzymatic activity, instead functioning as a scaffold. Upon Ras activation, RASSF1A bind Ras-GTP and connects it to modulator of apoptosis-1 (MOAP-1) [11], or the MST kinases [220], activating them and subsequently inducing apoptosis through Bax or the transcriptional activator YAP, respectively $[11,138,141,145,146,220,221]$. Thus, the frequent loss of RASSF1A in cancer, considered an early/premalignant lesion [130, 222, 223], permits Ras-mediated transformation by uncoupling Ras from its apoptotic effector pathways. However, this is not the full extent of deregulation caused by loss of RASSF1A expression. Indeed, multiple groups have reported upregulation of Ras mitogenic signaling, including Raf-Mek-Erk, PI3K-AKT, and RalGDS-Ral, upon 
downregulation of RASSF1A in vitro and in vivo $[13,14,17]$. Collectively, this work lends itself to the tantalizing possibility of a feedback inhibition activity of RASSF1A on Ras, an exceedingly common mechanism of protein inhibition generally, but one that has not yet been described for Ras [37].

RASSF1A has been shown previously to modulate the activation on AKT and Raf; however, the ultimate effect of these interactions is unclear. Raf can bind to the Hippo kinase MST2 and inhibit its activation [224]. However, this interaction also inhibits Raf by preventing its activation by Ras [16]. RASSF1A and Raf compete for binding with MST2, and disruption of the Raf-MST2 complex is required for RASSF1A-MST2-induced apoptosis [138]. This suggests that the RASSF1A-MST2 interaction would serve to counterintuitively activate Ras-RafMek-Erk [9]. Raf activity is regulated by phosphorylation, and S259 is an inhibitory residue. Phosphorylation of Raf at S259 is mediated by AKT and enhances its reciprocally inhibitory association with MST2 [225]. AKT also phosphorylates MST2, which enhances its interaction with Raf [15]. RASSF1A inhibits these phosphorylation events by blocking the activating phosphorylation of AKT on S473 [13]. The direct mechanism of AKT inhibition by RASSF1A has not been reported. S473 phosphorylation of AKT is regulated by the mammalian target of rapamycin complex 2 (mTORC2) [13, 226], which in turn is activated by Ras [227]. Thus, control of AKT by RASSF1A may not be direct, but instead mediated through control of RAS activation.

Because of its apoptotic nature and frequent inactivation in premalignant tissue, it was long suspected that RASSF1A suppression was an important step in 
Ras-mediated tumorigenesis. In 2018, the definitive experiment proving this hypothesis was performed [14].Using rassf1 transgenic mice that also harbored a doxycycline-inducible $k \mathrm{~s}^{G 12 V}$ mutation specifically in type II pneumocytes, it was shown that loss of one allele of rassf1 was sufficient to significantly enhance Rasmediated tumor initiation and growth. These tumors exhibited simultaneous activation of the three canonical Ras effector pathways. Moreover, loss of one allele of rassf1a alone-without induction of mutant kras-was sufficient to enhance Ras mitogenic signaling in normal lung tissue [14]. This suggested that perhaps RASSF1A loss can stimulate RAS. In the course of studying the tumor suppressive activities of RASSF1A, this lab commissioned a yeast two-hybrid screen, using RASSF1A as bait, to identify novel binding partners (Myriad Genetics, Salt Lake City, UT). The RasGAP DAB2IP was identified as a binding partner for the 37-120 aa region of RASSF1A, which contains the cysteine-rich domain CRD.

\subsection{Results}

We hypothesized that RASSF1A may regulate Ras by enhancing the RasRasGAP interaction. Thus, we began our investigation by confirming the interaction between RASSF1A and DAB2IP.

\subsubsection{DAB2IP co-localizes with RASSF1A at the microtubules}


RASSF1A is an important regulator of microtubule dynamics, and as such prominently localizes to the microtubules when overexpressed [151, 152, 228]. The subcellular localization of DAB2IP is more complex. DAB2IP plays an important role in regulating neuron and dendrite growth in the developing brain [229-231]. Thus, its localization in these specialized cells is well characterized. Its localization in other tissues has not been well characterized. DAB2IP has been detected at the plasma membrane, in a complex with TNFR in resting cells [182]. As DAB2IP is a RasGAP, it is undoubtedly recruited to the plasma membrane in response to Ras activation. We determined whether RASSF1A and DAB2IP colocalized in mammalian cells using transient transfection of fluorescent-tagged expression constructs in COS-7 cells (figure 8). GFP and Katushka (KATE) expression constructs were used as negative controls. Katushka is a far-red fluorescent protein derived from E. quadricolor [232, 233]. As expected, the negative controls nonspecifically filled the cytoplasm, whereas RASSF1A was localized to microtubules. When expressed alone, DA2BIP filled the cytoplasm; however, co-expression of RASSF1A and DAB2IP results in recruitment of DAB2IP to the microtubules with RASSF1A. 

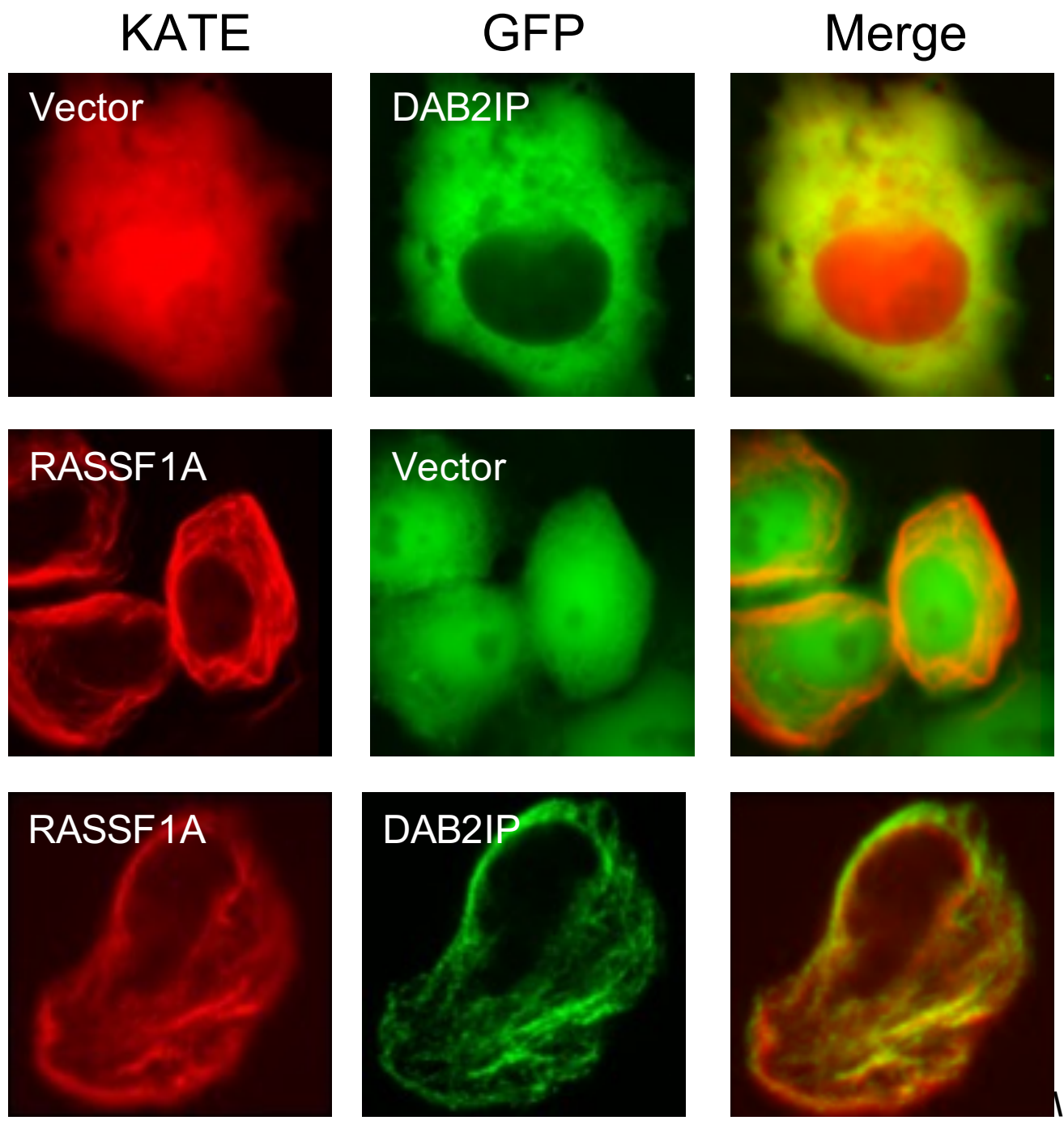

Figure 8. RASSF1A and DAB2IP colocalize in COS-7 cells. COS-7 cells were transiently transfected for 24 hours with GFP-tagged DAB2IP and KATE-tagged DAB2IP either together or with the empty expression vector of the other protein. RASSF1A prominently localizes at the microtubules when overexpressed alone, whereas DAB2IP fills the cytoplasm. When together, RASSF1a recruits DAB2IP to the microtubules. Representative images were captured using an IX50 inverted system microscope (Olympus) and a SPOT camera (Diagnostic Instruments, Inc.) 


\subsubsection{RASSF1A associates with DAB2IP independent of Ras}

To ensure the co-localization of DAB2IP and RASSF1A observed in COS7 cells was due to direct association of the two proteins, we performed transient overexpression of epitope-tagged constructs followed by co-immunoprecipitation assays (figure 9). We hypothesized that RASSF1A mediated its suppression of Ras through scaffolding activated Ras to its RasGAP inhibitor. Thus, we expected the RASSF1A-DAB2IP interaction to be dependent on Ras activation and so included a constitutively activate K-Ras ${ }^{\mathrm{G} 12 \mathrm{~V}}$ mutant in our study. To our surprise, we found that inclusion of the Ras mutant did not enhance the association between HA-RASSF1A and GFP-DAB2IP.

Finally, we sought to detect the endogenous association of RASSF1A and DAB2IP in human cells (figure 10). RASSF1A is a difficult protein to detect endogenously. It is a tumor suppressor and inhibitor of cell cycle progression, and thus is expressed at low levels in normal tissues. Its expression is commonly suppressed in human tumors and cancer cell lines, compounding the issue. Antibodies against RASSF1A that are suitable for immunoprecipitation are not commercially available. Moreover, $\alpha$-RASSF1A antibodies for Western blotting are not very sensitive in our hands, and detecting endogenous RASSF1A requires resolving large amounts of protein on gels. To provide the most favorable conditions possible, we performed endogenous co-immunopreciptation in MCF10A breast epithelial cells. This is a non-transformed epithelial cell line. While not a lung cancer cell line, we chose to use MCF-10A cells for this assay 


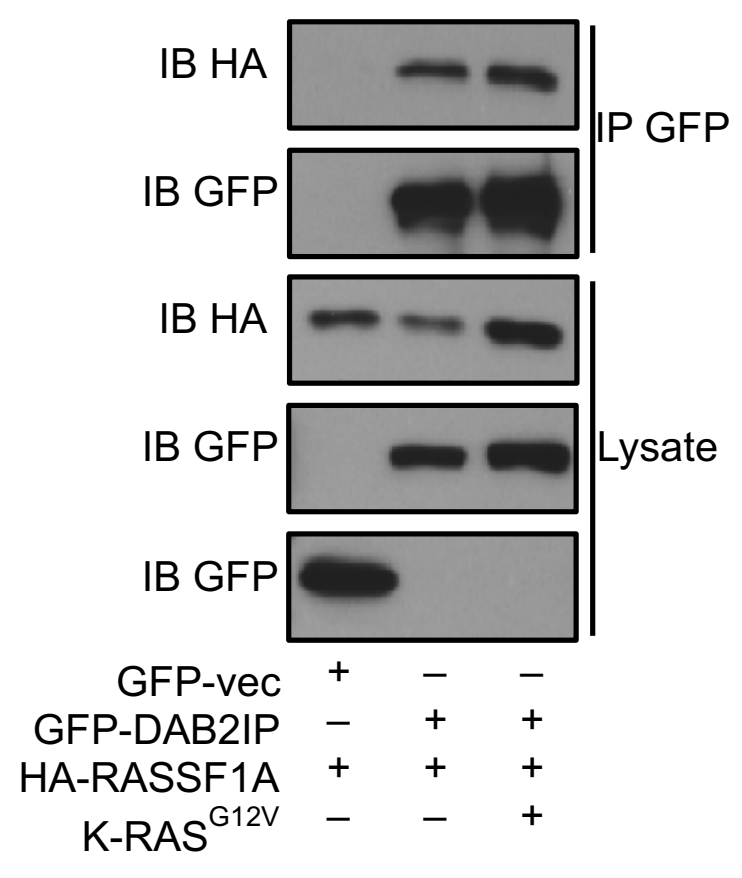

Figure 9: RASSF1A and DAB2IP co-immunoprecipitate when overexpressed. HEK-293T cells were co-transfected with GFP-DAB2IP, HA-RASSF1A and oncogenic K-Ras ${ }^{\mathrm{G} 12 \mathrm{~V}}$ for 24 hours. Cells were lysed and lysates were immunoprecipitated (IP) with GFP-nAb ${ }^{\mathrm{TM}}$ agarose beads and immunoblotted (IB) for the indicated epitope tags. 


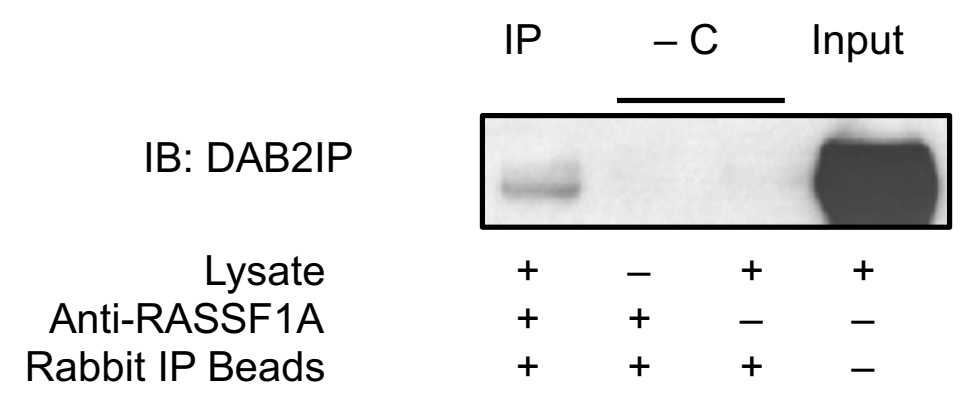

Figure 10: RASSF1A and DAB2IP form an endogenous complex. Whole cell lysates were prepared from MCF-10A cells. Lysates were immunoprecipitated (IP) with a rabbit polyclonal RASSF1A antibody (Prosci, Poway, CA) and anti-rabbit IgG immunoprecipitation beads for 16 hours and immunoblotted (IB) for DAB2IP. Whole cell lysates served as a positive control. Anti-RASSF1A/lgG beads incubated in lysis buffer and IgG beads incubated in whole cell lysate were used as negative controls. 
because they can be easily grown in large quantities and express relatively high amounts of RASSF1A compared to cancer cell lines. Using a rabbit polyclonal antibody against RASSF1A (generated by Prosci using the peptide ELRELAPAGRAGKGRTRLER, [14]) we successfully detected the endogenous interaction between DAB2IP and RASSF1A.

\subsubsection{RASSF1A regulates DAB2IP protein levels}

To identify a biological role for the novel RASSF1A-DAB2IP tumor suppressor complex, we chose to disrupt the interaction using shRNA-mediated knockdown of each protein alone and in combination. The use of shRNAs is not as clean or cutting-edge as newer techniques such as CRISPR-Cas9-mediated knockout. However, we chose this method of gene suppression because it more accurately mimics the method of RASSF1A and DAB2IP suppression in lung tumors of real patients. The expression and activities of RASSF1A and DAB2IP are both suppressed frequently in lung cancer; however, neither is usually lost entirely. Mutations in these genes are rare, therefore functional ablation of their signaling activities is not a physiological mechanism of suppression in this case. The major mechanism of RASSF1A and DAB2IP suppression in cancer is promoter hypermethylation [171, 234]. Thus, expression is reduced, sometimes substantially, but rarely completely absent. Indeed, the suppressed-but-not-absent state of Ras effectors in cancer may be of particular importance in Ras-driven tumors, as mutant Ras may be supported by the remaining wild-type alleles [137]. 
In the mouse study, effects of RASSF1A on Ras mitogenic signaling were observed in mutant K-Ras -induced and -uninduced tissues [14]. Thus, for these experiments we chose to employ the use of $\mathrm{NCl}-1437 \mathrm{NSCLC}$ cells, which retain wild-type Ras expression, and NCl-H1792 NSCLC cells, which harbor a heterozygous mutation in KRAS, resulting in a $\mathrm{G} 12 \mathrm{C}$ substitution $[207,235,236]$. When we confirmed the knockdown of RASSF1A and DAB2IP in these cells, we found that expression of the shRNA-mediated knockdown of RASSF1A caused a striking reduction in DAB2IP protein levels (figure 11). This was not a nonspecific effect of the shRNA as $\mathrm{NCl}-\mathrm{H} 1792$ and $\mathrm{NCl}-\mathrm{H} 1473$ were transfected with different shRNA constructs and selected using different resistance markers. Moreover, stable re-expression of RASSF1A in NCl-H1299 cells, which lack endogenous RASSF1A expression, increased DAB2IP protein levels (figure 12).

RASSF1A has been shown to regulate the stability of other cellular proteins, in part through regulating proteasomal degradation [144, 148, 237, 238]. DAB2IP has been shown to contain phosphodegron sequences that target it for degradation by FBW7-SCF complexes [171]. We hypothesized that RASSF1A may regulate DAB2IP stability by inhibiting its proteasomal degradation. To test this, we treated $\mathrm{NCl}-\mathrm{H} 1792$ cells with the proteasome inhibitor MG-132. MG-132 treatment had no significant effect on DAB2IP protein levels in these cells (Figure 13a). We also inhibited lysosomal activity by treating 
$\mathrm{H} 1792$

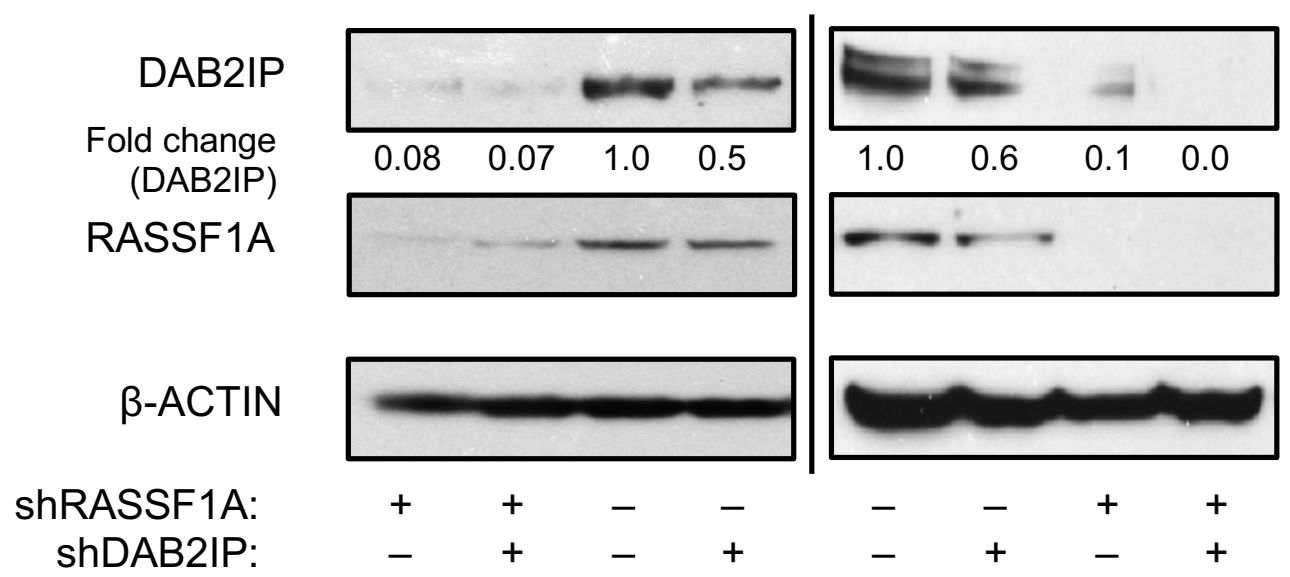

Figure 11: Confirmation of shRNA knockdown of RASSF1A/DAB2IP in NCIH1792 and NCI-H1437 cells. NCl-H1792 cells expressing pSM1-shRASSF1A or empty vector [11], were transfected for 24 hours with pGIPZ-shDAB2IP or empty vector. pGIPZ contains a GFP marker, and GFP-positive cells were isolated using a MoFlo XDP cell sorter (Beckman Coulter), and then selected in $2.5 \mu \mathrm{g} / \mathrm{mL}$ puromycin. $\mathrm{NCl}-1437$ cells were sequentially transfected and selected with pGIPZshDAB2IP/pBRS-shRASSf1A and $1.5 \mu \mathrm{g} / \mathrm{mL}$ puromycin $/ 6 \mu \mathrm{g} / \mathrm{mL}$ blasticidin, respectively. Cells were maintained as an early-passage pooled population and knockdown was confirmed via Western blot. Band density was quantified using ImageJ and DAB2IP fold change was calculated by normalizing to vectorexpressing cells. 
H1299
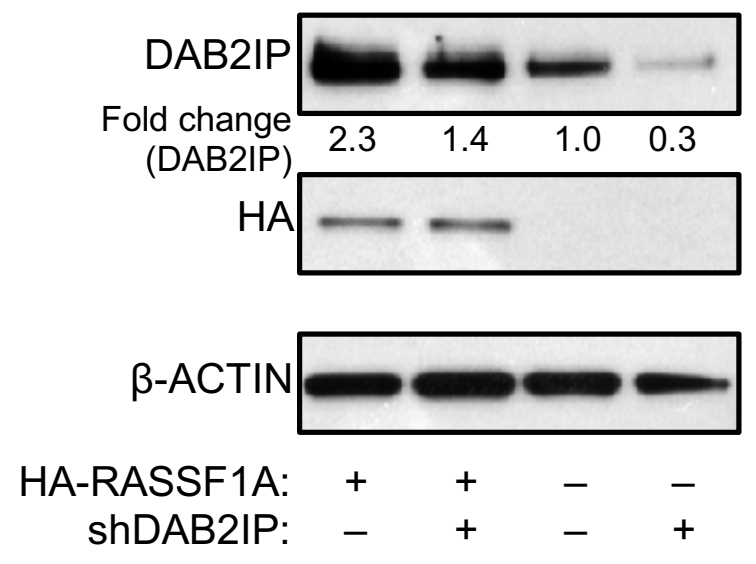

Figure 12: Exogenous re-expression of RASSF1A upregulates DAB2IP in lung cancer cells. $\mathrm{NCl}-\mathrm{H} 1299$ cells stably expressing pZip-HA-RASSF1A or empty vector [11] were transfected for 24 hours with pGIPZ-shDAB2IP or empty vector and selected in $1 \mu \mathrm{g} / \mathrm{mL}$ puromycin. Cells were maintained as an earlypassage pooled population of cells, and DAB2IP knockdown was confirmed via Western blot. Band density was quantified in Image J and DAB2IP fold change was calculated by normalizing to vector-expressing cells (lane 3 ). 


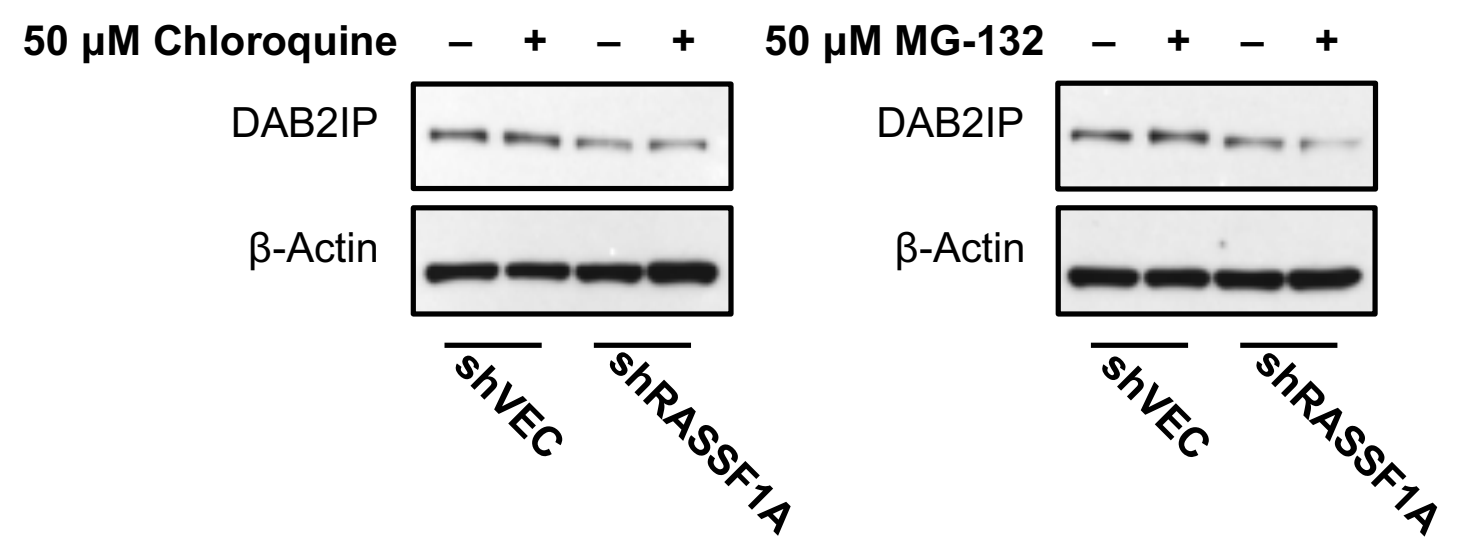

$\square$ CON
$\square$ ShRASSF1A

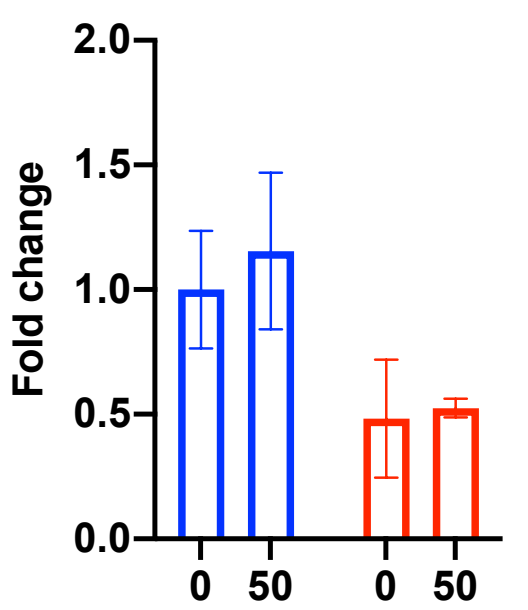

Conc. Chloroquine $(\mu \mathrm{M})$

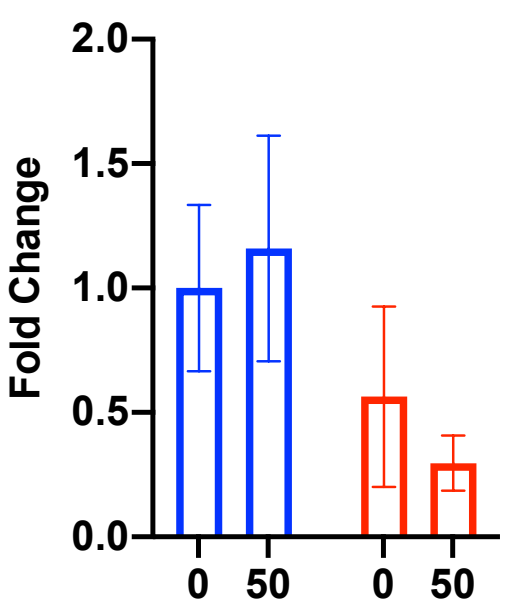

Conc. MG-132 ( $\mu \mathrm{M})$

Figure 13. Effects of chloroquine and MG-132 treatment on DAB2IP protein levels in $\mathrm{NCl}-\mathrm{H} 1792$ cells. $\mathrm{NCl}-\mathrm{H} 1792$ cells were treated with either $50 \mu \mathrm{M}$ chloroquine for 24 hours or $50 \mu \mathrm{M}$ MG-132 for 4 hours. Cells were lysed in RIPA buffer and DAB2IP levels were measured via Western blot. Experiments were performed in duplicate and quantified using ImageJ. 
the cells with chloroquine [239]; however, lysosomal inhibition also had no effect on DAB2IP protein levels (figure 13b).

\subsection{Discussion}

The RASSF1A tumor suppressor is an important mediator of Ras-induced apoptosis $[11,122,138,238,240]$. RASSF1A expression is frequently suppressed in human tumors by promoter hypermethylation [223, 241-245]. Loss of RASSF1A activity uncouples oncogenic Ras from pro-apoptotic signaling and facilitates unrestrained Ras mitogenic activity. Furthermore, reports of RASSF1A modulating Ras mitogenic activity suggest that RASSF1A may also directly regulate Ras activation $[13,14,16,17]$.

In our studies, we identified a novel binding interaction between RASSF1A and another tumor suppressor, DAB2IP, that is an important GAP for RAS [18, 37, 180]. Thus, we hypothesized and confirmed that RASSF1A and DAB2IP form an endogenous complex in human cells. However, while we expected this interaction to be regulated by Ras activation, we found that RASSF1A associated with DAB2IP irrespective of Ras activation. Perhaps our most important observation was that shRNA-mediated knockdown of RASSF1A significantly downregulated DAB2IP protein levels.

These results clearly demonstrate a physiological interaction between RASSF1A and DAB2IP, but the exact function of the interaction remains elusive. The function of RASSF1A as a scaffolding protein for Ras guided our initial 
investigation in to the RASSF1A-DAB2IP complex. Ras activation has been shown previously as a prerequisite for interactions between RASSF proteins and their effectors [11, 137, 246, 247]. However, in our co-immunoprecipitation studies we observed no such dependence on Ras activity of the interaction between DAB2IP and RASSF1A. What we did find was that RASSF1A upregulates DAB2IP proteins levels in human NSCLC cells.

Ras is rendered constitutively active by point mutation in many tumors [35]. However, this is not the only mechanism by which Ras can be rendered hyperactive. Aberrant activity of Ras-regulating proteins, GEFs and GAPs, can also give rise to Ras-driven tumors. Such is the case in the RASopathy Noonan syndrome, a familial cancer syndrome frequently caused by germline activating mutations in the Ras/MAPK pathway [248]. While germline mutations in Ras genes themselves are to blame for some cases, in others, mutations in upstream activators of Ras such as SOS1 have been reported [249, 250]. Another RASopathy, neurofibromatosis type 1 (NF1), is caused by deleterious mutation in the RasGAP gene NF1 [251]. In addition, deletions in NF1 may occur in up to $25 \%$ of breast tumors [252]. Multiple RasGAPs, including DAB2iP have been found to be dysregulated in human cancer [169]. This dysregulation can be critical tumor progression. Indeed, suppression of DAB2IP is a frequent event and primary driver in prostate cancer $[167,200]$. Thus, the loss of DAB2IP upon RASSF1A suppression is likely a significant contributor to the phenotype observed in RASSF1A-deficient cells. 
DAB2IP is regulated at the levels of transcription, translation, and posttranslation. Phosphorylation is the predominant post-translational modification of DAB2IP, resulting in its activation, inhibition, or targeting for proteasomal degradation depending on the phosphorylated residue [178, 184]. Interestingly, DAB2IP is inhibited by AKT via phosphorylation at S847, which targets DAB2IP for proteasomal degradation [178]. RASSF1A inhibits AKT [13]. Thus, RASSF1A may stabilize DAB2IP by inhibiting its AKT-mediated degradation. However, this mechanism involves the proteasome, and proteasomal inhibition with MG-132 did not significantly affect DAB2IP protein levels (figure 4). Antibodies to detect phosphorylated residues of DAB2IP are not commercially available, therefore the effect of RASSF1A on DAB2IP phosphorylation cannot be determined by Western blot. DAB2IP was not previously identified as being under the transcriptional control of RASSF1A [253]. However, comparison of RASSF1A and DAB2lp expression in lung adenocarcinoma tumors in The Cancer Genome Atlas (TCGA), reveals a strong correlation (figure 14), suggesting that the control of DAB2IP by RASSF1A may be transcriptional in nature after all. Additionally, DAB2IP expression is also regulated by microRNAs $[177,194,254,255]$. Thus, it is possible that RASSF1A may regulate the transcription of a microRNA that regulates DAB2IP. 


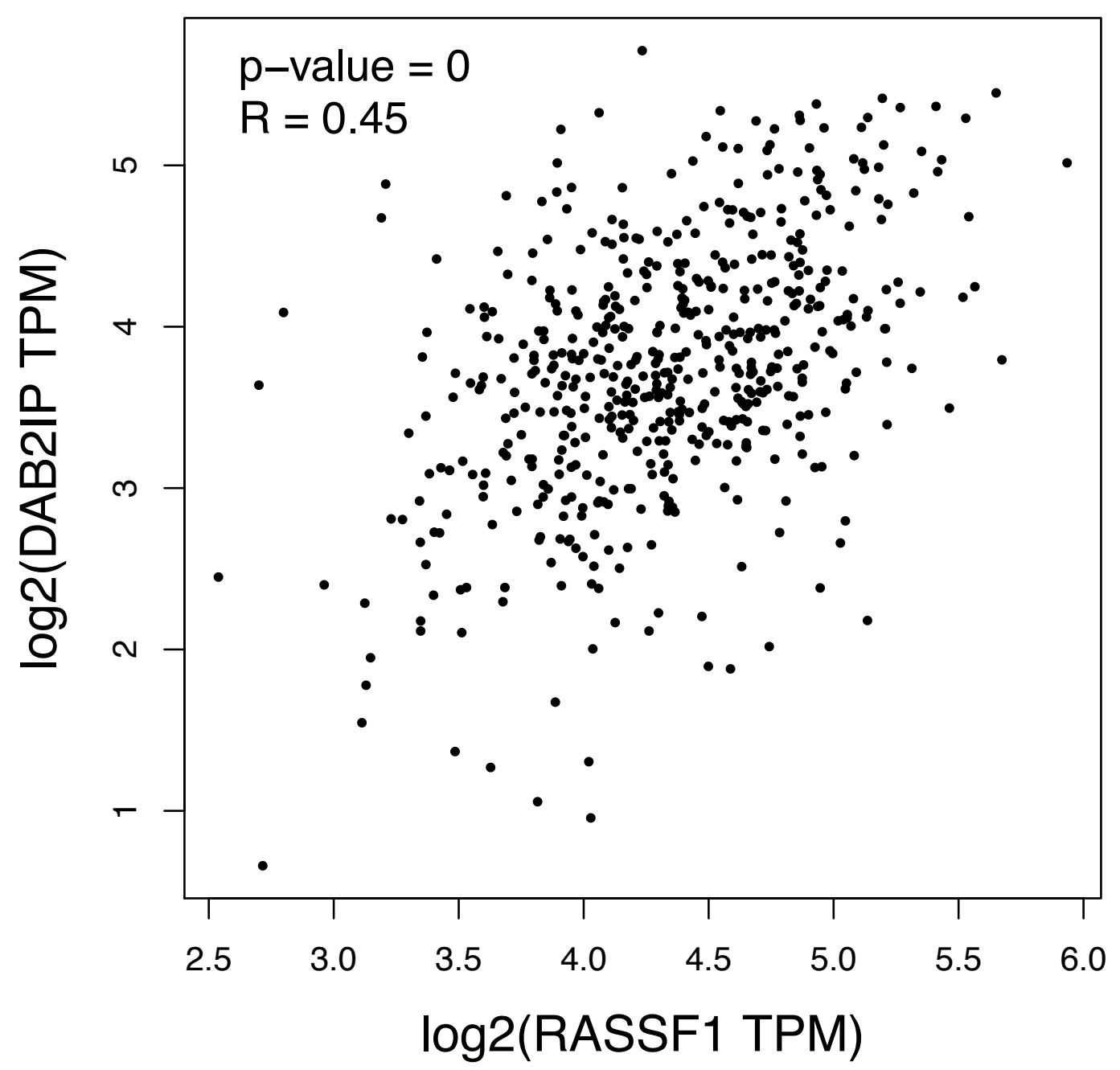

Figure 14: Correlation of RASSF1A and DAB2IP expression in patient lung adenocarcinoma tumors. RNA-seq expression analyses of RASSF1 and $D A B 2 I P$ genes in human lung adenocarcinoma tumor and normal tissue samples in The Cancer Genome Atlas (TCGA) were accessed through GEPIA [256]. Log 2 of transcripts per kilobase million (TMP) of DAB2IP was plotted against that of RASSF1. Correlation was calculated using Pearson's correlation coefficient. 


\section{CHAPTER IV}

\section{EFFECTS OF RASSF1A AND DAB2IP ON GROWTH AND RAS SIGNALING}

\subsection{Introduction}

While deregulated Ras is a potent oncoprotein, properly regulated Ras signaling plays an important, and sometimes indispensable role in embryogenesis and tissue homeostasis [257-259]. Normal activation of Ras involves a multiprotein complex consisting of Ras, receptor tyrosine kinases, adaptor molecules, and GEFs [24]. A classical example is EGFR-GRB2-SOS1-Ras. All of these proteins can be overexpressed or mutationally activated in cancer, leading to enhanced Ras-MAPK signaling [260-262]. Less is known about how the inactivation of Ras is regulated. However, the Ras-RasGAP interaction is direct, and the most common mutations in Ras render it constitutively active by preventing the catalytic subunit of RasGAPs from being properly positioned in the Ras active site [38]. Mutation of the RasGAP NF1 is both the basis of a familial cancer syndrome and detectable in sporadic human tumors [33, 34, 263]. Other RasGAPs, such as DAB2IP, are not commonly mutated in cancer. Rather, their expression is suppressed by epigenetic mechanisms [169, 171]. These alternative mechanisms of Ras dysregulation play important roles in disease. For example, 
Ras mutations occur in less than $5 \%$ of breast tumors [35]. However, elevated Ras-MAPK signaling is detected in approximately $50 \%$ of breast tumors, particularly in aggressive subtypes, due to dysregulation upstream and downstream of Ras [170, 197, 264-266].

DAB2IP is downregulated in breast, lung, prostate, and gastrointestinal cancer [171]. The GTPase activity of DAB2IP was identified when it was first discovered [18]. GAP activity against Ras is an important mechanism of DAB2IPmediated tumor suppression, but it is only partially responsible for the full tumor suppressive phenotype of DAB2IP [37]. DAB2IP is a multi-faceted tumor suppressor, that also acts independently of Ras to regulate multiple cellular processes critical to cancer progression, including EMT, proliferation, and apoptosis/survival [36].

DAB2IP utilizes independent domains to simultaneously suppress tumor initiation and metastasis [167]. Through the GAP domain, DAB2IP suppresses Ras-MAPK signaling and inhibits tumor initiation/growth. DAB2IP also inhibits metastasis by inhibiting NFKB activation. Ras stimulates NFKB $[267,268]$. Therefore, DAB2IP-mediated inhibition of Ras may indirectly suppress NFkB to some extent; however, GAP activity is dispensable for DAB2IP-mediated suppression of NFKB [167]. Indeed, suppression of NFKB is part of the proapoptotic transduction of TNFR signaling by DAB2IP, wherein phosphorylated DAB2IP simultaneously inhibits pro-survival signaling through NFKB and activates the pro-apoptotic ASK/JNK pathway [180, 182, 184, 189]. Interestingly, Raf inhibits 
ASK1 activation [269, 270]. Thus again, GAP activity may play an indirect role in potentiating a GAP-independent process of DAB2IP.

A third convergence of GAP-dependent and -independent activities of DAB2IP involves the PI3K-AKT pathway. As a canonical Ras effector, GAP activity obviously suppresses PI3K activation. However, it has been shown that DAB2IP can directly bind the p85 regulatory subunit of PI3K, sequestering the p85-p110 complex and preventing its activation of AKT [165]. This also requires TNFdependent phosphorylation of DAB2IP, and is therefore part of its anti-survival/proapoptotic activity.

DAB2IP is a complex tumor suppressor that is tightly interwoven with Ras signaling. DAB2IP restrains Ras-mediated tumorigenesis by inhibiting Ras itself and its effectors, canonical or otherwise, by distinct Ras-dependent and independent mechanisms. Thus, loss of DAB2IP expression in cancer substantially disrupts homeostatic signaling and favors tumor growth and metastasis $[37,169,171]$. We have found that DAB2IP protein levels are regulated by RASSF1A and that suppression of RASSF1A, an exceedingly common event in cancer [127, 131], markedly downregulates DAB2IP (see section 3.2). We suspected that this phenomenon may underlie the effects on Ras signaling observed upon suppression of RASSF1A, and thus analyzed the growth and signaling patterns in our matched sets of NSCLC cells.

\subsection{Results}


We hypothesized that RASSF1A knockdown cells would exhibit enhanced growth and activation of Ras mitogenic pathways due to elevated basal levels of Ras-GTP. As epigenetic suppression of DAB2IP is itself a frequent occurrence in lung cancer, we further hypothesized that co-suppression of RASSF1A and DAB2IP would synergistically enhance Ras activation.

\subsubsection{RASSF1A and DAB2IP cooperatively regulate Ras activation}

GAP activity is critical to DAB2IP-mediated suppression of tumor initiation and growth [167]. We have previously shown in a mouse model of K-Ras-driven lung cancer that loss of one allele of rassf1a stimulated signaling through canonical Ras mitogenic effectors Raf, PI3K, and RalGDS in mutant- and wild-type-Ras tissues, suggesting that RASSF1A may directly regulate Ras [14]. We wanted to determine if the loss of DAB2IP observed upon shRNA knockdown of RASSF1A resulted in a corresponding increase in GTP loading onto Ras. For this, we performed active Ras pulldown assays and compared the amount of Ras-GTP precipitated to the total amount of Ras in standardized aliquots of whole cell lysate (figure 15). Consistent with our hypothesis and previous results, elevated levels of Ras-GTP were detected in RASSF1A knockdown cells for both $\mathrm{NCl}-\mathrm{H} 1792$ and $\mathrm{NCl}-\mathrm{H} 1437$ cell lines. Moreover, in both cells, co-suppression of RASSF1A and DAB2IP potentiated this effect.

We chose to assess the activation state of a canonical Ras mitogenic pathway to confirm our results from the active Ras pulldown assay. Thus, we 
analyzed both cell lines for PI3K activity during log phase growth via Western blot, using P-S473 AKT as a readout (figure 16). We found in both cell lines that P-S473 AKT was undetectable in control and DAB2IP-knockdown cells. RASSF1A knockdown elevated AKT activation, and addition of the DAB2IP shRNA to RASSF1A knockdown cells potentiated this effect.

\subsubsection{Effects of RASSF1A and DAB2IP on NSCLC growth}

In the mouse model, heterozygosity at the rassf1a locus significantly increased lung tumor burden upon induction of the K-Ras mutant compared to wild-type littermates. Moreover, loss of one allele of rassf1a in normal, wild-type Ras tissue significantly increased Ras mitogenic signaling [14]. We wanted to determine if such a role could be established for RASSF1A in our knockdown cells. To that end, we measured in vitro growth in our mutant K-Ras cells (figure 17a). Knockdown of DAB2IP alone modestly but insignificantly enhanced 2D growth, whereas RASSF1A significantly enhanced growth. Co-suppression of DAB2IP/RASSF1A had little effect above that of RASSF1A knockdown alone.

We also assessed in vitro 2D growth in our wild-type Ras $\mathrm{NCl}-\mathrm{H} 1437$ matched set (figure 17b). Interestingly, here we observed synergy between RASSF1A and DAB2IP. Only co-suppression of both proteins significantly increased 2D growth. This synergistic effect fit well with the Ras and AKT activation

observed in these cells. So, we chose to further examine this cell line to determine if RASSF1A and DAB2IP would synergize in vivo. We injected our $\mathrm{NCl}-\mathrm{H} 1437$ 
matched set subcutaneously into NRG mice, and measured the volume of the resultant xenograft tumors over the course of several weeks (figure 18). Knockdown of DAB2IP alone had no effect on tumor growth, whereas RASSF1A knockdown modestly increased tumor growth. Similar to in vitro growth, cosuppression of RASSF1A and DAB2IP significantly enhanced in vivo growth of $\mathrm{NCl}-\mathrm{H} 1437$ cells.

Finally, we examined Ras pathway activation in tumor lysates via Western blot (figure 19). In the dual knockdown tumors, we observed consistent, statistically significant upregulation of MAPK pathway activation compared to control tumors. Dual knockdown also resulted in the highest PI3K-AKT pathway, although this effect was not statistically significant.

\subsection{Discussion}

RASSF1A plays an indispensable role in homeostasis in large part by restraining Ras-mediated transformation [129]. Canonical RASSF1A signaling is primarily centered on induction of apoptosis in response to Ras activation [9, 127]. Indeed, the growth-inhibitory response to mutant Ras activity constitutes a molecular hurdle that must be overcome in order for transformation to occur [271]. Hints of a more pleiotropic role for RASSF1A in modulating Ras activity have been published throughout the years $[13,14,16,17]$. Here, we provide further evidence for a novel, regulatory role for RASSF1A in Ras signaling. 


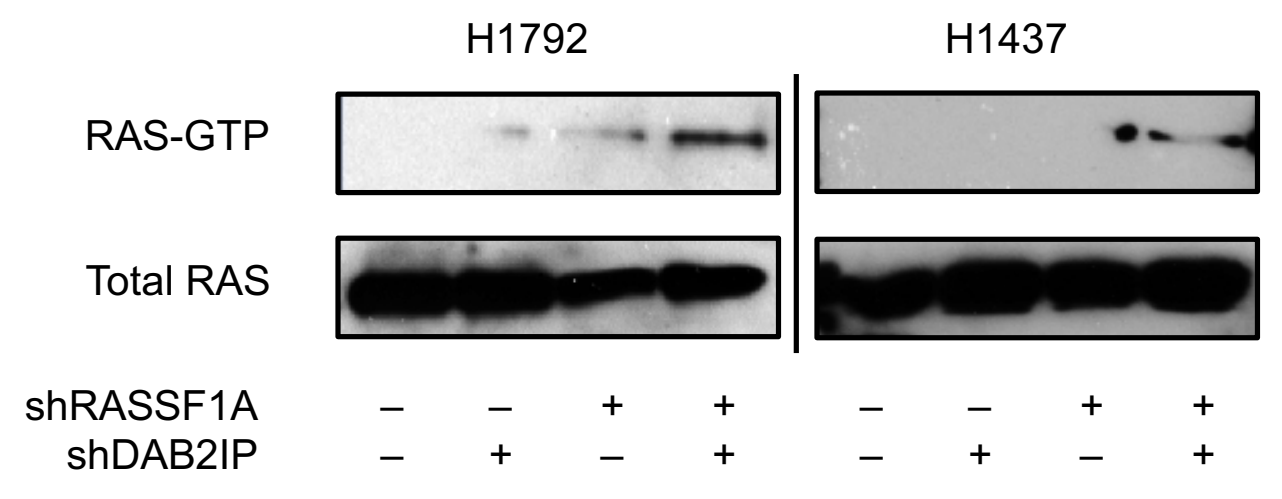

Figure 15. Effects of RASSF1A/DAB2IP suppression on Ras activation. Cells were seeded at low density in $10 \mathrm{~cm}$ dishes and growth for 72 hours, after which whole cell lysates were prepared. Ras-GTP was precipitated for 1 hour using the Ras binding domain (RBD) of Raf-1 conjugated to agarose. Precipitated Ras-GTP and total Ras levels were determined using a pan-Ras antibody (Cytoskeleton Inc.). 


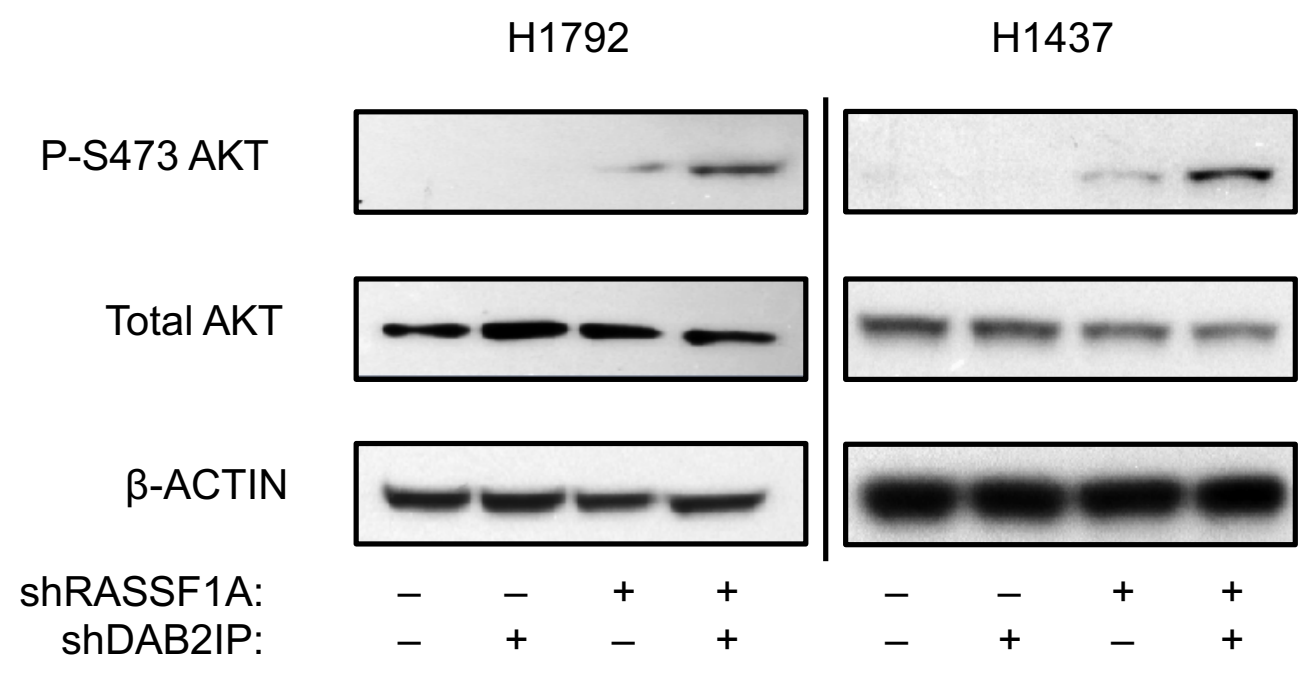

Figure 16: Effects if RASSF1A/DAB2IP suppression on in vitro Ras signaling. Cells were seeded at low density and growth for 48 hours, after which whole cell lysates were prepared. AKT activation was determined via Western blot analysis of serine-473 phosphorylation. 
A $\mathrm{H} 1792$

B $\quad \mathrm{H} 1437$

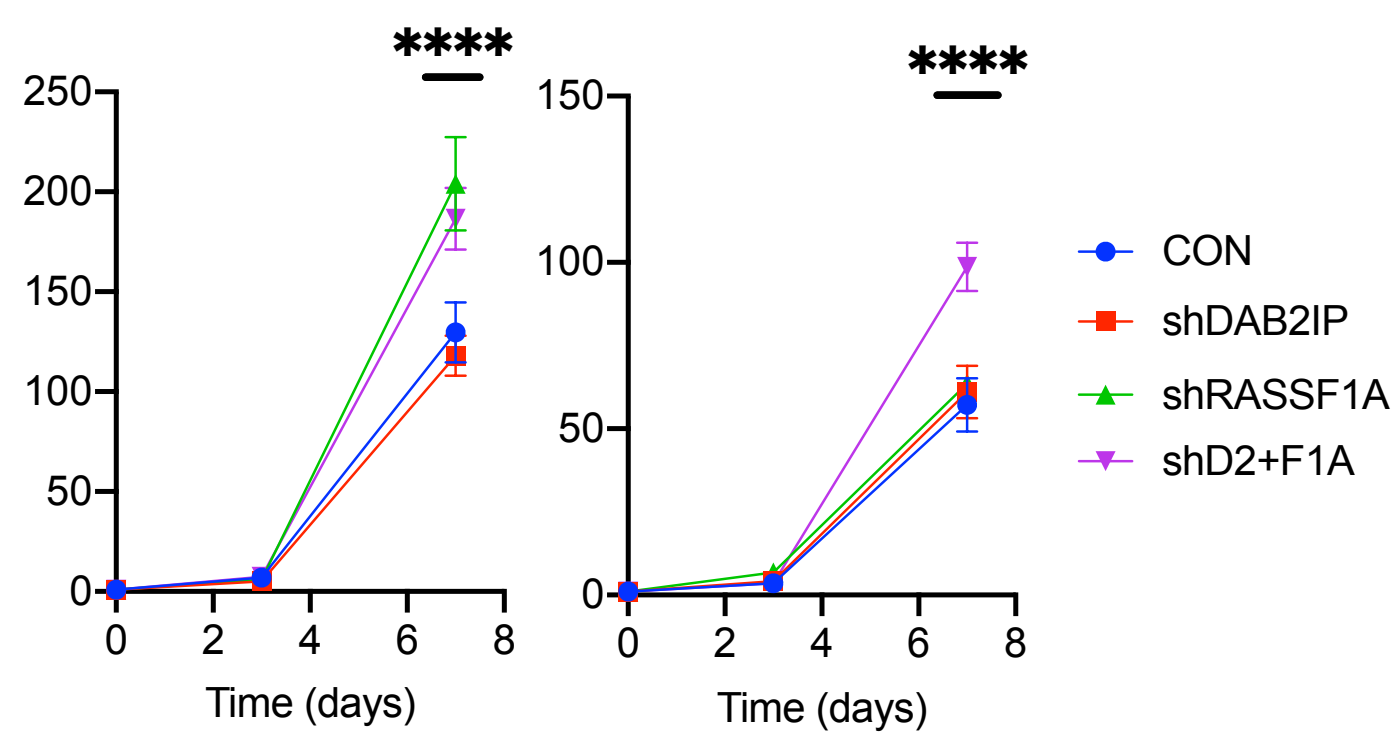

Figure 17. In vitro growth curves of $\mathrm{NCl}-\mathrm{H} 1792$ and $\mathrm{NCl}-\mathrm{H} 1437$ matched sets of cells. Cells were plated at $10^{4}$ cells per well in 9 wells of 6 -well plates. Triplicate wells were counted 24 hours after plating as day 0 , then again on days 3 and 7 . Cell numbers are reported as mean \pm s.e. ${ }^{* * * *} p<0.0001$ 


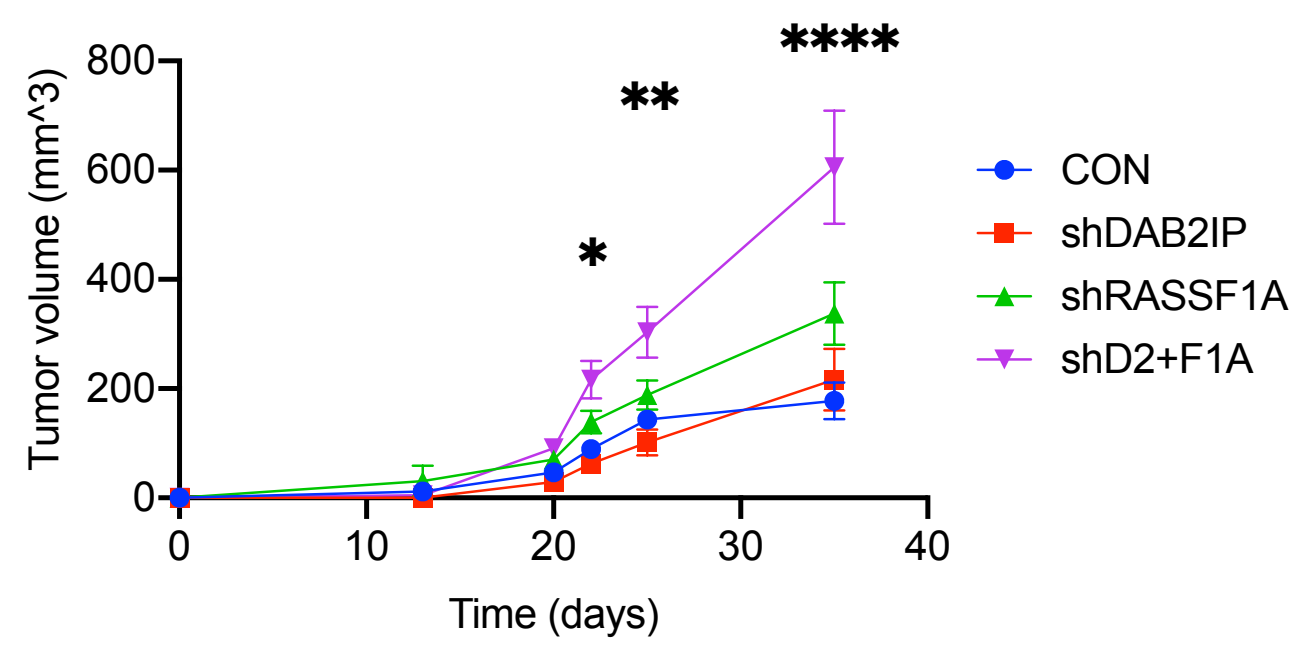

Figure 18: $\mathrm{NCl}-\mathrm{H} 1437$ xenograft growth curve. Cells were seeded at low density in several large flasks and incubated for 48 hours to achieve log-phase growth. $10^{6}$ cells in 1X PBS were injected subcutaneously into the left flank of NRG mice. Resultant tumors were measured using calipers. Tumor volume was calculated by the formula $V=\frac{L \times W^{2}}{2}$. Volumes are reported as mean \pm s.e. $\mathrm{n}=5$ or $6 . p \leq{ }^{*} 0.05$, ${ }^{* *} 0.01,{ }^{* * * *} 0.0001$. 

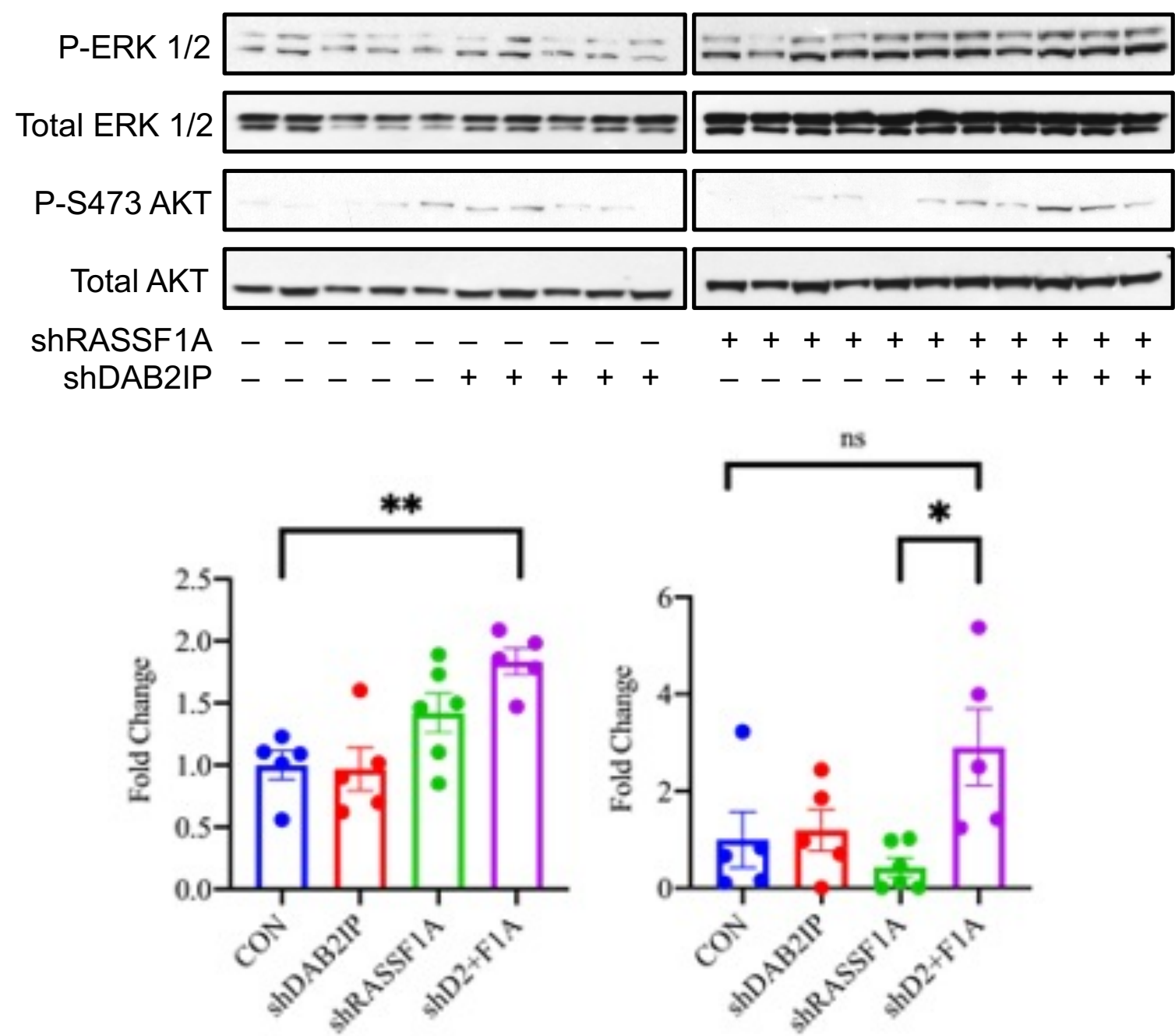

Figure 19: Effects of RASSF1A/DAB2IP suppression on in vivo Ras signaling. $\mathrm{NCl}-\mathrm{H} 1437$ xenograft tumors were harvested from sacrificed animals and lysates were prepared. Equal protein masses of each tumor lysate were analyzed for MAPK and PI3K-AKT activity via ERK 1/2 T-202/Y-205 and AKT S473 phosphorylation, respectively. Bands were quantified using ImageJ and activation fold change was calculated by normalization to control cells. $n=5$ or 6 . $p \leq{ }^{*} 0.05,{ }^{* *} 0.01$ 
Having demonstrated the ability of RASSF1A to upregulate DAB2IP, an important RasGAP, we speculated that this modulation of DAB2IP protein levels would be transduced through Ras mitogenic activity and affect the growth of our matched sets of NSCLC cells. We anticipated that the effects on Ras signaling and cell growth would apparent in both cell lines, despite the $\mathrm{NCl}-\mathrm{H} 1792$ cells harboring an oncogenic K-Ras mutant, for several reasons. First, the specific mutation found in $\mathrm{NCl}-\mathrm{H} 1792$ cells, G12C, actively—and rapidly—cycles between GTP-and GDPbound states, suggesting that it retains some sensitivity to GAP action [115, 272]. Second, we have reported that loss of RASSF1A potentiates mitogenic signaling mediated by mutant K-Ras in vivo [14]. Finally, the remaining wild-type Ras alleles are certainly still susceptible to GAP activity, and their activation may support the oncogenic action of the mutant allele [137].

In both wild-type and mutant Ras cell lines, we observed striking upregulation of Ras-GTP and downstream activation of AKT upon co-suppression RASSF1A and DAB2IP. Analysis of growth in these cells, however, gave disparate results. In the mutant Ras cells, suppression of RASSF1A alone significantly enhanced 2D growth compared control cells in agreement with the Ras activity detected in these cells. Dual inactivation of RASSF1A/DAB2IP had an insignificant effect over that of RASSF1A suppression alone, despite these cells exhibiting the strongest Ras activation in the pulldown and signaling assays. One possible explanation for this is that concomitant suppression of RASSF1A and mutation of Ras maximally stimulates growth, such that further stimulation of Ras from suppression of DAB2IP confers no additional benefit. The interplay between 
RASSF1A and DAB2IP has not been studied previously in any capacity. However, this explanation is in agreement with clinical observations in lung cancer patients, in that those tumors with dual mutation in KRAS and hypermethylation of the RASSF1A promoter are highly aggressive and confer a poor prognosis [273].

In wild-type Ras cells, we observed a synergistic effect between RASSF1A and DAB2IP suppression on 2D growth. Excited by this result, we chose to further examine the biology of these cells in vivo. Here, we found that suppression of RASSF1A alone significantly increased Ras activation and growth in $\mathrm{NCl}-\mathrm{H} 1437$ xenografts, and this effect was compounded by addition of the DAB2IP shRNA. The discrepancy between the in vitro and in vivo results remains unresolved; however, the effect of RASSF1A on DAB2IP protein levels may be responsible. DAB2IP is known to inhibit angiogenesis through inhibition of VEGFR-2 [164]. Angiogenesis is critical to tumor growth, as oxygen and nutrient availability at the center of the tumor become limited by diffusion in avascular tissue once the tumor is just a few cubic millimeters in size $[274,275]$. Hypoxia at the core of a tumor induces the expression of hypoxia-inducible factors (HIFs), transcription factors that regulate genes that aid cells in handling hypoxic stress [276]. Loss of DAB2IP has been shown to upregulate HIF-1 $\alpha$ and HIF-2 $\alpha[193,277,278]$. Thus, suppression of DAB2IP confers a growth and survival advantage in vivo that is not otherwise apparent experimentally. Since knockdown of RASSF1A caused a greater reduction in DAB2IP protein levels than the DAB2IP shRNA, disinhibition of VEGF/HIF signaling may contribute to in vivo growth in these cells. 


\section{CHAPTER V}

\section{CONCLUSIONS AND FUTURE DIRECTIONS}

\subsection{Conclusions}

The work presented in this dissertation identifies a novel role for RASSF1A in the regulation of the RasGAP DAB2IP. It tracks the transduction of this regulatory event from its start in regulating Ras activation, through the modulation of Ras mitogenic signaling, down to its terminal phenotypic output of suppressing tumor growth. In so doing, it furthers our mechanistic understand of RASSFmediated tumor suppression and begins to answer the lingering question of why loss of RASSF1A enhances the mitogenic activity of Ras.

We found that RASSF1A forms an endogenous complex with the RasGAP DAB2IP. Unexpectedly, this interaction was not regulated by Ras. Preliminarily, our data suggest that RASSF1A stabilizes DAB2IP protein; however, this was not mediated through inhibition of proteasomal or lysosomal degradation of DAB2IP.

RASSF1A has previously been shown by our group and others modulate the activation of Ras mitogenic pathways $[13,14,17]$. However, the mechanisms underlying these phenomena are not completely clear. Here, we demonstrate a clear upregulation of Ras-GTP in response to RASSF1A suppression. Thus, the 
effects of RASSF1A on Ras signaling are not caused by the complex interactions between RASSF1A and mitogenic Ras effectors, or at least not fully, but involves direct control of Ras activation. To our knowledge, this is the first example of a downstream effector of Ras modulating an upstream regulator of Ras.

Of note, the effect of RASSF1A on Ras activation is not limited to only wildtype Ras tumors, but can be observed in mutant Ras cancer cells as well. The implications of this novel regulatory event may not be immediately apparent. Gene therapy is not yet the standard of care in cancer treatment, and therefore knowing that one of the most frequently inactivated tumor suppressors can regulate the most frequently activated oncoprotein does not immediately reveal a useful therapeutic target. However, the renewed quest to effectively drug Ras as cancer treatment suggests that this regulatory event may be of therapeutic import after all.

Novel inhibitors of $\mathrm{K}-\mathrm{Ras}^{\mathrm{G} 12 \mathrm{C}}$ function by trapping mutant Ras in the inactive state, demonstrating that the mutant is not completely devoid of GTPase activity and may still be stimulated by RasGAPs. In fact, the notion that Ras mutants are locked in an active state has recently been brought into question, as other common Ras mutants (G13D and Q61L specifically) have also been shown to retain intrinsic GTPase activity that is, though diminished, still comparable to wild-type Ras [279]. Therefore, RASSF1A-mediated loss of GAP expression may dampen the hydrolytic potential of Ras mutants, thereby reducing the pool of Ras-GDP available for inhibitors to bind. These novel inhibitors may rely on the intact regulatory machinery of Ras. In the same vein, though in diametrical opposition to the former in approach, a 2019 report showed that growth of lung cancer cells 
could be inhibited by treatment with a small molecule agonist of K-RAS [280]. Pharmacological activation of K-Ras restricted cell growth by inducing apoptosis and autophagy. Loss of RASSF1A/DAB2IP dually uncouples Ras from its apoptotic effectors and substantially elevates the basal activation state of Ras. Hypothetically, then, RASSF1A/DAB2IP loss may elevate Ras activation and suppress Ras-mediated apoptosis to such a degree that further activation by the small molecule is incapable of eliciting an apoptotic response. As drug discovery in the Ras field continues, the importance of these little-known (and perhaps still unknown) regulatory mechanisms controlling Ras may become more apparent.

\subsection{Future Directions}

The original goal of this work was to confirm and characterize a novel binding interaction between RASSF1A and DAB2IP. While generating the reagents necessary to investigate the biological significance of the RASSF1ADAB2IP interaction, we made another novel-and unexpected-discovery: RASSF1A upregulates DAB2IP. Thus, we turned our attention to investigating the effects of this novel regulatory event on growth and signaling in cancer.

In the course of our studies, we did elucidate a novel mechanism of RASSF1A-mediated regulation of Ras activation. However, several questions remain as to the function of the RASSF1A-DAB2IP complex. First, mapping the site of interaction on both DAB2IP and RASSF1A would allow for the generation of binding-defective mutants. These mutants would be critical to elucidating what 
biological effects are directly attributable to the RASSF1A-DAB2IP interaction itself. RASSF1A and DAB2IP have several overlapping activities, including inhibition of AKT, induction of apoptosis, and regulation of inflammation. Therefore, it is important to distinguish which effects are due to the binding event versus the additive output of two independent mechanisms.

Additionally, the ability of other RASSF proteins to bind and/or regulate GAPs may be a worthwhile investigation. RASSF proteins are capable of dimerizing with each other, and therefore may cooperatively mediate tumor suppression [281]. Moreover, RASSF proteins exhibit some redundancy in effector binding and signaling activity $[9,37]$. Indeed, we have seen that other RASSF family members can bind DAB2IP in overexpression systems (unpublished observation). Thus, regulation of small GTPases may be a common attribute of classical RASSF proteins rather than a unique property of RASSF1A. 


\section{REFERENCES}

1. Siegel, R.L., K.D. Miller, and A. Jemal, Cancer statistics, 2020. CA Cancer J Clin, 2020. 70(1): p. 7-30.

2. Adjei, A.A., Blocking oncogenic Ras signaling for cancer therapy. J Natl Cancer Inst, 2001. 93(14): p. 1062-74.

3. Pylayeva-Gupta, Y., E. Grabocka, and D. Bar-Sagi, RAS oncogenes: weaving a tumorigenic web. Nat Rev Cancer, 2011. 11(11): p. 761-74.

4. Ulku, A.S. and C.J. Der, Ras Signaling, Deregulation of Gene Expression and Oncogenesis, in Signal Transduction in Cancer, S.T. Rosen, Editor. 2004, Kluwer Academic Publishers: New York, Boston, Dordrecht, London, Moscow. p. 310.

5. Gao, Q., et al., Mutant p53-induced immortalization of primary human mammary epithelial cells. Cancer Res, 1996. 56(13): p. 3129-33.

6. Newbold, R.F. and R.W. Overell, Fibroblast immortality is a prerequisite for transformation by EJ c-Ha-ras oncogene. Nature, 1983. 304(5927): $p$. $648-51$.

7. Ferbeyre, G., et al., Oncogenic ras and p53 cooperate to induce cellular senescence. Mol Cell Biol, 2002. 22(10): p. 3497-508.

8. Cox, A.D. and C.J. Der, The dark side of Ras: regulation of apoptosis. Oncogene, 2003. 22(56): p. 8999-9006. 
9. Donninger, H., et al., Ras signaling through RASSF proteins. Semin Cell Dev Biol, 2016. 58: p. 86-95.

10. Donninger, $\mathrm{H}$., et al., Cell cycle restriction is more important than apoptosis induction for RASSF1A protein tumor suppression. J Biol Chem, 2014. 289(45): p. 31287-95.

11. Vos, M.D., et al., The RASSF1A tumor suppressor activates Bax via MOAP-1. J Biol Chem, 2006. 281(8): p. 4557-63.

12. Dubois, F., et al., RASSF1A Suppresses the Invasion and Metastatic Potential of Human Non-Small Cell Lung Cancer Cells by Inhibiting YAP Activation through the GEF-H1/RhoB Pathway. Cancer Res, 2016. 76(6): p. $1627-40$.

13. Thaler, S., et al., RASSF1A mediates p21Cip1/Waf1-dependent cell cycle arrest and senescence through modulation of the Raf-MEK-ERK pathway and inhibition of Akt. Cancer Res, 2009. 69(5): p. 1748-57.

14. Schmidt, M.L., et al., RASSF1A Deficiency Enhances RAS-Driven Lung Tumorigenesis. Cancer Res, 2018. 78(10): p. 2614-2623.

15. Romano, D., et al., Proapoptotic kinase MST2 coordinates signaling crosstalk between RASSF1A, Raf-1, and Akt. Cancer Res, 2010. 70(3): p. 1195-203.

16. Romano, D., et al., Protein interaction switches coordinate Raf-1 and MST2/Hippo signalling. Nat Cell Biol, 2014. 16(7): p. 673-84.

17. Kilili, G.K. and J.M. Kyriakis, Mammalian Ste20-like kinase (Mst2) indirectly supports Raf-1/ERK pathway activity via maintenance of protein 
phosphatase-2A catalytic subunit levels and consequent suppression of inhibitory Raf-1 phosphorylation. J Biol Chem, 2010. 285(20): p. 15076-87.

18. Wang, Z., et al., The mechanism of growth-inhibitory effect of DOC2/DAB2 in prostate cancer. Characterization of a novel GTPase-activating protein associated with $\mathrm{N}$-terminal domain of DOC-2/DAB2. J Biol Chem, 2002. 277(15): p. $12622-31$.

19. Harvey, J.J., An Unidentified Virus Which Causes the Rapid Production of Tumours in Mice. Nature, 1964. 204: p. 1104-5.

20. Kirsten, W.H. and L.A. Mayer, Morphologic responses to a murine erythroblastosis virus. J Natl Cancer Inst, 1967. 39(2): p. 311-35.

21. Scolnick, E.M., et al., Studies on the nucleic acid sequences of Kirsten sarcoma virus: a model for formation of a mammalian RNA-containing sarcoma virus. J Virol, 1973. 12(3): p. 458-63.

22. Ellis, R.W., et al., The p21 src genes of Harvey and Kirsten sarcoma viruses originate from divergent members of a family of normal vertebrate genes. Nature, 1981. 292(5823): p. 506-11.

23. Malumbres, M. and M. Barbacid, RAS oncogenes: the first 30 years. Nat Rev Cancer, 2003. 3(6): p. 459-65.

24. Cox, A.D. and C.J. Der, Ras history: The saga continues. Small GTPases, 2010. 1(1): p. 2-27.

25. Marshall, C.J., A. Hall, and R.A. Weiss, A transforming gene present in human sarcoma cell lines. Nature, 1982. 299(5879): p. 171-3. 
26. Shimizu, K., et al., Isolation and preliminary characterization of the transforming gene of a human neuroblastoma cell line. Proc Natl Acad Sci U S A, 1983. 80(2): p. 383-7.

27. Zhang, F. and J.K. Cheong, The renewed battle against RAS-mutant cancers. Cell Mol Life Sci, 2016. 73(9): p. 1845-58.

28. Bos, J.L., H. Rehmann, and A. Wittinghofer, GEFs and GAPs: critical elements in the control of small G proteins. Cell, 2007. 129(5): p. 865-77.

29. McCormick, F., Going for the GAP. Curr Biol, 1998. 8(19): p. R673-4.

30. Trahey, M. and F. McCormick, A cytoplasmic protein stimulates normal Nras p21 GTPase, but does not affect oncogenic mutants. Science, 1987. 238(4826): p. 542-5.

31. Trahey, M., et al., Molecular cloning of two types of GAP complementary DNA from human placenta. Science, 1988. 242(4886): p. 1697-700.

32. Vogel, U.S., et al., Cloning of bovine GAP and its interaction with oncogenic ras p21. Nature, 1988. 335(6185): p. 90-3.

33. Ballester, R., et al., The NF1 locus encodes a protein functionally related to mammalian GAP and yeast IRA proteins. Cell, 1990. 63(4): p. 851-9.

34. Marchuk, D.A., et al., cDNA cloning of the type 1 neurofibromatosis gene: complete sequence of the NF1 gene product. Genomics, 1991. 11(4): p. $931-40$.

35. Prior, I.A., P.D. Lewis, and C. Mattos, A comprehensive survey of Ras mutations in cancer. Cancer Res, 2012. 72(10): p. 2457-67. 
36. King, P.D., B.A. Lubeck, and P.E. Lapinski, Nonredundant functions for Ras GTPase-activating proteins in tissue homeostasis. Sci Signal, 2013. 6(264): p. re1.

37. Harrell Stewart, D.R. and G.J. Clark, Pumping the brakes on RAS negative regulators and death effectors of RAS. J Cell Sci, 2020. 133(3).

38. Scheffzek, K., et al., The Ras-RasGAP complex: structural basis for GTPase activation and its loss in oncogenic Ras mutants. Science, 1997. 277(5324): p. 333-8.

39. Broek, D., et al., The S. cerevisiae CDC25 gene product regulates the RAS/adenylate cyclase pathway. Cell, 1987. 48(5): p. 789-99.

40. Robinson, L.C., et al., CDC25: a component of the RAS-adenylate cyclase pathway in Saccharomyces cerevisiae. Science, 1987. 235(4793): p. 1218-21.

41. Jones, S., M.L. Vignais, and J.R. Broach, The CDC25 protein of Saccharomyces cerevisiae promotes exchange of guanine nucleotides bound to ras. Mol Cell Biol, 1991. 11(5): p. 2641-6.

42. Rogge, R.D., C.A. Karlovich, and U. Banerjee, Genetic dissection of a neurodevelopmental pathway: Son of sevenless functions downstream of the sevenless and EGF receptor tyrosine kinases. Cell, 1991. 64(1): p. 3948.

43. Bonfini, L., et al., The Son of sevenless gene product: a putative activator of Ras. Science, 1992. 255(5044): p. 603-6. 
44. Vetter, I.R. and A. Wittinghofer, The guanine nucleotide-binding switch in three dimensions. Science, 2001. 294(5545): p. 1299-304.

45. Cherfils, J. and M. Zeghouf, Regulation of small GTPases by GEFs, GAPs, and GDls. Physiol Rev, 2013. 93(1): p. 269-309.

46. Boriack-Sjodin, P.A., et al., The structural basis of the activation of Ras by Sos. Nature, 1998. 394(6691): p. 337-43.

47. Taparowsky, E., et al., Activation of the T24 bladder carcinoma transforming gene is linked to a single amino acid change. Nature, 1982. 300(5894): p. 762-5.

48. Reddy, E.P., et al., A point mutation is responsible for the acquisition of transforming properties by the T24 human bladder carcinoma oncogene. Nature, 1982. 300(5888): p. 149-52.

49. Tabin, C.J., et al., Mechanism of activation of a human oncogene. Nature, 1982. 300(5888): p. 143-9.

50. Capon, D.J., et al., Activation of Ki-ras2 gene in human colon and lung carcinomas by two different point mutations. Nature, 1983. 304(5926): p. $507-13$

51. Rodbell, M., The role of hormone receptors and GTP-regulatory proteins in membrane transduction. Nature, 1980. 284(5751): p. 17-22.

52. Pulciani, S., et al., Oncogenes in solid human tumours. Nature, 1982. 300(5892): p. 539-42.

53. Barbacid, M., ras genes. Annu Rev Biochem, 1987. 56: p. 779-827. 
54. Hobbs, G.A., C.J. Der, and K.L. Rossman, RAS isoforms and mutations in cancer at a glance. J Cell Sci, 2016. 129(7): p. 1287-92.

55. Johnson, C.W., et al., The small GTPases K-Ras, N-Ras, and H-Ras have distinct biochemical properties determined by allosteric effects. J Biol Chem, 2017. 292(31): p. 12981-12993.

56. Karnoub, A.E. and R.A. Weinberg, Ras oncogenes: split personalities. Nat Rev Mol Cell Biol, 2008. 9(7): p. 517-31.

57. Bourne, H.R., D.A. Sanders, and F. McCormick, The GTPase superfamily: conserved structure and molecular mechanism. Nature, 1991. 349(6305): p. 117-27.

58. Gasper, R. and F. Wittinghofer, The Ras switch in structural and historical perspective. Biol Chem, 2019. 401(1): p. 143-163.

59. Nakhaeizadeh, H., et al., The RAS-Effector Interface: Isoform-Specific Differences in the Effector Binding Regions. PLoS One, 2016. 11(12): $\mathrm{p}$. e0167145.

60. Simanshu, D.K., D.V. Nissley, and F. McCormick, RAS Proteins and Their Regulators in Human Disease. Cell, 2017. 170(1): p. 17-33.

61. Shih, T.Y., et al., Identification of a sarcoma virus-coded phosphoprotein in nonproducer cells transformed by Kirsten or Harvey murine sarcoma virus. Virology, 1979. 96(1): p. 64-79.

62. Willingham, M.C., et al., Localization of the src gene product of the Harvey strain of MSV to plasma membrane of transformed cells by electron microscopic immunocytochemistry. Cell, 1980. 19(4): p. 1005-14. 
63. Sefton, B.M., et al., The transforming proteins of Rous sarcoma virus, Harvey sarcoma virus and Abelson virus contain tightly bound lipid. Cell, 1982. 31(2 Pt 1): p. 465-74.

64. Willumsen, B.M., et al., Harvey murine sarcoma virus $p 21$ ras protein: biological and biochemical significance of the cysteine nearest the carboxy terminus. EMBO J, 1984. 3(11): p. 2581-5.

65. Cox, A.D. and C.J. Der, The ras/cholesterol connection: implications for ras oncogenicity. Crit Rev Oncog, 1992. 3(4): p. 365-400.

66. Reiss, Y., et al., Inhibition of purified p21ras farnesyl:protein transferase by Cys-AAX tetrapeptides. Cell, 1990. 62(1): p. 81-8.

67. Otto, J.C., et al., Cloning and characterization of a mammalian prenyl protein-specific protease. J Biol Chem, 1999. 274(13): p. 8379-82.

68. Dai, Q., et al., Mammalian prenylcysteine carboxyl methyltransferase is in the endoplasmic reticulum. J Biol Chem, 1998. 273(24): p. 15030-4.

69. Hancock, J.F., Ras proteins: different signals from different locations. Nat Rev Mol Cell Biol, 2003. 4(5): p. 373-84.

70. Choy, E., et al., Endomembrane trafficking of ras: the CAAX motif targets proteins to the ER and Golgi. Cell, 1999. 98(1): p. 69-80.

71. Apolloni, A., et al., $H$-ras but not $K$-ras traffics to the plasma membrane through the exocytic pathway. Mol Cell Biol, 2000. 20(7): p. 2475-87.

72. Dharmaiah, S., et al., Structural basis of recognition of farnesylated and methylated KRAS4b by PDEdelta. Proc Natl Acad Sci U S A, 2016. 113(44): p. E6766-E6775. 
73. Schmick, M., et al., KRas localizes to the plasma membrane by spatial cycles of solubilization, trapping and vesicular transport. Cell, 2014. 157(2): p. 459-471.

74. Tsai, F.D., et al., K-Ras4A splice variant is widely expressed in cancer and uses a hybrid membrane-targeting motif. Proc Natl Acad Sci U S A, 2015. 112(3): p. 779-84.

75. Kamata, T. and J.R. Feramisco, Epidermal growth factor stimulates guanine nucleotide binding activity and phosphorylation of ras oncogene proteins. Nature, 1984. 310(5973): p. 147-50.

76. Lowenstein, E.J., et al., The SH2 and SH3 domain-containing protein GRB2 links receptor tyrosine kinases to ras signaling. Cell, 1992. 70(3): p. $431-42$.

77. Simon, M.A., G.S. Dodson, and G.M. Rubin, An SH3-SH2-SH3 protein is required for p21Ras1 activation and binds to sevenless and Sos proteins in vitro. Cell, 1993. 73(1): p. 169-77.

78. Egan, S.E., et al., Association of Sos Ras exchange protein with Grb2 is implicated in tyrosine kinase signal transduction and transformation. Nature, 1993. 363(6424): p. 45-51.

79. Chardin, P., et al., Human Sos1: a guanine nucleotide exchange factor for Ras that binds to GRB2. Science, 1993. 260(5112): p. 1338-43.

80. Gale, N.W., et al., Grb2 mediates the EGF-dependent activation of guanine nucleotide exchange on Ras. Nature, 1993. 363(6424): p. 88-92. 
81. Rapp, U.R. and G.J. Todaro, Generation of oncogenic mouse type C viruses: in vitro selection of carcinoma-inducing variants. Proc Natl Acad Sci U S A, 1980. 77(1): p. 624-8.

82. Dickson, B., et al., Raf functions downstream of Ras1 in the Sevenless signal transduction pathway. Nature, 1992. 360(6404): p. 600-3.

83. Han, M., et al., C. elegans lin-45 raf gene participates in let-60 rasstimulated vulval differentiation. Nature, 1993. 363(6425): p. 133-40.

84. Moodie, S.A., et al., Complexes of Ras.GTP with Raf-1 and mitogenactivated protein kinase kinase. Science, 1993. 260(5114): p. 1658-61.

85. Vojtek, A.B., S.M. Hollenberg, and J.A. Cooper, Mammalian Ras interacts directly with the serine/threonine kinase Raf. Cell, 1993. 74(1): p. 205-14.

86. Zhang, X.F., et al., Normal and oncogenic p21ras proteins bind to the amino-terminal regulatory domain of c-Raf-1. Nature, 1993. 364(6435): $p$. $308-13$.

87. Seger, R. and E.G. Krebs, The MAPK signaling cascade. FASEB J, 1995. 9(9): p. 726-35.

88. Marais, R., et al., Ras recruits Raf-1 to the plasma membrane for activation by tyrosine phosphorylation. EMBO J, 1995. 14(13): p. 3136-45.

89. Avruch, J., et al., Ras activation of the Raf kinase: tyrosine kinase recruitment of the MAP kinase cascade. Recent Prog Horm Res, 2001. 56: p. 127-55. 
90. Liebmann, C., Regulation of MAP kinase activity by peptide receptor signalling pathway: paradigms of multiplicity. Cell Signal, 2001. 13(11): $p$. 777-85.

91. Sjolander, A., et al., Association of p21ras with phosphatidylinositol 3kinase. Proc Natl Acad Sci U S A, 1991. 88(18): p. 7908-12.

92. Rodriguez-Viciana, P., et al., Phosphatidylinositol-3-OH kinase as a direct target of Ras. Nature, 1994. 370(6490): p. 527-32.

93. Hemmings, B.A. and D.F. Restuccia, PI3K-PKB/Akt pathway. Cold Spring Harb Perspect Biol, 2012. 4(9): p. a011189.

94. Vivanco, I. and C.L. Sawyers, The phosphatidylinositol 3-Kinase AKT pathway in human cancer. Nat Rev Cancer, 2002. 2(7): p. 489-501.

95. Yang, J., et al., Targeting PI3K in cancer: mechanisms and advances in clinical trials. Mol Cancer, 2019. 18(1): p. 26.

96. Duronio, V., The life of a cell: apoptosis regulation by the PI3KJPKB pathway. Biochem J, 2008. 415(3): p. 333-44.

97. Nave, B.T., et al., Mammalian target of rapamycin is a direct target for protein kinase B: identification of a convergence point for opposing effects of insulin and amino-acid deficiency on protein translation. Biochem J, 1999. 344 Pt 2: p. 427-31.

98. Asati, V., D.K. Mahapatra, and S.K. Bharti, PI3K/Akt/mTOR and Ras/Raf/MEKJERK signaling pathways inhibitors as anticancer agents: Structural and pharmacological perspectives. Eur J Med Chem, 2016. 109: p. 314-41. 
99. Gentry, L.R., et al., Ral small GTPase signaling and oncogenesis: More than just 15minutes of fame. Biochim Biophys Acta, 2014. 1843(12): $p$. 2976-2988.

100. Kikuchi, A., et al., ralGDS family members interact with the effector loop of ras p21. Mol Cell Biol, 1994. 14(11): p. 7483-91.

101. Hofer, F., et al., Activated Ras interacts with the Ral guanine nucleotide dissociation stimulator. Proc Natl Acad Sci U S A, 1994. 91(23): p. 1108993.

102. Spaargaren, M. and J.R. Bischoff, Identification of the guanine nucleotide dissociation stimulator for $\mathrm{Ral}$ as a putative effector molecule of $\mathrm{R}$-ras, $\mathrm{H}$ ras, K-ras, and Rap. Proc Natl Acad Sci U S A, 1994. 91(26): p. 12609-13.

103. Bodemann, B.O. and M.A. White, Ral GTPases and cancer: linchpin support of the tumorigenic platform. Nat Rev Cancer, 2008. 8(2): p. 13340.

104. Gonzalez-Garcia, A., et al., Ra/GDS is required for tumor formation in a model of skin carcinogenesis. Cancer Cell, 2005. 7(3): p. 219-26.

105. Santos, E., et al., Malignant activation of a K-ras oncogene in lung carcinoma but not in normal tissue of the same patient. Science, 1984. 223(4637): p. 661-4.

106. Feig, L.A., et al., Somatic activation of rasK gene in a human ovarian carcinoma. Science, 1984. 223(4637): p. 698-701.

107. Sistonen, L. and K. Alitalo, Activation of c-ras oncogenes by mutations and amplification. Ann Clin Res, 1986. 18(5-6): p. 297-303. 
108. Seeburg, P.H., et al., Biological properties of human c-Ha-ras1 genes mutated at codon 12. Nature, 1984. 312(5989): p. 71-5.

109. Gideon, P., et al., Mutational and kinetic analyses of the GTPaseactivating protein (GAP)-p21 interaction: the C-terminal domain of GAP is not sufficient for full activity. Mol Cell Biol, 1992. 12(5): p. 2050-6.

110. Gremer, L., et al., Fluoride complexes of oncogenic Ras mutants to study the Ras-RasGap interaction. Biol Chem, 2008. 389(9): p. 1163-71.

111. Der, C.J., T. Finkel, and G.M. Cooper, Biological and biochemical properties of human rasH genes mutated at codon 61. Cell, 1986. 44(1): p. 167-76.

112. Waters, A.M. and C.J. Der, KRAS: The Critical Driver and Therapeutic Target for Pancreatic Cancer. Cold Spring Harb Perspect Med, 2018. 8(9).

113. Dinu, D., et al., Prognostic significance of KRAS gene mutations in colorectal cancer--preliminary study. J Med Life, 2014. 7(4): p. 581-7.

114. Westcott, P.M. and M.D. To, The genetics and biology of KRAS in lung cancer. Chin J Cancer, 2013. 32(2): p. 63-70.

115. Patricelli, M.P., et al., Selective Inhibition of Oncogenic KRAS Output with Small Molecules Targeting the Inactive State. Cancer Discov, 2016. 6(3): p. 316-29.

116. Lito, P., et al., Allele-specific inhibitors inactivate mutant KRAS G12C by a trapping mechanism. Science, 2016. 351(6273): p. 604-8. 
117. Echevarria-Vargas, I.M. and J. Villanueva, Combating Nras Mutant Melanoma: From Bench to Bedside. Melanoma Manag, 2017. 4(4): p. 183-186.

118. Brendel, C., et al., Oncogenic NRAS Primes Primary Acute Myeloid Leukemia Cells for Differentiation. PLoS One, 2015. 10(4): p. e0123181.

119. Hayward, N.K., et al., Whole-genome landscapes of major melanoma subtypes. Nature, 2017. 545(7653): p. 175-180.

120. Vavvas, D., et al., Identification of Nore1 as a potential Ras effector. J Biol Chem, 1998. 273(10): p. 5439-42.

121. Dammann, R., et al., Epigenetic inactivation of a RAS association domain family protein from the lung tumour suppressor locus 3p21.3. Nat Genet, 2000. 25(3): p. 315-9.

122. Vos, M.D., et al., Ras uses the novel tumor suppressor RASSF1 as an effector to mediate apoptosis. J Biol Chem, 2000. 275(46): p. 35669-72.

123. Iwasa, H., S. Hossain, and Y. Hata, Tumor suppressor C-RASSF proteins. Cell Mol Life Sci, 2018. 75(10): p. 1773-1787.

124. Volodko, N., et al., RASSF tumor suppressor gene family: biological functions and regulation. FEBS Lett, 2014. 588(16): p. 2671-84.

125. Underhill-Day, N., V. Hill, and F. Latif, N-terminal RASSF family: RASSF7RASSF10. Epigenetics, 2011. 6(3): p. 284-92.

126. Lerman, M.I. and J.D. Minna, The 630-kb lung cancer homozygous deletion region on human chromosome 3p21.3: identification and evaluation of the resident candidate tumor suppressor genes. The 
International Lung Cancer Chromosome 3p21.3 Tumor Suppressor Gene Consortium. Cancer Res, 2000. 60(21): p. 6116-33.

127. Donninger, H., M.D. Vos, and G.J. Clark, The RASSF1A tumor suppressor. J Cell Sci, 2007. 120(Pt 18): p. 3163-72.

128. Gordon, M. and S. Baksh, RASSF1A: Not a prototypical Ras effector. Small GTPases, 2011. 2(3): p. 148-157.

129. Dubois, F., et al., RASSF1A, puppeteer of cellular homeostasis, fights tumorigenesis, and metastasis-an updated review. Cell Death Dis, 2019. 10(12): p. 928.

130. Malpeli, G., et al., Methylation Dynamics of RASSF1A and Its Impact on Cancer. Cancers (Basel), 2019. 11(7).

131. Dammann, R., et al., The tumor suppressor RASSF1A in human carcinogenesis: an update. Histol Histopathol, 2005. 20(2): p. 645-63.

132. Pan, Z.G., et al., High frequency somatic mutations in RASSF1A in nasopharyngeal carcinoma. Cancer Biol Ther, 2005. 4(10): p. 1116-22.

133. Tommasi, S., et al., Tumor susceptibility of Rassf1a knockout mice. Cancer Res, 2005. 65(1): p. 92-8.

134. Fausti, F., et al., Hippo and rassf1a Pathways: A Growing Affair. Mol Biol Int, 2012. 2012: p. 307628.

135. Meng, Z., T. Moroishi, and K.L. Guan, Mechanisms of Hippo pathway regulation. Genes Dev, 2016. 30(1): p. 1-17.

136. Han, Y., Analysis of the role of the Hippo pathway in cancer. J Transl Med, 2019. 17(1): p. 116. 
137. Matallanas, D., et al., Mutant K-Ras activation of the proapoptotic MST2 pathway is antagonized by wild-type K-Ras. Mol Cell, 2011. 44(6): p. 893906.

138. Matallanas, D., et al., RASSF1A elicits apoptosis through an MST2 pathway directing proapoptotic transcription by the p73 tumor suppressor protein. Mol Cell, 2007. 27(6): p. 962-75.

139. Oh, H.J., et al., Role of the tumor suppressor RASSF1A in Mst1-mediated apoptosis. Cancer Res, 2006. 66(5): p. 2562-9.

140. Guo, C., X. Zhang, and G.P. Pfeifer, The tumor suppressor RASSF1A prevents dephosphorylation of the mammalian STE20-like kinases MST1 and MST2. J Biol Chem, 2011. 286(8): p. 6253-61.

141. Zhao, B., et al., Inactivation of YAP oncoprotein by the Hippo pathway is involved in cell contact inhibition and tissue growth control. Genes Dev, 2007. 21(21): p. 2747-61.

142. Zhao, B., et al., A coordinated phosphorylation by Lats and CK1 regulates YAP stability through SCF(beta-TRCP). Genes Dev, 2010. 24(1): p. 72-85.

143. Kim, S.T., et al., Substrate specificities and identification of putative substrates of ATM kinase family members. J Biol Chem, 1999. 274(53): $p$. 37538-43.

144. Song, M.S., et al., The tumour suppressor RASSF1A promotes MDM2 self-ubiquitination by disrupting the MDM2-DAXX-HAUSP complex. EMBO J, 2008. 27(13): p. 1863-74. 
145. Baksh, S., et al., The tumor suppressor RASSF1A and MAP-1 link death receptor signaling to Bax conformational change and cell death. Mol Cell, 2005. 18(6): p. 637-50.

146. Pawlowski, J. and A.S. Kraft, Bax-induced apoptotic cell death. Proc Natl Acad Sci U S A, 2000. 97(2): p. 529-31.

147. Dallol, A., et al., Involvement of the RASSF1A tumor suppressor gene in controlling cell migration. Cancer Res, 2005. 65(17): p. 7653-9.

148. Donninger, $\mathrm{H}$., et al., The RASSF1A tumor suppressor regulates XPAmediated DNA repair. Mol Cell Biol, 2015. 35(1): p. 277-87.

149. Dubois, F., et al., A role for RASSF1A in tunneling nanotube formation between cells through GEFH1/Rab11 pathway control. Cell Commun Signal, 2018. 16(1): p. 66.

150. Gordon, M., et al., The tumor suppressor gene, RASSF1A, is essential for protection against inflammation -induced injury. PLoS One, 2013. 8(10): p. e75483.

151. Liu, L., et al., Control of microtubule stability by the RASSF1A tumor suppressor. Oncogene, 2003. 22(50): p. 8125-36.

152. Dallol, A., et al., RASSF1A interacts with microtubule-associated proteins and modulates microtubule dynamics. Cancer Res, 2004. 64(12): p. 41126.

153. Jung, H.Y., et al., RASSF1A Suppresses Cell Migration through Inactivation of HDAC6 and Increase of Acetylated alpha-Tubulin. Cancer Res Treat, 2013. 45(2): p. 134-44. 
154. Hinchcliffe, E.H., The centrosome and bipolar spindle assembly: does one have anything to do with the other? Cell Cycle, 2011. 10(22): p. 3841-8.

155. Song, M.S., et al., The tumour suppressor RASSF1A regulates mitosis by inhibiting the APC-Cdc20 complex. Nat Cell Biol, 2004. 6(2): p. 129-37.

156. Rong, R., et al., Tumor suppressor RASSF1A is a microtubule-binding protein that stabilizes microtubules and induces G2/M arrest. Oncogene, 2004. 23(50): p. 8216-30.

157. Vlahov, N., et al., Alternate RASSF1 Transcripts Control SRC Activity, ECadherin Contacts, and YAP-Mediated Invasion. Curr Biol, 2015. 25(23): p. 3019-34.

158. Whang, Y.M., et al., RASSF1A suppresses the c-Jun-NH2-kinase pathway and inhibits cell cycle progression. Cancer Res, 2005. 65(9): p. 3682-90.

159. Coussens, L.M. and Z. Werb, Inflammation and cancer. Nature, 2002. 420(6917): p. 860-7.

160. Shalapour, S. and M. Karin, Immunity, inflammation, and cancer: an eternal fight between good and evil. J Clin Invest, 2015. 125(9): p. 334755.

161. Zhou, T.Y., et al., Interleukin-6 induced by YAP in hepatocellular carcinoma cells recruits tumor-associated macrophages. J Pharmacol Sci, 2018. 138(2): p. 89-95.

162. Li, W., et al., Suppressor of hepatocellular carcinoma RASSF1A activates autophagy initiation and maturation. Cell Death Differ, 2019. 26(8): p. 1379-1395. 
163. Cinar, B., et al., The pro-apoptotic kinase Mst1 and its caspase cleavage products are direct inhibitors of Akt1. EMBO J, 2007. 26(21): p. 4523-34.

164. Zhang, H., et al., AIP1 functions as an endogenous inhibitor of VEGFR2mediated signaling and inflammatory angiogenesis in mice. J Clin Invest, 2008. 118(12): p. 3904-16.

165. Xie, D., et al., DAB2IP coordinates both PI3K-Akt and ASK1 pathways for cell survival and apoptosis. Proc Natl Acad Sci U S A, 2009. 106(47): p. 19878-83.

166. Sun, L., et al., DAB2IP Downregulation Enhances the Proliferation and Metastasis of Human Gastric Cancer Cells by Derepressing the ERK1/2 Pathway. Gastroenterol Res Pract, 2018. 2018: p. 2968252.

167. Min, J., et al., An oncogene-tumor suppressor cascade drives metastatic prostate cancer by coordinately activating Ras and nuclear factor-kappaB. Nat Med, 2010. 16(3): p. 286-94.

168. Chen, $\mathrm{H}$., et al., Epigenetic regulation of a novel tumor suppressor gene (hDAB2IP) in prostate cancer cell lines. J Biol Chem, 2003. 278(5): p. 3121-30.

169. Maertens, O. and K. Cichowski, An expanding role for RAS GTPase activating proteins (RAS GAPS) in cancer. Adv Biol Regul, 2014. 55: p. 114.

170. Sears, R. and J.W. Gray, Epigenomic Inactivation of RasGAPs Activates RAS Signaling in a Subset of Luminal B Breast Cancers. Cancer Discov, 2017. 7(2): p. 131-133. 
171. Bellazzo, A., G. Di Minin, and L. Collavin, Block one, unleash a hundred. Mechanisms of DAB2IP inactivation in cancer. Cell Death Differ, 2017. 24(1): p. 15-25.

172. Chen, H., S.W. Tu, and J.T. Hsieh, Down-regulation of human DAB2IP gene expression mediated by polycomb Ezh2 complex and histone deacetylase in prostate cancer. J Biol Chem, 2005. 280(23): p. 22437-44.

173. Dote, $\mathrm{H}$., et al., Aberrant promoter methylation in human DAB2 interactive protein (hDAB2IP) gene in breast cancer. Clin Cancer Res, 2004. 10(6): $p$. 2082-9.

174. Yano, M., et al., Aberrant promoter methylation of human DAB2 interactive protein (hDAB2IP) gene in lung cancers. Int J Cancer, 2005. 113(1): p. 5966.

175. Dote, $\mathrm{H}$., et al., Aberrant promoter methylation in human DAB2 interactive protein (hDAB2IP) gene in gastrointestinal tumour. Br J Cancer, 2005. 92(6): p. 1117-25.

176. Smits, M., et al., EZH2-regulated DAB2IP is a medulloblastoma tumor suppressor and a positive marker for survival. Clin Cancer Res, 2012. 18(15): p. 4048-58.

177. $\mathrm{Xu}, \mathrm{Y}$., et al., miR-889 promotes proliferation of esophageal squamous cell carcinomas through DAB2IP. FEBS Lett, 2015. 589(10): p. 1127-35.

178. Dai, X., B.J. North, and H. Inuzuka, Negative regulation of DAB2IP by Akt and SCFFbw7 pathways. Oncotarget, 2014. 5(10): p. 3307-15. 
179. Di Minin, G., et al., Mutant p53 reprograms TNF signaling in cancer cells through interaction with the tumor suppressor DAB2IP. Mol Cell, 2014. 56(5): p. 617-29.

180. Zhang, R., et al., AIP1 mediates TNF-alpha-induced ASK1 activation by facilitating dissociation of ASK1 from its inhibitor 14-3-3. J Clin Invest, 2003. 111(12): p. 1933-43.

181. Davis, R.J., Signal transduction by the JNK group of MAP kinases. Cell, 2000. 103(2): p. 239-52.

182. Zhang, H., et al., AIP1/DAB2IP, a novel member of the Ras-GAP family, transduces TRAF2-induced ASK1-JNK activation. J Biol Chem, 2004. 279(43): p. 44955-65.

183. Ji, W., et al., Both internalization and AIP1 association are required for tumor necrosis factor receptor 2-mediated JNK signaling. Arterioscler Thromb Vasc Biol, 2012. 32(9): p. 2271-9.

184. Zhang, H., et al., RIP1-mediated AIP1 phosphorylation at a 14-3-3-binding site is critical for tumor necrosis factor-induced ASK1-JNK/p38 activation. J Biol Chem, 2007. 282(20): p. 14788-96.

185. Hsu, H., J. Xiong, and D.V. Goeddel, The TNF receptor 1-associated protein TRADD signals cell death and NF-kappa B activation. Cell, 1995. 81(4): p. 495-504.

186. Wajant, H., K. Pfizenmaier, and P. Scheurich, Tumor necrosis factor signaling. Cell Death Differ, 2003. 10(1): p. 45-65. 
187. Varfolomeev, E.E. and A. Ashkenazi, Tumor necrosis factor: an apoptosis JuNKie? Cell, 2004. 116(4): p. 491-7.

188. Cabal-Hierro, L., et al., TRAF-mediated modulation of NF-kB AND JNK activation by TNFR2. Cell Signal, 2014. 26(12): p. 2658-66.

189. Min, W., et al., AIP1 recruits phosphatase PP2A to ASK1 in tumor necrosis factor-induced ASK1-JNK activation. Circ Res, 2008. 102(7): p. 840-8.

190. Piva, R., G. Belardo, and M.G. Santoro, NF-kappaB: a stress-regulated switch for cell survival. Antioxid Redox Signal, 2006. 8(3-4): p. 478-86.

191. Kim, A.H., et al., Akt phosphorylates and negatively regulates apoptosis signal-regulating kinase 1. Mol Cell Biol, 2001. 21(3): p. 893-901.

192. Bai, D., L. Ueno, and P.K. Vogt, Akt-mediated regulation of NFkappaB and the essentialness of NFkappaB for the oncogenicity of PI3K and Akt. Int $\mathrm{J}$ Cancer, 2009. 125(12): p. 2863-70.

193. Wang, B., et al., DAB2IP regulates EMT and metastasis of prostate cancer through targeting PROX1 transcription and destabilizing HIF1alpha protein. Cell Signal, 2016. 28(11): p. 1623-30.

194. Huang, J., et al., miR-92b targets DAB2IP to promote EMT in bladder cancer migration and invasion. Oncol Rep, 2016. 36(3): p. 1693-701.

195. Min, J., et al., Absence of DAB2IP promotes cancer stem cell like signatures and indicates poor survival outcome in colorectal cancer. Sci Rep, 2015. 5: p. 16578. 
196. Fan, X., et al., Deletion of SMURF 1 represses ovarian cancer invasion and EMT by modulating the DAB2IP/AKT/Skp2 feedback loop. J Cell Biochem, 2019. 120(6): p. 10643-10651.

197. Olsen, S.N., et al., Loss of RasGAP Tumor Suppressors Underlies the Aggressive Nature of Luminal B Breast Cancers. Cancer Discov, 2017. 7(2): p. 202-217.

198. MacDonald, B.T., K. Tamai, and X. He, Wnt/beta-catenin signaling: components, mechanisms, and diseases. Dev Cell, 2009. 17(1): p. 9-26.

199. Valenta, T., G. Hausmann, and K. Basler, The many faces and functions of beta-catenin. EMBO J, 2012. 31(12): p. 2714-36.

200. Xie, D., et al., Role of DAB2IP in modulating epithelial-to-mesenchymal transition and prostate cancer metastasis. Proc Natl Acad Sci U S A, 2010. 107(6): p. 2485-90.

201. Wu, D. and W. Pan, GSK3: a multifaceted kinase in Wnt signaling. Trends Biochem Sci, 2010. 35(3): p. 161-8.

202. Mayo, M.W., et al., Requirement of NF-kappaB activation to suppress p53-independent apoptosis induced by oncogenic Ras. Science, 1997. 278(5344): p. 1812-5.

203. Zhang, J., et al., AIP1-mediated stress signaling in atherosclerosis and arteriosclerosis. Curr Atheroscler Rep, 2015. 17(5): p. 503.

204. Allen, N.P., et al., RASSF6 is a novel member of the RASSF family of tumor suppressors. Oncogene, 2007. 26(42): p. 6203-11. 
205. Wu, K., et al., The role of DAB2IP in androgen receptor activation during prostate cancer progression. Oncogene, 2014. 33(15): p. 1954-63.

206. Shivakumar, L., et al., The RASSF1A tumor suppressor blocks cell cycle progression and inhibits cyclin D1 accumulation. Mol Cell Biol, 2002. 22(12): p. 4309-18.

207. Hofmann, I., et al., K-RAS mutant pancreatic tumors show higher sensitivity to MEK than to PI3K inhibition in vivo. PLoS One, 2012. 7(8): p. e44146.

208. Qu, Y., et al., Evaluation of MCF10A as a Reliable Model for Normal Human Mammary Epithelial Cells. PLoS One, 2015. 10(7): p. e0131285.

209. Santos, E., et al., T24 human bladder carcinoma oncogene is an activated form of the normal human homologue of BALB- and Harvey-MSV transforming genes. Nature, 1982. 298(5872): p. 343-7.

210. Der, C.J., T.G. Krontiris, and G.M. Cooper, Transforming genes of human bladder and lung carcinoma cell lines are homologous to the ras genes of Harvey and Kirsten sarcoma viruses. Proc Natl Acad Sci U S A, 1982. 79(11): p. 3637-40.

211. Parada, L.F., et al., Human EJ bladder carcinoma oncogene is homologue of Harvey sarcoma virus ras gene. Nature, 1982. 297(5866): p. 474-8.

212. Campbell, S.L., et al., Increasing complexity of Ras signaling. Oncogene, 1998. 17(11 Reviews): p. 1395-413.

213. Cox, A.D., et al., Drugging the undruggable RAS: Mission possible? Nat Rev Drug Discov, 2014. 13(11): p. 828-51. 
214. Serrano, M., et al., Oncogenic ras provokes premature cell senescence associated with accumulation of $p 53$ and p16INK4a. Cell, 1997. 88(5): $p$. 593-602.

215. Land, H., L.F. Parada, and R.A. Weinberg, Tumorigenic conversion of primary embryo fibroblasts requires at least two cooperating oncogenes. Nature, 1983. 304(5927): p. 596-602.

216. Hahn, W.C., et al., Enumeration of the simian virus 40 early region elements necessary for human cell transformation. Mol Cell Biol, 2002. 22(7): p. 2111-23.

217. Hahn, W.C., et al., Creation of human tumour cells with defined genetic elements. Nature, 1999. 400(6743): p. 464-8.

218. Liu, S., et al., Homozygous deletion of glycogen synthase kinase 3beta bypasses senescence allowing Ras transformation of primary murine fibroblasts. Proc Natl Acad Sci U S A, 2008. 105(13): p. 5248-53.

219. Xie, Q., et al., YAP/TEAD-mediated transcription controls cellular senescence. Cancer Res, 2013. 73(12): p. 3615-24.

220. Khokhlatchev, A., et al., Identification of a novel Ras-regulated proapoptotic pathway. Curr Biol, 2002. 12(4): p. 253-65.

221. Tan, K.O., et al., MAP-1, a novel proapoptotic protein containing a BH3like motif that associates with Bax through its Bcl-2 homology domains. J Biol Chem, 2001. 276(4): p. 2802-7. 
222. Peters, I., et al., RASSF1A promoter methylation and expression analysis in normal and neoplastic kidney indicates a role in early tumorigenesis. Mol Cancer, 2007. 6: p. 49.

223. Markulin, D., et al., Association Between RASSF1A Promoter Methylation and Testicular Germ Cell Tumor: A Meta-analysis and a Cohort Study. Cancer Genomics Proteomics, 2017. 14(5): p. 363-372.

224. O'Neill, E., et al., Role of the kinase MST2 in suppression of apoptosis by the proto-oncogene product Raf-1. Science, 2004. 306(5705): p. 2267-70.

225. Zimmermann, S. and K. Moelling, Phosphorylation and regulation of Raf by Akt (protein kinase B). Science, 1999. 286(5445): p. 1741-4.

226. Ikenoue, T., et al., Essential function of TORC2 in PKC and Akt turn motif phosphorylation, maturation and signalling. EMBO J, 2008. 27(14): p. 1919-31.

227. Lone, M.U., et al., Direct physical interaction of active Ras with mSIN1 regulates mTORC2 signaling. BMC Cancer, 2019. 19(1): p. 1236.

228. Vos, M.D., et al., A role for the RASSF1A tumor suppressor in the regulation of tubulin polymerization and genomic stability. Cancer Res, 2004. 64(12): p. 4244-50.

229. Qiao, S., et al., Dab2IP GTPase Activating Protein Regulates Dendrite Development and Synapse Number in Cerebellum. 2013. 8(1): p. e53635.

230. Qiao, S. and R. Homayouni, Dab2IP Regulates Neuronal Positioning, Rap1 Activity and Integrin Signaling in the Developing Cortex. Dev Neurosci, 2015. 37(2): p. 131-41. 
231. Lee, G.H., et al., Dab2ip regulates neuronal migration and neurite outgrowth in the developing neocortex. PLoS One, 2012. 7(10): p. e46592.

232. Shcherbo, D., et al., Far-red fluorescent tags for protein imaging in living tissues. Biochem J, 2009. 418(3): p. 567-74.

233. Shcherbo, D., et al., Bright far-red fluorescent protein for whole-body imaging. Nat Methods, 2007. 4(9): p. 741-6.

234. Hesson, L.B., W.N. Cooper, and F. Latif, The role of RASSF1A methylation in cancer. Dis Markers, 2007. 23(1-2): p. 73-87.

235. Vicent, S., et al., Wilms tumor 1 (WT1) regulates KRAS-driven oncogenesis and senescence in mouse and human models. J Clin Invest, 2010. 120(11): p. 3940-52.

236. Sunaga, N., et al., Knockdown of oncogenic KRAS in non-small cell lung cancers suppresses tumor growth and sensitizes tumor cells to targeted therapy. Mol Cancer Ther, 2011. 10(2): p. 336-46.

237. Lee, M.G., et al., RASSF1A Directly Antagonizes RhoA Activity through the Assembly of a Smurf1-Mediated Destruction Complex to Suppress Tumorigenesis. Cancer Res, 2016. 76(7): p. 1847-59.

238. Papaspyropoulos, A., et al., RASSF1A uncouples Wnt from Hippo signalling and promotes YAP mediated differentiation via $p 73$. Nat Commun, 2018. 9(1): p. 424.

239. Steinman, R.M., et al., Endocytosis and the recycling of plasma membrane. J Cell Biol, 1983. 96(1): p. 1-27. 
240. Donninger, H., et al., Salvador protein is a tumor suppressor effector of RASSF1A with hippo pathway-independent functions. J Biol Chem, 2011. 286(21): p. 18483-91.

241. Jiang, Y., et al., The prognostic role of RASSF1A promoter methylation in breast cancer: a meta-analysis of published data. PLoS One, 2012. 7(5): p. e36780.

242. Schagdarsurengin, U., et al., Frequent epigenetic inactivation of the RASSF1A gene in hepatocellular carcinoma. Oncogene, 2003. 22(12): $p$. 1866-71.

243. Dammann, R., et al., Frequent RASSF1A promoter hypermethylation and K-ras mutations in pancreatic carcinoma. Oncogene, 2003. 22(24): $p$. 3806-12.

244. Niu, H., et al., The relationship between RASSF1A promoter methylation and thyroid carcinoma: A meta-analysis of 14 articles and a bioinformatics of 2 databases (PRISMA). Medicine (Baltimore), 2017. 96(46): p. e8630.

245. Wong, I.H., et al., Ubiquitous aberrant RASSF1A promoter methylation in childhood neoplasia. Clin Cancer Res, 2004. 10(3): p. 994-1002.

246. Donninger, $\mathrm{H}$., et al., NORE1A is a Ras senescence effector that controls the apoptotic/senescent balance of p53 via HIPK2. J Cell Biol, 2015. 208(6): p. 777-89.

247. Barnoud, T., H. Donninger, and G.J. Clark, Ras Regulates Rb via NORE1A. J Biol Chem, 2016. 291(6): p. 3114-23. 
248. Roberts, A.E., et al., Noonan syndrome. Lancet, 2013. 381(9863): p. 33342.

249. Schubbert, S., et al., Germline KRAS mutations cause Noonan syndrome. Nat Genet, 2006. 38(3): p. 331-6.

250. Kratz, C.P., et al., Germline mutations in components of the Ras signaling pathway in Noonan syndrome and related disorders. Cell Cycle, 2006. 5(15): p. 1607-11.

251. Kresak, J.L. and M. Walsh, Neurofibromatosis: A Review of NF1, NF2, and Schwannomatosis. J Pediatr Genet, 2016. 5(2): p. 98-104.

252. Dischinger, P.S., et al., NF1 deficiency correlates with estrogen receptor signaling and diminished survival in breast cancer. NPJ Breast Cancer, 2018. 4: p. 29.

253. Agathanggelou, A., et al., Identification of novel gene expression targets for the Ras association domain family 1 (RASSF1A) tumor suppressor gene in non-small cell lung cancer and neuroblastoma. Cancer Res, 2003. 63(17): p. 5344-51.

254. Barik, S., An intronic microRNA silences genes that are functionally antagonistic to its host gene. Nucleic Acids Res, 2008. 36(16): p. 5232-41.

255. Liao, $\mathrm{H}$. , et al., microRNA-32 induces radioresistance by targeting DAB2IP and regulating autophagy in prostate cancer cells. Oncol Lett, 2015. 10(4): p. $2055-2062$. 
256. Tang, Z., et al., GEPIA: a web server for cancer and normal gene expression profiling and interactive analyses. Nucleic Acids Res, 2017. 45(W1): p. W98-W102.

257. Khavari, T.A. and J. Rinn, Ras/Erk MAPK signaling in epidermal homeostasis and neoplasia. Cell Cycle, 2007. 6(23): p. 2928-31.

258. Fuentes-Mateos, R., et al., Concomitant deletion of HRAS and NRAS leads to pulmonary immaturity, respiratory failure and neonatal death in mice. Cell Death Dis, 2019. 10(11): p. 838.

259. Johnson, L., et al., K-ras is an essential gene in the mouse with partial functional overlap with N-ras. Genes Dev, 1997. 11(19): p. 2468-81.

260. Bethune, G., et al., Epidermal growth factor receptor (EGFR) in lung cancer: an overview and update. J Thorac Dis, 2010. 2(1): p. 48-51.

261. Giubellino, A., T.R. Burke, Jr., and D.P. Bottaro, Grb2 signaling in cell motility and cancer. Expert Opin Ther Targets, 2008. 12(8): p. 1021-33.

262. Tartaglia, M., et al., Gain-of-function SOS1 mutations cause a distinctive form of Noonan syndrome. Nat Genet, 2007. 39(1): p. 75-9.

263. Philpott, C., et al., The NF1 somatic mutational landscape in sporadic human cancers. Hum Genomics, 2017. 11(1): p. 13.

264. McLaughlin, S.K., et al., The RasGAP gene, RASAL2, is a tumor and metastasis suppressor. Cancer Cell, 2013. 24(3): p. 365-78.

265. Siewertsz van Reesema, L.L., et al., RAS pathway biomarkers for breast cancer prognosis. Clin Lab Int, 2016. 40: p. 18-23. 
266. von Lintig, F.C., et al., Ras activation in human breast cancer. Breast Cancer Res Treat, 2000. 62(1): p. 51-62.

267. Staudt, L.M., Oncogenic activation of NF-kappaB. Cold Spring Harb Perspect Biol, 2010. 2(6): p. a000109.

268. Norris, J.L. and A.S. Baldwin, Jr., Oncogenic Ras enhances NF-kappaB transcriptional activity through Raf-dependent and Raf-independent mitogen-activated protein kinase signaling pathways. J Biol Chem, 1999. 274(20): p. 13841-6.

269. Chen, C. and A.J. Sytkowski, Apoptosis-linked gene-2 connects the Raf-1 and ASK1 signalings. Biochem Biophys Res Commun, 2005. 333(1): p. $51-7$.

270. Chen, J., et al., Raf-1 promotes cell survival by antagonizing apoptosis signal-regulating kinase 1 through a MEK-ERK independent mechanism. Proc Natl Acad Sci U S A, 2001. 98(14): p. 7783-8.

271. Evan, G.I. and K.H. Vousden, Proliferation, cell cycle and apoptosis in cancer. Nature, 2001. 411(6835): p. 342-8.

272. O'Bryan, J.P., Pharmacological targeting of RAS: Recent success with direct inhibitors. Pharmacol Res, 2019. 139: p. 503-511.

273. Kim, D.H., et al., Relationship of Ras association domain family 1 methylation and K-ras mutation in primary non-small cell lung cancer. Cancer Res, 2003. 63(19): p. 6206-11. 
274. Hillen, F. and A.W. Griffioen, Tumour vascularization: sprouting angiogenesis and beyond. Cancer Metastasis Rev, 2007. 26(3-4): p. 489502.

275. Carmeliet, P. and R.K. Jain, Angiogenesis in cancer and other diseases. Nature, 2000. 407(6801): p. 249-57.

276. Kumar, H. and D.K. Choi, Hypoxia Inducible Factor Pathway and Physiological Adaptation: A Cell Survival Pathway? Mediators Inflamm, 2015. 2015: p. 584758.

277. Li, S., et al., High glucose and/or high insulin affects HIF-1 signaling by regulating AIP1 in human umbilical vein endothelial cells. Diabetes Res Clin Pract, 2015. 109(1): p. 48-56.

278. Zhou, J., et al., Loss of DAB2IP in RCC cells enhances their growth and resistance to mTOR-targeted therapies. Oncogene, 2016. 35(35): p. 466374.

279. Smith, M.J., B.G. Neel, and M. Ikura, NMR-based functional profiling of RASopathies and oncogenic RAS mutations. Proc Natl Acad Sci U S A, 2013. 110(12): p. 4574-9.

280. Xu, K., et al., Small Molecule KRAS Agonist for Mutant KRAS Cancer Therapy. Mol Cancer, 2019. 18(1): p. 85.

281. Ortiz-Vega, S., et al., The putative tumor suppressor RASSF1A homodimerizes and heterodimerizes with the Ras-GTP binding protein Nore1. Oncogene, 2002. 21(9): p. 1381-90. 


\section{CURRICULUM VITAE \\ Desmond Ramón Harrell Stewart}

7414 Steeplecrest Circle \#306

Louisville, KY 40222

Education

2014- University of Louisville School of Medicine - Louisville, present $\quad \mathrm{KY}$

M.D./Ph.D. Candidate, expected May 2022

2010-2014 Xavier University of Louisiana - New Orleans, LA Bachelor of Science Biochemistry, Magna Cum Laude

Research Experience

2016-2020 University of Louisville School of Medicine, Dept. of Pharmacology \& Toxicology, Dr. Geoffrey Clark graduate training

"Causes and Consequences of RASSF1A and DAB2IP Inactivation" 
University of Louisville School of Medicine Dept. of Biochemistry, Dr. Geoffrey Clark - NCl Cancer Education Program

"The Role of DAB2IP in RASSF-Mediated Tumor Suppression"

2012-2014 Xavier University of Louisiana Dept. of Chemistry, Dr. Kelly Johanson - Research Assistant

"Determining the Binding Sequence of PAX3-FOXO1"

Presentations

Stewart DR, Schmidt ML, Clark GJ. "The Role of DAB2IP in RASSF1A-mediated Tumor Suppression." Research!Louisville. Louisville, KY.

Stewart DR, Schmidt ML, Clark GJ. "RASSF1A forms a direct complex with the RasGAP DAB2IP." RAS Initiative Symposium. NCl-Frederick Campus. Frederick, MD. 
Harrell-Stewart DR, Schmidt ML, Clark GJ. "Causes and consequences of RASSF1A and DAB2IP inactivation." National MD/PhD Student Conference. Keystone, CO. Novel Mechanism of RAS Regulation." Southeastern Medical Scientist Symposium. Vanderbilt University. Nashville, TN.

Publications

Harrell Stewart D, Hobbing K, Schmidt ML, Donninger H, Clark GJ. The role of RASSF proteins in modulating RAS driven lung tumors in vivo. J Thorac Dis 2019 May; 11(Suppl 9): S1436-1437. doi: 10.21037/jtd.2019.03.60. PMID: 31245154

Harrell Stewart DR, Clark GJ. Pumping the brakes on RAS—negative regulators and death effectors of RAS. J Cell Sci 2020 Feb 10;133(3). pii: jcs238864. doi: 10.1242/jcs.238865. Review. PMID: 32041893 
Harrell Stewart DR, Schmidt ML, Donninger H, Clark GJ. The tumor suppressor RASSF1A binds the Ras GTPase Activating Protein DAB2IP and modulates RAS activation in lung cancer. In press. 